If) 0) 13) II)

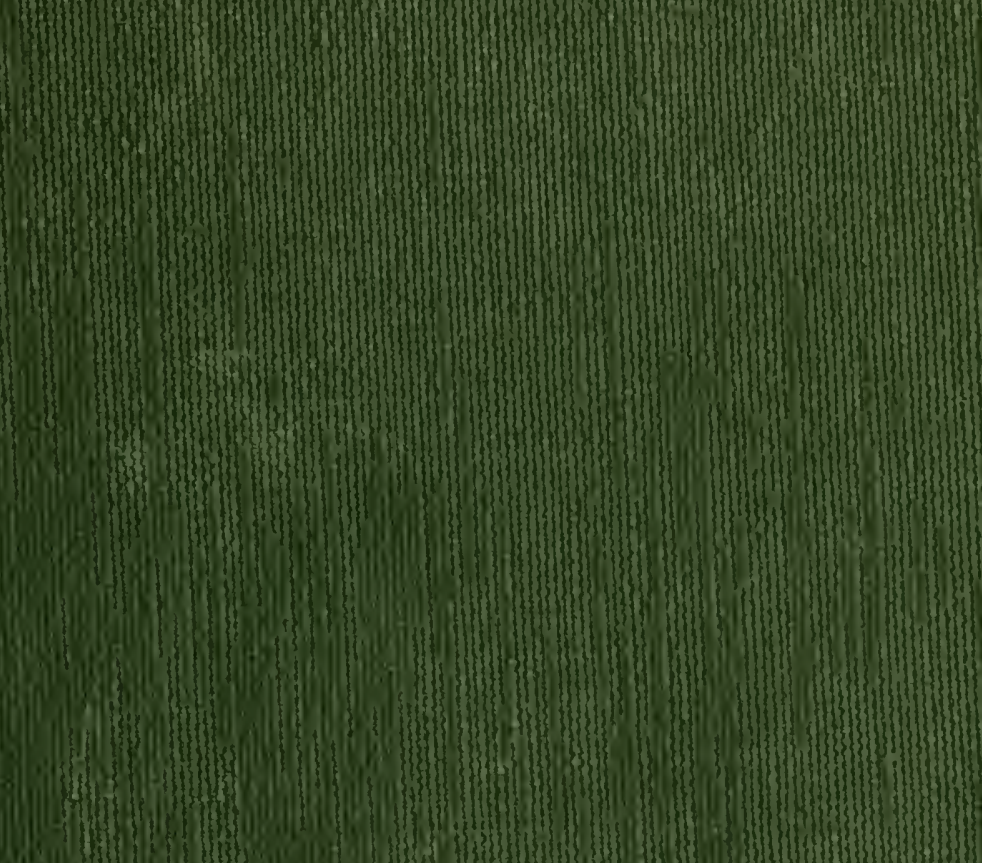


$(10)$ 

$K-1-i$ bicotor mene 


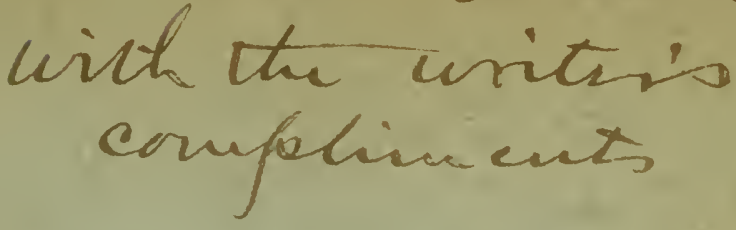

LELAND STANFORD JUNIOR UNIVERSITY PUBLICATIONS UNIVERSITY SERIES

No. 2

$$
\text { Division of Mollustes }
$$

\section{THE \\ OPISTHOBRANCHIATE MOLLUSCA \\ OF THE \\ BRANNER-AGASSIZ EXPEDITION TO BRAZIL}

BY

FRANK MACE MACFARLAND

Professor of Histology

Leland Stanford Junior University

WITH PLATES I - XIX 


\section{UNIVERSITY SERIES}

No. 1

Inheritance in Silkworms, I. Vernon Lyman Kellogg, Professor of Entomology. 89 pp., 4 pl. 1908. 
LELAND STANFORD JUNIOR UNIVERSITY PUBLICATIONS UNIVERSITY SERIES

No. 2

\section{THE \\ OPISTHOBRANCHIATE MOLLUSCA}

OF THE

\section{BRANNER-AGASSIZ EXPEDITION \\ TO BRAZIL}

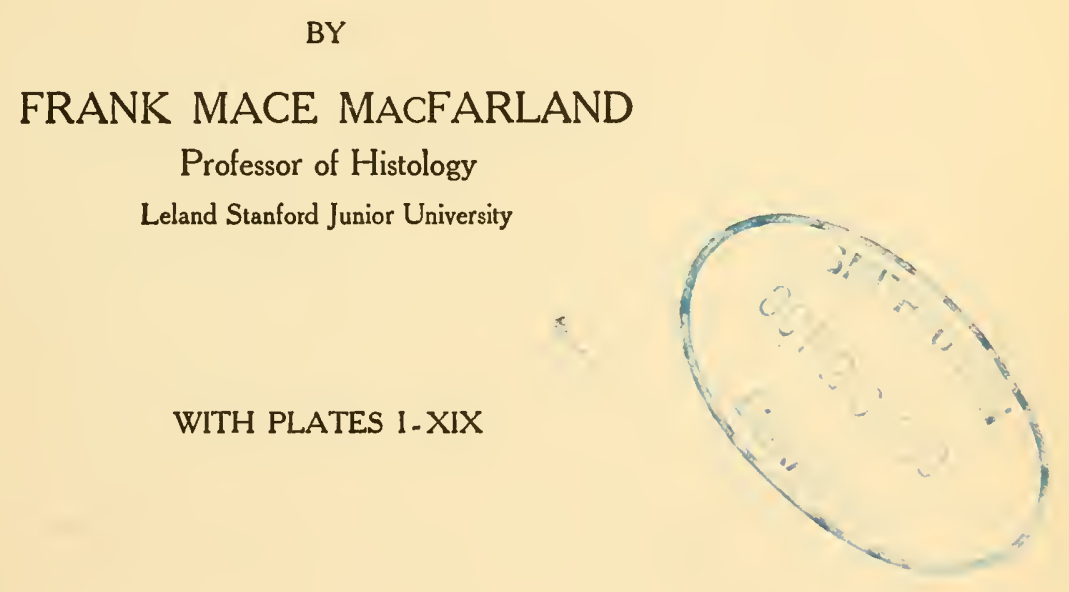





\section{CONTENTS}

Page

INTRODUCTION

List of Opisthobranchiate Mollusca Collected by the Branner-Agassiz Expedition . . . . . 6

List of Opisthobranchiate Mollusca Thus Far ReCORDED FROM THE COAST OF BRAzIL . • . . 7

Detailed Descriptions of the Species Collected-

I. Tethys dactylomela (Rang) . . . . . . 14

2. Tethys cervina Dall and Simpson . . . . . 38

3. Pleurobranchus agassizii sp. nov. . . . . 59

4. Discodoris branneri sp. nov. . . . . . 66

5. Discodoris voniheringi sp. nov. . . . . . 73

6. Peltodoris greeleyi sp. nov. . . . . . . 84

7. Spurilla braziliana sp. nov. . . . . . . $9 \mathrm{I}$

Literature Cited . . . . . . . . . . . IOO

Explanation of Plates . . . . . . . . . . . 105 



\section{THE OPISTHOBRANCHIATE MOLLUSCA OF THE BRANNER-AGASSIZ EXPEDITION TO BRAZIL.*}

During the explorations of the Branner-Agassiz expedition to Brazil in 1899 a small collection of Opisthobranchiate Mollusca was made by Mr. A. W. Greeley, a member of the expedition. These were turned over to the writer for study, and the results obtained are embodied in the present paper. The Opisthobranchs of the Brazilian coast are but little known, no systematic effort having been made as yet to collect and study them, and it is only occasionally that reference to them is to be found in the literature upon the subject. Several shell-bearing Opisthobranchs have been described by various authors, but the naked members of the group have received but scant attention, and Von Thering is practically the only author who has examined the Brazilian forms. His list and description of six species of Nudibranchs published in I886, has remained for twenty years with but scanty additions.

The collection made by Mr. Greeley, though but small and made without any especial attention to the group, adds seven to the list of species thus far known from Brazilian waters, and is an indication of the results which careful and extended collecting in those regions might secure. Two shell-bearing Opisthobranchs were also found in the collection made by Mr. Greeley and studied by Professor W. H. Dall, and are listed in his "Mollusks from the Vicinity of Pernambuco," Proceedings of the Washington Academy of Sciences, III. I89I. p. I39-I47. These are added to the list given in the present paper.

There is so little known about the structure of the Opisthobranchs from this region that a somewhat detailed examination of the collection in this respect has seemed warranted, especially since external characters afford so meagre a basis for classification in this group. Unfortunately the number of specimens secured is but small, so that, in most cases, the minute anatomical study was hampered by the lack of material. No notes save those

* Other reports upon the collections made by the Branner-Agassiz Expedition have appeared in Volume III of the Proceedings of the Washington Academy of Sciences. 
of locality and date were taken by the collector, so that nothing can be given as to the color, or form of body in the living animal. In the study of the collection most of the specimens have been dissected, and many parts have been cut into serial sections, or otherwise prepared for microscopical study. All of these preparations, as well as the animals themselves, or what remains of them, are deposited in the Zoological Museum of the Leland Stanford Junior University, and their serial numbers are given under each species in the present paper.

The following is a conspectus of the seven forms discussed in the following pages.

\section{Order OPISTHOBRANCHIATA.}

Suborder Tectibranchiata.

Tribe Aplysoidea.

Family Aplysiidae.

I. Tethys dactylomela (Rang).

2. Tethys cervina Dall and Simpson.

Tribe Pleurobranchoidea.

Family Pleurobranchidae.

3. Pleurobranchus agassizii sp. nov.

Suborder Nudibranchiata.

Tribe Doridoidea.

Family Dorididae.

Subfamily Discodoridinae.

4. Discodoris branneri sp. nov.

5. Discodoris voniheringi sp. nov.

Subfamily Diaululinae.

6. Peltodoris greeleyi sp. nov.

Tribe Aeolidoidea.

Family Aeolididae.

7. Spurilla braziliana sp. nov.

The complete list of the Opisthobranchiate Mollusca of the Brazilian coast thus far described, together with those above listed is as follows. Those marked with an asterisk are deep water forms, i. e. Ioo fathoms and over, and are of wide distribution throughout the Atlantic Ocean. 


\section{Order OPISTHOBRANCHIATA.}

Suborder Tectibranchiata.

Tribe Bulloidea.

Family Actaeonidae.

I. Actaeon cumingii A. Adams.

Rio Janeiro, A. Adams, Proc. Zool. Soc., London, I854, p. 59.

Family Ringiculidae.

*2. Ringicula peracuta Watson.

Off Pernambuco, 350 fathoms. Watson, Challenger Gasteropoda, p. 636. $=$ Ringicula nitida Verrill. Dall, Bulletin Museum Comp. Zool. Harvard, XVIII, I889, p. 43.

Family Tornatinidae.

3. Tornatina liratispira Smith.

Rio Janeiro, E. A. Smith. Annals and Magazine Nat. Hist., (4), IX, p. 354 .

4. Tornatina canaliculata (Say).

Anchorage off Fernando Noronha, 7-25 fath. Watson, Chall. Gasterop., p. 655 .

*5. Retusa ovata (Jeffreys).

Off Pernambuco, 350 fath. Watson, Chall. Gasterop., p. 664.

Family Scaphandridae.

*6. Diaphana seguenzae (Watson).

Off Pernambuco, 350 fath. Watson, Chall. Gasterop., p. 646.

7. Cylichna noronyensis Watson.

Anchorage off Fernando de Noronha, 7-25 fath. Watson, Chall. Gasterop., p. 666.

8. Cylichna bidentata (d'Orbigny).

Canal de San Sebastiao, Von Ihering. Revista Museu Paulista, II, I897, p. I69. 
Family Bullidae.

9. Bulla rubiginosa Gould.

Near mouth of Rio Janeiro Harbor, Couth. Gould, U. S. Exploring Exp., XII, Mollusca and Shells, 1852, p. $221 . \dagger$

Io. Bulla striata Bruguière.

Canal de San Sebastiao, Von Ihering, Revista Museu Paulista, II, I897, p. 169.

Mangosoules, Managuas, Maçeio. Dall, Proc. Wash. Acad. Sci., III, I90I, p. I42.

Family Aceratidae.

II. Haminea elegans (Gray).

? Bulla diaphana Couthouy.

Rio Janeiro, Gould, Mollusca and Shells, U. S. Exploring Ex., XII, I852, p. 222. $\dagger$

Family Hydatinidae.

I2. Micromelo undata (Bruguière).

Goyana, on the reef. Dall, Proc. Wash. Acad. Sci., III, I90I, p. I42.

Tribe Aplysoidea.

Family Aplysiidae.

I3. Tethys livida (d'Orbigny).

Bay of Rio Janeiro. d'Orbigny, Voy. dans l'Amérique Mérid., V, 3, I835I843, p. 206.

I4. Tethys braziliana (Rang).

Bay of Rio Janeiro. Quoy and Gaimard. Rang, Histoire Naturelle des Aplysiens, I828, p. 55.

I5. Tethys dactylomela (Rang).

Maçeio, Alagoas. Pernambuco.

†The place of the original descriptions of Bulla rubiginosa Gould, and Bulla diaphana Couthouy, is given by Gould in his report upon the Mollusca of the $U$. $S$. Exploring Expedition as Proc. Boston Soc. Natural History, III, 1849, pp. 107 and 91 respectively. This has been cited in several recent works, e. g. by Pilsbry in Tryon's Conchology, XVI, pp. 330 and 356 . I am unable to find any such description in any of the earlier volumes of the Proceedings, nor any earlier descriptions than the ones indicated above. 
I6. Tethys cervina Dall and Simpson.

Maçeio, Alagoas.

I7. Notarchus lacinulatus (Couthouy).

Rio Janeiro Harbor. Gould, U. S.

Explor. Exp. Moll., p. 223.

Tribe Pleurobranchoidea.

Family Pleurobranchidae.

I8. Pleurobranchus agassizii MacFarland, sp. nov.

Riacho Doce, Alagoas.

I9. Pleurobranchaea inconspicua Bergh.

Mouth of Cotinguiba River. Bergh, Semper's Reisen, Wissenschaftliche Resultate, VII: Malacol. Unters., IV, I, I, I897, p. 49.

Suborder Nudibranchiata.

Tribe Tritonoidea.

Family Tritoniidae.

20. Tritonia cucullata Gould.

Coast of Brazil. Gould, U. S. Expl. Exp. Moll., I852, p. 308.

$=$ Marionia occidentalis Bergh. Challenger Exp., X, I884, p. 49, La Plata and Buenos Aires.

Tribe Doridoidea.

Family Dorididae.

Subfamily Archidoridinae.

2I. Staurodoris verrucosa (Cuvier).

Armaçao, Province Santa Catarina.

Von Ihering, Jahrb. deutsch. Malakozool. Ges., XIII, 3, I886, p. 230. $=$ Staurodoris januarii Bergh. Mal. Unters., XIII, I878, p. 583 ; Sup. H. I, I88o, p. 37 ; System. I892, p. IOI. Subfamily Discodoridinae.

22. Discodoris branneri MacFarland. sp. nov.

Riacho Doce, Alagoas. 
23. Discodoris voniheringi MacFarland. sp. nov.

Riacho Doce, Alagoas.

Subfamily Diaululinae.

24. Thordisa ladislavii (Von Ihering).

Armaçao, Prov. Santa Catarina. Von Ihering, Jahrb. d. Mal. Ges., XIII, 3 , I886, p. 234.

25. Thordisa dubia Bergh.

Rio Janeiro Harbor, Rat Island, Bergh, Bull. Mus. Comp. Zool. Harvard, XXV, I894, p. I78.

26. Peltodoris greeleyi MacFarland. sp. nov.

Riacho Doce, Alagoas.

Family Doriopsididae.

27. Doriopsis atropos Bergh.

Rio Janeiro. Bergh, Jahrb. d. D. Mal. Ges., VI, I879, p. 49.

Tribe Aeolidoidea.

Family Aeolidiadae.

Subfamily Aeolidianae.

28. Spurilla braziliana MacFarland, sp. nov.

Riacho Doce, Alagoas.

Subfamily Favorininae.

29. Phidiana selencae Bergh.

Rio Janeiro. Bergh, Beitraege zur Kenntniss der Aeolidiaden. VI. Verl. d. k. k. zool.-bot. Gesellsch. in Wien, 1878 , p. 560.

Family Pleurophyllididae.

30. Pleurophyllidia muelleri Von Ihering. Armaçao, Prov. Santa Catarina, Von Ihering, Jahrb. d. Mal. Ges., XIII, 3, I886, p. 223.

In the above list the gymnosomatous and thecosomatous Pteropods have been left out of consideration. Of the thirty 
species enumerated, the Bulloidea are represented by twelve, the Aplysoidea by five, the Pleurobranchoidea by two, the Tritonoidea by one, the Doridoidea by seven and the Aeolidoidea by three, or nineteen Tectibranchs and eleven Nudibranchs as the total Opisthobranch fauna of some four thousand miles of coast line, extending from $4^{\circ} 22^{1} / 2^{\prime} \mathrm{N}$. Lat. to $33^{\circ} 44^{\prime} \mathrm{S}$. Lat. Of these all the Bulloidea and Aplysoidea are of wide distribution, many of them occurring throughout the North Atlantic, and others in the Antilles. It is readily seen from this that our information about the group in general, and the Nudibranchs in particular makes any theorizing as to distribution for the present somewhat premature.

The appearance of this paper, much of which has been in manuscript for several years, has been delayed by other duties. Six months spent at the Zoological Station at Naples in 1903 enabled me to compare and dissect the Mediterranean forms related to those discussed in this paper. I again take the pleasant opportunity of expressing my most cordial appreciation of the many kindnesses shown me while there by Professor Dohrn and his staff, as well as to the Smithsonian Institution for the grant of a table in the Station, which opened these privileges to me.

In the systematic arrangement of the Opisthobranchiata adopted in the present paper the plan of Pelseneer has been followed in the main. The characterizations of the different subdivisions have been more or less modified from those of Pilsbry, Pelseneer and Bergh in the majority of cases. 


\section{ORDER OPISTHOBRANCHIATA.}

Marine Euthyneura with aquatic respiration; the ventricle of the heart is generally anterior, and the pallial cavity, when present, is widely open. There is a marked tendency to a reduction of the shell, which may become internal or disappear. In the naked forms spicules are sometimes developed.

\section{SUBorder TECTIBRANCHIATA.}

Hermaphroditic opisthobranchiate Mollusca provided in the adult state with a mantle and shell, with certain exceptions; with one branchial plume and osphradium, with certain exceptions.

\section{Tribe I. Bulloidea.}

Shell usually well developed, sometimes wanting, external or internal. Operculum seldom present. Pallial cavity well developed and containing the usually plicate ctenidium. Head usually without tentacles, and with dorsal surface forming a shield, usually separate from the neck, and with more or less scalloped margins. Edges of foot continuous with its ventral face and often modified into fins. Stomach usually with chitinous or calcified masticatory plates. Visceral commissure usually rather long. The monaulic genital duct usually connected with the penis by a ciliated groove.

\section{Tribe II. Aplysoidea.}

Shell much reduced, more or less internal, or lost altogether in the adult state. Head with two pairs of tentacles. Margins of the parapodia separate from the ventral surface of the foot, and generally modified into natatory lobes. Visceral commissure usually very much shortened, except in Tethys. Genital duct monaulic, the hermaphroditic duct connected with the penis by a ciliated groove. 


\section{Family APLYSIIDAE.}

Animal lengthened, not protected by a shell, the neck and head narrower than the body; mouth a vertical fissure; anterior angles of the head produced into two tentacular lobes folded above; behind them the cylindrical or conical rhinophores, slit above, in front of which are the minute eyes. Parapodia recurved over the back, forming two lateral or dorsal lobes enclosing the mantle and ctenidium. Genital orifice between the dorsal lobes, communicating by a long furrow with the evertible penis which is near the anterior right tentacle. Shell nearly or entirely covered by the mantle, uncoiled, in the form of a concave plate, sometimes absent. Mouth with corneous jaws and a large, multiserial radula composed of similar teeth; stomach armed with horny nodules; anus behind the branchial plume.

\section{Subfamily APLYSIINAE.}

Parapodial lobes well-developed, their anterior ends separated; genital orifice in front of the branchia; radula with wide, denticulate, rhachidian teeth, and narrower, serrate and denticulate laterals. Shell flexible.

\section{Genus TETHYS Linné, 1758.}

Tethys, Linné, Systema Naturae, Ioth ed. I758, p. 653. Laplysia, Linné, Systema Naturae, I2th ed. I767, p. ro89. Aplysia, Gmelin, Systema Naturae, I3th ed. I788, I, VI, p. 3 Io3. Tethys, Pilsbry, Proc. Acad. Nat. Sci., Philadelphia, I895, p. 347. Tethys, Pilsbry, Manual of Conchology, Tryon, XVI, I896, p. 65.

Animal swollen behind, narrower in front, with rather long neck and head, bearing folded tentacles and slit rhinophores as usual in the family, the latter about midway between tentacles and dorsal slit. Parapodia arising in front of the middle of the animal's length, ample, freely mobile, free throughout their length, or united for a distance behind, functional as swimming lobes; anterior ends separated. Mantle nearly covering the ctenidium, having a median tube, foramen, or orifice communicating with shell cavity, and produced behind in a more or less developed 
lobe or lobes, rolled to form an excurrent siphon. Genital orifice under front edge of mantle, in front of ctenidium; hypobranchial gland present, a short distance behind genital opening. Foot well developed.

Shell very thin, membranaceous, with a thin, calcareous inner layer, nearly as large as mantle, concave, with pointed, small apex, bearing a recurved lamina, and having a concave, posterior sintus.

This genus is usually known as Aplysia, an etymological correction by Gmelin of the name Laply'sia, used by Linné in the I2th edition of the Systema Naturae. As pointed out by Pilsbry, the name Tethys is unmistakably applied to this genus by Linné himself in the Ioth edition in 1758 , and hence must stand, despite the common but erroneus usage.

Two species of this genus and one of Notarchus have already been recorded from the coast of Brazil, and to them are to be added the following two, already known from the Antilles.

\section{Tethys dactylomela (Rang, 1828).}

Pl. I, Figs. 1-7; P1. II, Fig. 8; P1. III, Figs. 9-14; P1. IX, Fig. 38. Aplysia dactylomela Rang. Histoire Naturelle des Aplysiens, I828, p. 56, pl. IX.

Tethy's dactylomela (Rang). Pilsbry, in Tryon, Manual of Conchology, XVI, I896, p. 75-76, pl. 32, figs, i6-19.

"Length about $\mathrm{I} 7 \mathrm{~cm}$. Always much swollen with elongated head and tail; rugose. Mantle or gill cover with a minute, central tube and a well developed siphon behind. Swimming lobes not united as far forward as the siphon.

"Color pale yellow of various shades, more or less covered in different individuals, with black rings, irregular and of various sizes. Inner sides of lobes and the mantle with large black spots of different forms. Borders of the swimming lobes tinged with violet.

"Shell large, much dilated, a little diaphanous, amber colored outside with a visible enamel within; posterior sinus deeply arcuate; beak recurved, triangular, thick and calloused. Altitude, forty-two millimeters." 


\section{External Characters.}

Six specimens of this widely distributed Antillean species were found in the collection, five of them taken from the same locality, "Coral reef, Maceio, Alagoas, July 30, I899," and the sixth from "Pernambuco stone reef, July 7, I899," and collected in both cases by A. W. Greeley. No further notes accompanied the specimens, but, according to a verbal communication from Mr. Greeley, the preserved material was of nearly the same coloration as in life, the ground color being slightly deeper, a yellowish brown. The characteristic ink ejected on being disturbed was of a deep purple color. Of the six specimens taken, one was quite large, being over twice the length of any of the others, which were of nearly the same dimensions throughout. All were in a good state of preservation, but all more or less contracted, especially in the region of the mouth and head. The following table gives a comparison of the principal dimensions.

\begin{tabular}{|c|c|c|c|c|c|c|c|c|}
\hline No. & Lengtb & Width & Height & $\begin{array}{c}\text { Length } \\
\text { base of } \\
\text { parapodia }\end{array}$ & $\begin{array}{c}\text { Width } \\
\text { space } \\
\text { bet. ant. } \\
\text { ends para- } \\
\text { podia }\end{array}$ & $\begin{array}{c}\text { Width } \\
\text { space } \\
\text { bet. post } \\
\text { ends para- } \\
\text { podia }\end{array}$ & $\begin{array}{c}\text { Length } \\
\text { of } \\
\text { foot }\end{array}$ & $\begin{array}{l}\text { Width } \\
\text { of } \\
\text { foot }\end{array}$ \\
\hline 1. & $140 \mathrm{~mm}$ & $70 \mathrm{~mm}$. & $60 \mathrm{~mm}$. & $97 \mathrm{~mm}$. & $18 \mathrm{~mm}$. & $7 \mathrm{~mm}$. & $135 \mathrm{~mm}$. & $40 \mathrm{~mm}$. \\
\hline 2. & 70 ، & 40 & 50 '6 & 55 66 & 176 & 18 '، & $60 "$ & 18 " \\
\hline 3. & 65 ، & 406 & 40 ، & $56 \quad 6$ & $\ldots$. & 36 & 63 ، & $20 " 6$ \\
\hline 4. & $\ldots \ldots$ & $\ldots$ & & 56 6 & 9 ، & 5 ، & .. & \\
\hline 5. & 56 ، & 20 "6 & 2066 & 3466 & 8 " & $1.5^{66}$ & 40 & 186 \\
\hline 6. & .... & $\cdots \cdot$ & $\ldots$ & $\ldots$. & 86 & $1.5^{66}$ & ..... & $\ldots$. \\
\hline
\end{tabular}

In individual No. 3 the anterior end of the left parapodium was Io $\mathrm{mm}$. behind that of the right side. In individuals Nos. 4 and 6 the contraction of the head region was so great as to invalidate the measurements omitted in the table for all purposes of comparison.

Color. The general plan of coloration is the same as that given in the revised description of this species in Tryon's Manual of Conchology, Vol. XVI, p. 75, and quoted above. The black rings form a very striking color characteristic, their centers being free from pigment. They reach a diameter in the largest speci- 
men of $7.0 \mathrm{~mm}$., the band of pigment itself ranging up to 3.0 $\mathrm{mm}$. in width. The inner surface of the parapodial lobes bears several branching bands of black, running in a generally vertical direction, near the thin margins, with occasional isolated blotches of pigment between them, and below merging into the black to greenish black area at the bases of the parapodia. Between the posterior ends of the parapodia is situated a median longitudinal dark band, which dilates posteriorly into a broad crescentic spot, the points of which are prolonged upward for a short distance along the inner face of the margins of the parapodia. The dorsal surface of the mantle is marked with irregular blotches of black, tending to form a series of incomplete rings. The under surface of the mantle is yellowish brown, the branchia brownish black, or nearly free from color.

Parapodia. The parapodia are prominent and high, their margins thin. The posterior half of the mantle is rolled into an erect tube, the siphon, the thin crenulate upper margin of which, in its slightly contracted state reaches just below the margins of the parapodia.

Shell. About midway of the length of the mantle in the median line is a single minute opening, borne upon a well marked, short cylindrical papilla, communicating with the shell sac, or mantle cavity. The shell is of good size, rather convex, very thin and translucent, but slightly calcareous, externally very pale yellow in color. In all the specimens unfortunately it was somewhat broken, the inner calcareous surface being reduced usually to fragments. The thin membranaceous margin of the shell projects beyond the calcified portion beneath, its anterior and right borders are rounded, the posterior border concave, the beak much thickened, triangular and recurved. In general it is similar to the figures of Rang for the species. Length $23 \mathrm{~mm}$., width 16 $\mathrm{mm}$., in an animal of $70 \mathrm{~mm}$. total body length.

Tentacles. The tentacles and head region generally are more or less contracted in all the specimens. In the best preserved ones the postcrior tentacles, or rhinophores are slender, auriform, the external slit being carried down posteriorly nearly to the base of the organ.

The anterior tentacles are much broader, stout, auriform, triangular in general outline, their outer margins being con- 
tinued downward to the mouth, the tips auriculate, their posterior margins forming a prominent flap closely applied to the anterior portion.

Just below and in front of the bases of the rhinophores the minute black eyes shimmer through the integument.

Reproductive opening. The male genital opening lies just below the base of the right anterior tentacle, a strongly defined groove extending backward from it and dorsally between the parapodia to the hermaphroditic orifice in front of the base of the branchia. This groove is marked by a narrow black line on its right margin throughout its whole length. Behind and below the genital opening is a large conspicuous circular orifice, the opening of the hypobranchial gland, or gland of Bohadsch.

The anal opening is situated upon the base of the posterior wall of the siphon, presenting a pocket-like appearance.

The renal opening is small and slit like, $1.2 \mathrm{~mm}$. in length, and lies deep in the mantle cavity above the posterior end of the ctenidium, some distance in front of the anus.

Foot. The foot is broad and well developed, its anterior end rounded, the posterior one more bluntly pointed. Its margin is clearly defined in all the specimens, its well developed musculature being contracted, giving it a firm rugose texture, in contrast to the smooth soft surface of the remainder of the body.

In the literature scarcely anything is to be found upon the internal anatomy of this species, a fact too frequently true of the majority of the members of this family, many of them having been described by the shell alone, which, as Pilsbry has pointed out, is probably the least characteristic organ of the animal. The interrelations of this widely distributed group cannot at present even be approximated on account of this lack. With a view to aiding in filling up this gap in our knowledge $I$ have made detailed dissections of the Aplysiidae found in this collection.

\section{Internal Anatomy.}

In the description of the internal anatomy, unless otherwise stated, all of the measurements given are taken from an individual of $70 \mathrm{~mm}$. total length in the well preserved alcoholic specimen.

The body wall is similar to that of other members of the group, the external integument being reinforced by interlacing 
bands of strong muscle fibres. The body cavity is roomy, and nearly filled by the viscera, its pseudo-peritoneum being colorless or slightly yellowish in hue.

\section{Alimentary System.}

Pharyngeal bulb. The mouth communicates by a very short tube with the pharyngeal bulb, a strong, muscular organ of conical form. Its length is I I.O mm. with a maximum diameter of 10.0 $\mathrm{mm}$. Opened from above the deep, rich amber-colored radula is exposed, and in front of it, upon each side, the mandibular plates of a similar color. The latter are situated at the anterior end of the pharyngeal bulb, almost completely encircling the opening and nearly touching each other above and below. The opalescent lip disc is elliptical in outline, the opening appearing as a vertical slit, $4.0 \mathrm{~mm}$. in length, while immediately within it the margins of the mandibular plates are seen. These plates are roughly rectangular in outline (P1. I, fig. 7), their length being $5.5 \mathrm{~mm}$. and their breadth $3.0 \mathrm{~mm}$. The posterior margin is bounded by a sharp, regularly curved line of opalescent hue, while the anterior margin is irregular, and more or less jagged and worn. Each plate is made up of densely packed rodlets, nearly straight, or slightly bent, and of approximately the same diameter throughout their whole length. At the posterior margin of the plate the arrangement of these rodlets may be easily seen (P1. III, fig. I2), but in the anterior portion such an arrangement cannot be made out clearly, owing to the overlapping of the rodlets as they increase in length. The shorter rodlets are flattened antero-posteriorly, with a strong tendency to the formation of a slight concavity, or longitudinal groove upon the posterior face, and a corresponding convexity in front. Their average, greatest width is $0.005 \mathrm{~mm}$. Toward the anterior border the rodlets increase in length, their basal diameter remaining nearly the same, while the length may reach $0.124 \mathrm{~mm}$. The outer extremity is bluntly rounded, the distal one-third being sometimes slightly enlarged, or club-shaped, or, in other cases, entirely straight throughout (P1. III, fig. I3). The bending and distortion, incident to microscopic preparation as a whole mount, indicate a considerable degree of flexibility.

Radula. The radula is broad, deeply grooved behind, and of 
a dark amber color. As is usual the anterior rows of teeth are very much worn and broken, so that even their number is uncertain. About eleven such imperfect rows may be made out, which gradually pass over into forty-seven complete rows, of which the last twenty are still inclosed in the radula sheath. The total number of rows is thus about fifty-eight. The greatest length of the radula is $9.0 \mathrm{~mm}$., and its greatest width $3.0 \mathrm{~mm}$.

The number of teeth varies in the different rows, being quite small in the most anterior rows, and increasing regularly in the succeeding ones to $26: 1: 26$ in the twenty-fifth row, and $38: 1: 38$ in the fifty-fifth one. In the anterior twenty to twentyfive rows the teeth are much worn, scarcely any being perfect, the cusps being usually blunted, or broken entirely away. Typical teeth, taken at intervals across the radula from neighboring rows, are shown in figs. I, 2 and 3 , of Pl. I. Fig. I represents the median and first lateral teeth of the 49th and 5oth rows; fig. 2 shows the 8th, 9th and Ioth teeth of the same rows, while figs. 3 and 4 give the I8th to 20 th of the 5 oth row and the $32 \mathrm{~d}$ to 37 th teeth of the 54 th row respectively all under the same magnification. The rhachis bears a single large tooth in each row. Its base is broad and trapezoidal in form, the broader end being directed posteriorly. It varies but slightly in size throughout the length of the radula, averaging $0.216 \mathrm{~mm}$. in the diameter of its broader posterior end and $0.06 \mathrm{~mm}$. in the diameter of its anterior end, with a length of $0.156 \mathrm{~mm}$. In the anterior end of the radula the base is often divided longitudinally, or a thinning away of the median line may indicate such a division as incomplete. The posterior margin is very slightly concave, the anterior one deeply emarginate, the notch being carried up on the back of the hook as a deep groove. The anterior end bears a strong hook, which is as broad as the full width of the base at its anterior end. The length of this hook averages $0.126 \mathrm{~mm}$., seven-twelfths the length of the base. It terminates in a large median blunt cusp, and two much smaller lateral cusps. The sides of the median cusp bear from four to ten thin irregular denticles on either side in the posterior portion of the radula. These denticles are either separate or, more usually, united at their bases. In the anterior portion these denticles are either worn away or undeveloped. The lateral cusps (Pl. I, fig. I), are 
one-fourth to one-half the length of the median one, and, in the last few rows may bear very minute serrulations, chiefly upon their outer margins.

The pleural teeth are rather uniform in outline, the innermost and outermost being slightly smaller than the remaining ones, into which they pass in a graded series. The general form of the pleural teeth is shown in Pl. I, figs. 5 and 6, in dorsal and lateral view. The base is broadest and thickest at its anterior end, tapering to a rounded posterior one which is produced strongly toward the outer border of the radula. In the posterior portion of the radula the base is broader throughout than in the anterior region. The same lateral prolongation is shown throughout the whole length of each row, being most strongly marked about the middle of each (PI. I, fig. 3). The anterior end of the base is recurved dorsally in a strong, broad hook, projecting upward at an angle of about $45^{\circ}$ and bearing two strong unequal cusps, which are about as broad as long near the innermost ends of the row, and increase in length progressively until they become about two and one-half times as long as broad, a proportion reached by the tenth tooth (P1. I, figs. I, 2). The smaller external cusp measures one-half to one-third the length of the larger, and is of the same general form. Both cusps bear typically a varying number of well marked irregular denticles upon their margins, which may be entirely separate, or, as is usually the case, are united at their bases into a thin marginal band. These denticles may be fairly uniform in size and shape (Pl. I, fig. 2, IO), or more often, very irregular (P1. I, figs. 2,3 ). The small external cusp bears a lesser number of denticles, which may be few and small, or large and irregular, often attaining such a size as to give the cusp the appearance of being divided (P1. I, fig. 3). The dimensions of a typical large pleural tooth are: length of base, $0.288 \mathrm{~mm}$., greatest width of base, $0.108 \mathrm{~mm}$., length of larger cusp, $0.102 \mathrm{~mm}$., length of smaller cusp $0.042 \mathrm{~mm}$. The external pleurae decrease progressively in size outwards, the outermost two or three in many cases being reduced to the base alone, the recurved hooks being undeveloped (Pl. I, fig. 4).

Dobson in the Journal of the Linnaean Society (XV, I880, p. 159), figures several teeth from Tethys dactylomela which agree 
in general with those here given. Eliot, in his "Notes on Tectibranchs and Naked Mollusks from Samoa," Proc. Philadelphia Academy, I899, p. 5I5, states that the radula of a Tethys dactylomela examined by him possessed a unicuspid central tooth, the laterals having an inner, but no outer cusp, a condition decidedly different from that described above in the specimens which $I$ have examined.

Salivary glands. The ducts of the salivary glands emerge from the buccal mass on its posterior surface on either side of the anterior end of the esophagus. The glands are long flattened strap-shaped structures, $1.5 \mathrm{~mm}$. in greatest width. They pass through the esoplageal collar formed by the central nervous system, extend backward along the left side of the visceral mass, the left one above, and dwindle away posteriorly, their tips being attached to the sides of the anterior portion of the first triturating stomach, the tip of the left one being situated dorsally, that of the right one ventrally.

Esophagus and stomach. The esophagus is a short broad thin-walled tube about $6.5 \mathrm{~mm}$. in length, dilating posteriorly into the capacious stomach. Its inner surface is smooth, save for a few low longitudinal ridges. In the stomach may be distinguished three divisions. The first, or ingluvies, is everywhere very thin walled, its inner surface is smooth and passes gradually into that of the esoplagus in front. In all the specimens examined the ingluvies was greatly distended with fragments of algae. In its lower posterior portion the ingluvies suddenly constricts into the "first triturating stomach" of Mazzarelli, clearly marked externally by its strong muscular wall, the fibres of which are mainly arranged in a circular direction. The width of this band varies from II.O $\mathrm{mm}$. to $18.0 \mathrm{~mm}$. in the specimens examined, the diameter of the contracted stomach at this point ranging from $15.0 \mathrm{~mm}$. to $20.0 \mathrm{~mm}$. Borne upon the inner surface of this wall is a series of strong horny pyramidal teeth of a light amber color. The sides of these teeth are formed by four roughly triangular faces, and, the two anterior ones being larger than the two posterior ones, the tip of the tooth is, in consequence, inclined backward. The teeth are borne upon plate-like elevations of the epithelium, corresponding in shape to the bases of the teeth. In alcoholic material the teeth are readily separable 
from these elevations. The largest one of the basal impressions thus left measured $6.0 \mathrm{~mm}$. in length by $5.0 \mathrm{~mm}$. in width. The teeth are arranged in a sort of quincunx in about six transverse rows, the larger ones occupying the middle and posterior portion, and in front of these the smaller ones are alternately arranged. The largest of these teeth measured $4.0 \mathrm{~mm}$. in height. In the contracted state of this portion of the stomach, the apices of these teeth meet in the center of the lumen and fit closely together, thus nearly closing the opening.

Succeeding this first triturating stomach is a somewhat wider and longer, much thinner walled division of the alimentary canal, the "second triturating stomach" of Mazzarelli. Its walls are much less muscular than those of the first stomach, being of practically the same thickness as those of the ingluvies. Instead of bearing numerous small teeth as in those Mediterranean species studied by Mazzarelli ('93), the teeth are reduced to a single series arranged in a transverse row, about midway of the length of the organ. These teeth are very small and readily dehiscent; their basal impressions are nearly round in outline, and about $0.7 \mathrm{~mm}$. in diameter. There are seven such impressions in the first specimen dissected, six and eight in others, arranged in a transverse row, and occupying about one-half of the total circumference of the whole organ. The remainder of the lining of the second stomach is entirely smooth.

Posterior visceral complex. The hinder portion of the second stomach is situated between the two anterior lobes of the large liver, thence passing rather abruptly into the intestine. The posterior visceral mass is made up of the liver, the intestine and the hermaphroditic gland, and is broadly conical in general form, the apex being directed posteriorly, and the elliptical base lying against the posterior part of the stomach and partially inclosing it. It is covered by a delicate membrane of connective tissue, the peritoneal lining of the pseudo-coelom. The intestine is very thin walled, and is filled with finely divided detritus of algal nature. It describes a series of complicated loops upon the liver, in the surface of which it is imbedded. The intestine enters the liver at its lower border, passes backward, thence upward and forward describing a long loop upon the upper surface of the liver toward its right side, to return again to the left, from which 
it passes in a sinuous course to the anus, situated upon the posterior wall of the siphon. At the beginning of the intestine its dilated lumen receives two large biliary ducts, which ramify throughout the substance of the liver. Two low ridges, bounding a shallow groove, lie along the intestinal wall in contact with the liver, near the beginning of the tube. These may be followed backward into a long curved blind tube, in the wall of which they become overlapping elevations, dividing it into two longitudinal chambers which are in communication at the end of the tube. This, the hepatic coecum, is imbedded in the substance of the liver throughout nearly its whole length, but its blind termination reappears at the surface as a small rounded area, which might readily be mistaken for a portion of the wall of the intestine. The coecum describes a $\mathrm{C}$ shaped loop of nearly $10.0 \mathrm{~mm}$. in length with a fairly constant diameter of $1.5 \mathrm{~mm}$.

\section{Central Nervous System.}

The ganglia. The central nervous system of Tcthys dactylomela (P1. II, fig. 8) is made up of eight paired ganglia grouped around the anterior end of the esophagus, close to its origin from the pharyngeal bulb. These are the cerebral, the pleural, the pedal and the buccal ganglia, the right and left components of each pair being united by commissures, while the ganglia of each side are united by the cerebro-pedal, the cerebro-pleural, the cerebro-buccal and the pleuro-pedal connectives. In addition to these centrally located ganglia, there are others, more or less distant from the central system. Chief of these are the parietovisceral, the genital, and the ganglia of the anterior and the posterior tentacles. The central nervous system is closely enveloped by a capsule of connective tissue in a firm sheath, which renders the dissection of the nerves a matter of some difficulty. The ganglia, their commissures, connectives and nerves will be taken up in order in the following description. The figures and descriptions given by Von Ihering ('77), Mazzarelli ('93), and Vayssière ('85), based upon European species of Tethys, vary so much from the results which I have obtained in Tethys dactylomela and in $T$. cervina that considerable detail seems to be justified in the following account. In fig. 8 of Pl. II I have endeavored to give an accurate representation of the central nervous system 
of this species in dorsal view, the abbreviations in the following description all referring to this figure. The nerves are numbered rather arbitrarily in the order of their origin from the ganglia, from above and in front, downward and backward, the relative peripheral distribution not being primarily considered in this arrangement.

Cerebral Nerves. The cerebral ganglia (cer.g.) are situated upon the dorsal side of the esophagus at its anterior end, and are so closely applied to each other that the cerebral commissures connecting them are very short, the two ganglia being practically fused together in the median line into a single mass. They are rounded, and flattened upon their dorsal surface, and fit closely down upon the underlying esophagus. From the sides of the ganglia, close up to the origin of the fifth nerves, arise the strong cerebro-buccal connectives, (c. b. con.), which curve downward, around the esophagus, to the buccal ganglia. Below and behind the origin of these arise the cerebro-pedal connectives, (c. p. con.), which pass downward and outward to the large pedal ganglia, (ped. g.), beneath the esophagus, and, close to the origin of the latter pair, the equally stout cerebro-pletural connectives (c. pl. con.) are given off. These pass downward, outward and backward, and terminate in the small pleural ganglia ( $p l . g$.$) , resting$ upon the upper border of the pedal ganglia.

From the cerebral ganglia arise six pairs of nerves, the origin and distribution of which is the same for both sides, unless otherwise noted in the following description.

The first nerve $(c I)$ is a strong one, arising from the anterior border of the ganglion, passing forward over the pharyngeal bulb, and is distributed to the skin and muscles in the region of the mouth.

The second nerve (c2), is broad and strong, arising immediately behind the first. After a short course it bifurcates, its more slender external division passing to the anterior tentacle, and terminating in a small ganglion at its distal extremity. The stout inner branch splits up into a number of smaller branches, all terminating in the integument in the neighborhoor of the mouth.

The third nerve $\left(c_{3}\right)$, arises immediately behind the first, but more dorsally. It is more slender, and passes to the rhino- 
phore, giving off a few delicate branches to the integument near its base, and terminating in a small ganglion at its distal extremity.

The fourth, or optic nerve $\left(c_{4}\right)$, is very slender and quite long. It arises immediately behind and exterior to the third, and is inclosed in a common sheath of connective tissue with it for a very short distance, much less than that described by Mazzarelli for the Mediterranean species. It is unbranched, and passes directly to the eye. No trace of an optic ganglion can be made out at its base with the dissecting microscope, though sections might show its presence.

The fifth nerve $\left(c_{5}\right)$, arises from the lateral border, immediately in front of the cerebro-buccal connectives and is rather slender. On the left side it courses forward and is distributed to the body wall in the region of the mouth. Its fellow of the right side passes forward, and divides into two branches, one of which is soon lost among the muscles of the body wall, immediately below the anterior portion of the penis. The second, more slender branch courses forward, parallel to the penis, giving off three branches at intervals, which pass to the latter organ, the main nerve being finally distributed to the muscles of the mouth region.

The sixth pair form the acoustic nerves. They are included in the cerebro-pedal connectives for about one-half of their length, and then become separate from them as very delicate nerves, passing directly to the otocysts, rounded capsules lying close to the bases of the cerebro-pedal connectives upon each side. These nerves are not shown on Pl. II.

Pedal ganglia. The pedal ganglia (ped. g.), are the largest of the central nervous system, $3.0 \mathrm{~mm}$. in greatest diameter, approximately circular in general outline, flattened upon the antero-ventral surface and strongly arched upon the posterodorsal face, thus having a nearly hemispherical form. They are united below the esophagus by a stout, transverse commissure, (p.com.), $3.0 \mathrm{~mm}$. in length, and $1.0 \mathrm{~mm}$. in diameter. This is inclosed within a broad, flattened sheath of connective tissue, which also contains near its upper anterior margin a very delicate subcerebral commissure, connecting the cerebral ganglia together below the esophagus. This latter commissure is so fine that it is made out with certainty only in transverse, serial sections of 
the whole band. From the ventro-posterior margin of each pedal ganglion a much more slender parapedal commissure ( $p . p$. com.) arises. It is $7.0 \mathrm{~mm}$. in length, being more than double that of the thicker pedal commissure, and describes a posteriorly directed loop below the esophagus. Somewhat to the left of its middle point a long slender unpaired nerve $(a)$ is given off, in one case being formed by a union of a short branch from each side of the loop, in others coming from the left side alone. It passes backward and is distributed to the pedal artery and foot.

From the pedal ganglia arise ten pairs of nerves, which show such differences in the two sides that they are here described separately.

Left pedal nerves. The first nerve (p.I), is quite slender. It arises from the upper outer border of the ganglion and passes backward and is distributed to the peritoneum and muscles of the posterior dorsum.

The second nerve $(p .2)$, arises close below the first and is of similar size. It bifurcates close to the ganglion, one of the rami thus formed passing backward to a similar distribution as that of the first nerve; the other ramus divides into $(a)$ a branch curving forward and forming an anastomosis with a branch of the second pleural nerve, described below, and $(b)$ a second branch which is distributed to the muscles of the dorso-lateral region.

The third $(p \cdot 3)$, is a rather slender nerve arising just below the first and second, and more upon the anterior face of the ganglion. In one instance it appeared as two nerves very close together. It branches to the integument and muscles of the dorsal wall above the pharyngeal bulb, one branch passing undivided to the region of the eye.

The fourth nerve $(p .4)$, arises from the lateral margin of the ganglion, is rather long and strong, passing backward to its distribution in the anterior portion of the parapodium.

The fifth $(p .5)$, is a strong nerve from the mid-lateral margin of the ganglion. It soon divides into three branches, the anterior one of which passes to the muscles of the body wall, the other two to the parapodium.

The sixth nerve $(p .6)$, is the largest of the pedal group. It arises close to the root of the fifth, and from its distribution is 
termed the posterior pedal nerve. It soon divides into two main branches of unequal size, which pass backward and ramify to the posterior portion of the foot, giving off a few slender branches to the mid-lateral region of the same.

From the ventro-anterior face of the ganglion, near the entrance of the cerebro-pedal connectives arises a very slender nerve, the seventh $(p \cdot 7)$. A short distance below it, and from the same face, the ninth nerve ( $p .9)$, is also given off. These two nerves are closely enmeshed in the capsule of connective tissue enveloping the posterior end of the pharyngeal bulb, and may be easily overlooked. A short distance from their origin they are connected by an anastomosis, and beyond this the two have a similar distribution, branching richly to the peritoneum, the aorta, and the muscles of the dorso-lateral wall of the body.

The eighth, or median pedal nerve, $(p .8)$, arises at the outer lower margin of the ganglion, passes outward and backward, dividing into two nearly equal rami, which are distributed to the median region of the foot.

The tenth, or anterior pedal nerve (p.ro), is the lowermost one of the series. It is of about equal caliber to the eighth, and divides into three main branches which curve forward to the anterior portion of the foot.

Right pedal nerves. The first pedal nerve (p.I), arises as a slender process from the outer upper margin of the ganglion, and soon divides into two unequal branches. The larger of these passes directly to the muscles of the lateral wall. The other branch subdivides again, in a short distance, into an anterior and a posterior branch. The posterior one of these innervates the penis, the anterior one runs parallel to the latter organ, gives off two or more delicate twigs to it, which anastomose with the subdivisions of the posterior branch, the main trunk terminating in the muscles of the mouth region on the right side.

The second and third nerves are closely associated at their origin, some individuals showing them as separate nerves, while others show the two united as a single nerve for a very short distance. In fig. 8 of P1. II I have shown the separate condition. In Tethys cervina, as will be seen, the united condition was found, and further comment will be made in the description of the central nervous system of that form. 
The second nerve ( $p .2)$, arises slightly in front of and below the third, in the instance figured on the plate, passes outward and gives off a branch which forms an anastomosis with the nerve from the right pleural ganglion described below. The main branch passes to the lateral retractor muscle of the head, a slender branch also being distributed to the dorso-lateral wall.

The third nerve $(p \cdot 3)$, is usually stronger, and is much longer, coursing backward. It sends one branch to the muscles of the dorsum, another farther on to the muscles and integument of the side, a third to the Organ of Bohadsch, or hypobranchial gland, and, after giving off one or two branches to the muscles of the body wall, finally terminates in the right parietal ganglion, thus forming a pedo-parietal connective. The branch given off to the Organ of Bohadsch also forms an anastomosis with a recurrent branch from the second nerve of the left visceral ganglion, to be described farther on.

The fourth $(p .4)$, is a moderate nerve in diameter but quite long. It arises from the right margin of the ganglion, courses backward, and is distributed to the right parapodium, like its fellow of the opposite side.

The fifth nerve $(p .5)$, arises close in front of the root of the sixth from the median margin of the ganglion. Its strong trunk soon splits into three nearly equal subdivisions, the most anterior one of which is distributed to the body wall in front of the parapodium, the remaining two ramifying in the parapodium itself.

The sixth, or posterior pedal nerve, $(p .6)$, is, as on the left side, one of the largest nerves from the ganglion. Its origin and relations are similar to those of its fellow, which is also true of the eighth $(p .8)$ and tenth $(p . I O)$, the median and anterior pedal nerves respectively. In the last named there is a slight tendency to variation in the number of the main branches close to the ganglion, but otherwise these nerves present no great differences on the two sides, nor in different individuals.

Close to the root of the eighth nerve and a little behind it, on the outer, posterior face of the ganglion is found the origin of the parapedal commissure ( $p . p$. com.). Upon the left side this commissure originates from the inner ventral margin of the ganglion.

The seventh $(p \cdot 7)$, and ninth (p.9), nerves, like the cor- 
responding nerves of the left side, arise from the ventro-anterior face of the ganglion, and present some difficulty as to their exact numerical order with respect to the other nerves of the same ganglion. They are also closely bound up in the connective tissue sheath surrounding the end of the pharyngeal bulb. The seventh nerve is slightly larger than the ninth, and is distributed mainly to the penis, and the body wall in the immediate neighborhood of that organ. It also forms a strong anastomosis with a branch of the ninth, as is shown in the fig. 8 of Pl. II. The ninth nerve is distributed mainly to the muscles of the body wall below the lateral retractor of the head.

Plcural ganglia. The pleural ganglia $(p l . g)$, the "protovisceral ganglia" of Mazzarelli ('93), are quite small, 1.o mm. in diameter, and nearly spherical. They are situated upon the upper posterior face of the pedal ganglia, and are connected with them by the extremely short pleuro-pedal connectives. From the posterior surface of the left pleural ganglion arises the long and strong pleuro-visceral connective ( $p l . v$. con.), while from a nearly similar position upon the pleural ganglion of the right side is given off the pleuro-parietal connective ( $p l$. par. con.), nearly equal in length. These two connectives pass directly backward, converging to terminate in a pair of ganglia, the parietovisceral ganglia, lying on the inner surface of the dorsal body wall at a point midway between the anterior bases of the pleuropodia and close to the anterior insertion of the mantle.

The pleural ganglia are usually described, e. g. by Mazzarelli ('93, p. 108), as not giving off any nerves in the Aplysiidae. But in Aplysiella petalifera Rang Pelseneer ('94) describes a lateral nerve arising from each pletural ganglion and forming an anastomosis with a pedal nerve of the same side, which condition, he further states, also exists in certain species of Aplysia and the Gymnosomata. Vayssière ('85) describes and figures a nerve from each lateral visceral (pleural) ganglion in Notarchus punctatus Philippi, which is associated in a part of its course with a pedal nerve to the mantle, and is distributed to the lateral tissues of the body on the right side, at the base of the branchia. Whether an anastomosis of these two nerves occurs or not does not appear from his description. In the two species of Aplysiidae from Brazil unmistakable though slender nerves do arise from the 
pleural ganglia, and equally unmistakable anastomoses occur with a pedal nerve in each case. These relations will be taken up in their order.

Left pleural nerves. From the outer upper margin of the left pleural ganglion arise two nerves $(p l . I, p l .2)$ close together, and are closely enmeshed in the capsule of dense connective tissue surrounding the central nervous system. They are both distributed to the muscles of the lateral and dorsal body wall in the immediate vicinity of the ganglion. The second of these nerves is connected by an anastomosing branch with the second pedal nerve of the same side as is seen in the figure.

Right pleural nerves. From the right pleural ganglion a single, fair sized nerve arises $(p l . I)$ below and in front of the origin of the pleuro-parietal connective. It passes outward and forms an anastomosis with a branch of the second pedal nerve (p.2) of the right side. The double trunk thus formed then breaks up into a number of branches in the peritoneal membranes and in the dorso-lateral wall of the body.

Buccal ganglia. The buccal ganglia (buc. g) are nearly vertically placed upon the posterior face of the pharyngeal bulb just below the beginning of the esophagus (P1. III, fig. 9) and present an anterior slightly concave face in contact with the bulb, and a posterior arched one, turned away from it. These ganglia are plump rounded bodies of an elliptical outline, slightly flattened, and closely united in the median line by a broad and very short commissure. On Plate II the buccal ganglia are shown in their relations with the remainder of the central nervous system; in figures IO and II of Plate III they are shown isolated in ventro-posterior and dorso-anterior views respectively. The short strong cerebro-buccal connectives (c.b. con.) unite them to the cerebral ganglia above, being inserted laterally upon the posterior surface, between the bases of the second and third buccal nerves (Pl. III, figs. 9, Io and II), and curving laterally upward to the cerebral ganglia. All the nerves of the buccal ganglia bear small white pigment spots arranged in a single series at regular intervals along their proximal portions.

Buccal nerves. In the description following the numbering of the nerves follows their order of origin from the anterior end of the ganglia backward, an order followed by Mazzarelli on p. 
IO7 of his Monografia, but the notation of his fig. 9, tav. IV does not follow the same, nor is there any reference made to the figure in the description.

The first nerve is a strong, unpaired, median one arising upon the dorsal, median region of the group by the union of a large bundle of fibres from each ganglion (Pl. III, fig. I I, $r$ ). It almost immediately bifurcates into two equal subdivisions which pass directly into the pharyngeal bulb, and are distributed to the muscles of the rotella, bearing the radula.

The second nerve (Pl. III, figs. 9, IO, II, 2), arises anterolaterally and courses around the external face of the pharyngeal bulb to the attachment of the lateral $M$. retractor bulbi. Here it divides into two branches, the posterior one passing directly inward, ramifies among the deep muscles of the radula, while the anterior branch courses forward and is distributed to the M. ant. lateralis bulbi, and to the deeper muscles of the bulb.

The third nerve (P1. III, figs. 9, IO, I I, 3), arises close above the base of the second nerve and passes around the side of the bulb above and diverging slightly from it. At the posterior border of the M. antero-lateralis bulbi it forks and passes beneath that muscle, giving off branches to it as it passes deeper into the bulb. It may be traced forward to the anterior end of the bulb, where its delicate branches are finally lost among the deeper, circular muscle fibres.

The fourth nerve (P1. III, figs. 9, Io, II, 4) arises from the lateral margin of the ganglion, behind and above the origin of the third, and passes upward over the postero-dorsal face of the pharyngeal bulb, following closely the external border of the proximal portion of the salivary gland to the appearance of its duct at the surface of the bulb. Near this point it penetrates the outer layers of the muscular wall, and passes forward in it to the anterior end of the bulb, giving off numerous branches to the muscles of the dorsal portion.

The fifth nerve (P1. III, figs. 9, IO, II, 5) is quite small, and may be readily overlooked, or considered as a branch of the sixth one. It arises close to the base of the latter, between it and the fourth, and, on the left side, seems indeed to be a basal branch of the sixth in many cases (P1. III, fig. Io, 5). On the right side, however, it is distinct in origin. It is probably to be 
regarded as a salivary branch of the sixth, as it is distributed to the salivary gland, and thus would correspond to the branch shown by Mazzarelli in the Neapolitan forms as arising well up from the base of that nerve.

The sixth nerve is a strong and important one. It corresponds to No. III of Mazzarelli's text, and to No. 4 of his fig. 9, tav. IV. It is shown in figs. 9, Io and II, of Pl. III as arising from the posterior margin of the buccal ganglion, and bifurcating after a short course. Its anterior division soon gives off a median branch which breaks up in the wall of the esophagus, while the remainder continues forward between that organ and the salivary gland, giving off slender branches to each, and is finally distributed to the roof of the pharyngeal cavity at the beginning of the esophagus. The posterior division of the sixth nerve forms the esophageo-gastric nerve of each side. It courses backward along the esophagus, over the ingluvies, giving off fine branches at intervals to its walls. At the anterior boundary of the first triturating stomach these two main lateral trunks, together with several of their branches, unite in a circular plexus of fibres around the anterior margin of this division of the stomach. From this plexus, in which no ganglionic enlargements were found, nerves pass into the wall of the digestive tube, and several (six or more) branches course backward to the second triturating stomach, in the wall of which they branch and anastomose irregularly, and thence are continued further back along the intestinal tract in a similar manner.

Parieto-visceral ganglia. The position of the parieto-visceral ganglia, the "deuto-visceral ganglia" of Mazzarelli ('92) has been mentioned above in connection with the pleural ganglia. The two ganglia (Pl. III, fig. I4), are completely fused together, forming a pear shaped mass, and show indications of their double nature at their anterior end alone, at the entrance of the two connectives. The right, or pleural ganglion is uppermost, lying directly above the left, or visceral ganglia. From them are given off the following important nerves.

Visceral nerves. From the left visceral ganglion arise three nerves. The first of these $(l . v . I)$, is the smallest. It originates from the postero-dorsal side of the ganglion, and, dividing into 
three main branches, is distributed to the vesicle of Swammerdam and its duct.

The second $(l, v .2)$, is a strong, flattened nerve from the posterior right side of the ganglion. It passes backward along the body wall, giving off a branch to the liver, another to the large hermaphroditic duct, a third which soon bifurcates, one subdivision being distributed to the dorsal peritoneum and muscles, the other, recurving forward, gives off a number of delicate branches to the dorsal peritoneum and muscles, and itself anastomoses with a branch of the third right pedal nerve, the united nerves sending a branch to the posterior face of the Organ of Bohadsch. The main trunk of the nerve continues backward, penetrates the dorsal body wall, and bifurcates to the anal portion of the alimentary canal and to the walls of the siphon.

Close to the left of the second nerve arises an equally strong nerve, very soon dividing into two main trunks, which pass backward, diverging from each other. In the largest specimen these two trunks arose as separate nerves from the ganglion. The left one $(l \cdot v \cdot 3 a)$, of these sends a branch to the liver, a more slender one to the muscles of the dorsal body wall, while the main trunk curves upward around the posterior wall of the pericardium, and thence forward in its dorsal wall, and is distributed to the heart and the kidney. The right main branch (l. $v .3 b$ ), of the third nerve sends a branch to the liver, another to the large hermaphroditic duct, and, crossing the base of the adnexed genital mass, gives off a branch to the small genital ganglion lying upon it. Crossing the small hermaphroditic duct, it gives off two branches to it, and, continuing backward, finally terminates among the muscles in front of the posterior portion of the alimentary canal.

Parietal nerves. From the right, or parietal ganglion arise two nerves. A short distance behind the junction of the pleuroparietal connective with the anterior end of the parietal ganglion the first nerve $(r . p . I)$, is given off. It is a small trunk, sending a number of branches to the region of the genital opening, while another branch ( $I a)$, courses forward and unites with a branch of the third pedal nerve, thus forming a parieto-pedal connective. In one individual the branch of the third pedal nerve continued on to unite directly with the parietal ganglion, close to the entrance 
of the pleuro-parietal connective, simply receiving a small anastomosing branch of the first parietal nerve.

The second $(r, p, 2)$, is a very large nerve originating from the dorsal side of the posterior end of the parietal ganglion. It passes backward for a short distance, and terminates in a good sized ganglion, lying below the integument in front of the branchia. From this ganglion a nerve is sent to the ctenidium and the wall of the branchial chamber, another penetrates deeply among the muscles of the body wall, in front of the kidney and is probably distributed to the mantle, though its course could not be made out with certainty. The main portion of the ganglion supplies the osphradium, or organ of Spengel, a conspicuous oval elevation with a depressed center, situated just in front of and slightly above the base of the ctenidium.

\section{The Reproductive System.}

The excellent work of Mazzarclli ('9I) upon the reproductive apparatus of the Aplysiidae has cleared up many doubtful points in the structure and functions of this complicated system, though much remains still to be done. In the following discussion of this system in Tethys dactylomela I use the nomenclature adopted by him.

The reproductive system of the Aplysiidae is made up of the following structures, given in their order of occurrence from behind forward.

I. The ovotestis, or hermaphroditic gland.

2. The small hermaphroditic duct.

3. The adnexed genital mass, consisting of the nidamental anci albumen glands, the fertilization chamber, and the convoluted and spiral portions of the genital duct.

4. The spermatocyst and duct of Cuvier.

5. The large hermaphroditic duct.

6. The spermatotheca, or vesicle of Swammerdamm.

7. The external spermatic groove.

8. The penis and its sheath.

The ovotestis forms the posterior end of the visceral mass, being more or less extensive depending upon the degree of sexual maturity of the individual. In the largest specimen at hand ( $140.0 \mathrm{~mm}$. in total length) the ovotestis is large, flattened 
ovoidal in shape, all its surface being convex, save the anterior one, which is irregularly concave to correspond with the surface of the posterior end of the liver and intestine, with which it is in close contact. Its surface is finely lobulate, light brown in color. From the antero-dorsal surface appears the light brown small hermaphroditic duct, very strongly convoluted in its course, $0.20 \mathrm{~mm}$. in average diameter, its length being approximately $45.0 \mathrm{~mm}$., though this could be estimated only, as it was impossible to straighten out its windings. Its distal end passes obliquely across the ventral side of the adnexed genital mass, thence recurving dorsally to enter the latter. The "adnexed genital mass" is a term applied by Robert ('89) to designate a complex made up principally of the nidamental and albumen glands and certain modifications of the genital duct. It is in the form of a dorso-ventrally flattened cone, situated obliquely to the longitudinal axis of the body. In the smaller specimens it was nearly flat, in the largest one quite large and more prismatic in form, its ventro-anterior surface flattened, the dorsoposterior one strongly arched. In length it varies from $2.0 \mathrm{~mm}$. to $13.0 \mathrm{~mm}$., and in width from $1.0 \mathrm{~mm}$. to $10.0 \mathrm{~mm}$. The texture of the largest one was very firm and somewhat brittle, the great increase in size being due to the activity of the nidamental and albumen glands. The small hermaphroditic duct, entering the anterior side of the basal portion of the mass, dilates into an irregular cavity, the fertilization chamber, into which open the duct of the albumen gland and the duct of Cuvier from the spermatocyst. Beyond this fertilization chamber the genital duct becomes very much convoluted for a short distance, passing thence over into the spiral portion, which largely constitutes by its windings the free portion of the mass, and incloses in its loops the greater portion of the albumen gland. Throughout the turns of this spiral one side of the duct is modified into the nidamental gland by a series of complicated foldings, the lumina of which communicate freely with the duct proper. Returning upon itself from the apex of the mass, the spiral portion widens out into the large hermaphroditic duct proper. By two longitudinal folds from opposite sides of this large hermaphroditic duct it is incompletely divided into two conduits. Owing to secondary twisting the relation at first existing of a right and a left portion 
becomes modified in the course of the duct. At the proximal end the spiral portion of the genital duct is continued into the right half, while that on the left is prolonged into the duct of the spermatocyst and the duct of Cuvier, the latter communicating with the fertilization chamber. These relations may be more readily made out in an immature than in an adult specimen, and best of all, in serial sections. The spermatocyst is a pear shaped sack, doubled upon itself, situated at the anterior margin of the base of the adnexed genital mass, from which it projects freely for the greater portion of its length. It is ca. $4.9 \mathrm{~mm}$. long and $2.3 \mathrm{~mm}$. in maximum diameter in the largest specimen examined, but much smaller in the others.

The large hermaphroditic duct extends from the adnexed genital mass to the vulvar opening, with a length of $17.9 \mathrm{~mm}$. and a diameter of $0.5 \mathrm{~mm}$. in the largest individual. It is externally marked to correspond to its internal differentiation into two ducts, the one on the right the ovo-spermatic, that on the left the copulatory duct. The latter duct, beyond the entrance of the duct of the spermatocyst, becomes the vagina. The outer surface of the right of these ducts is of a yellowish brown color and transversely rugose. The surface of the left half is smooth and dark brown. At a distance from the vulvar opening of about one-fifth the whole length of the large hermaphroditic duct, the duct of the spermatotheca, or vesicle of Swammerdam opens into the left or copulatory duct. The vesicle itself is a large, spherical structure, $5.0 \mathrm{~mm}$. in maximum diameter, lying immediately to the left of the parieto-visceral ganglion. By a slender duct, $0.9 \mathrm{~mm}$. in diameter and $6.2 \mathrm{~mm}$. in length, in the largest specimen, it communicates with the copulatory duct.

The right half of the large hermaphroditic duct, which functions alike as oviduct and vas deferens, the ovo-spermatic duct, the "ovidutto-deferente" of Mazzarelli, is continued forward as a narrow external groove along the right side of the animal from the genital opening to the right side of the head, close below the right anterior tentacle. In the largest specimen the external spermatic groove measured $85.00 \mathrm{~mm}$. in length. Here it is continued inward along the inner wall of the penis sheath to its base, whence it recurves along the side of the penis to its tip, thus forming a conduit for the spermatozoa in copulation. 
The penis sheath has moderately thick, muscular walls, is nearly cylindrical, slightly tapering in the retracted condition. The diameter of its proximal end is $2.0 \mathrm{~mm}$. the total length II.5 mm. in an individual of $70.0 \mathrm{~mm}$. total length. To its proximal end are attached two strong retractor muscles, a dorsal and a ventral one. Along the outer dorsal side of the lumen the spermatic groove is continued as a deep depression, the margins of which are elevated into prominent ridges, and more or less sprinkled with brown pigment, which in some case is aggregated into continuous narrow longitudinal lines. At the basal end of the penis sack this groove is reflected forward upon the surface of the penis along its full length to the tip. The penis is a flattened muscular organ, tapering distally to a blunt point. In the specimen of $70.0 \mathrm{~mm}$. total body length, it measured $1.9 \mathrm{~mm}$. in maximum basal diameter, with a total length of $7.5 \mathrm{~mm}$., though the presence of numerous transverse folds in the basal portion indicated that this was not the full normal length. No trace of pigmentation is evident, nor is there any specialized armature developed. The external groove is ciliated throughout its whole extent.

\section{The Organ of Bohadsch.}

The organ of Bohadsch, or hypobranchial gland, (P1. III, fig. I7), is a large yellowish white structure, irregularly spherical in form, and $15.5 \mathrm{~mm}$. in diameter in the largest specimen. Its surface has the characteristic nodular appearance due to the very large cells of which it is composed. In the largest specimen the texture of the gland was for the most part quite firm, in the smaller ones very soft, a difference apparently due to the large amount of secretion present in the former. The single duct is short and broad, the large, external opening conspicuously located below and slightly behind the anterior margin of the base of the ctenidium.

\section{Excretory and Circulatory Systems.}

The relations of the kidney and the pericardium are substantially the same as described by Cunningham ('83) for the Mediterranean species, and will not be taken up in detail.

Leland Stanford Junior University Zoological Museum, Invertebrate Series No. I43. 


\section{Tethys cervina Dall and Simpson.}

Plates. III-VIII, Figs. 15-35; Plates IX-X, Figs. 39-42.

Tethy's cervina Dall and Simpson, The Mollusca of Porto Rico.

Bulletin U. S. Fish Commission, XX, I900, Part I. (Issued Nov. 29, I901). p. 365, Pl. 56, fig. 2.

One specimen of a Tethy's different from the foregoing, labeled "Sand Beach, Maceio, Alagoas. July 31, I899. A. W. Greeley col." was found in the collection, no other notes accompanying it. In my opinion it is identical with the Tethys cervina of Dall and Simpson taken at Mayaguez, Porto Rico, and described in the publication cited above. The description of Dall and Simpson is as follows:

"Body elongated, flabby; mouth encircled by thick lips; tentacles short; eyes inserted in front of the tentacles. Swimming lobes thick, united behind at some distance in front of the hinder extremity; mantle orifice minute; mantle ending behind in a small fold; foot narrow, nearly smooth.

"Colors: The body is a lurid gray, overlaid with reticulations and blotches of darker color. It also has scattered, small, nearly round, smoky brown spots throughout its surface. The foot is smoky brown, lighter color than the spots. The inner edges of the swimming lobes are beautifully and distinctly maculate, with alternating light and dark patches. The mantle is colored like the body, but the dark spots are wanting, and the dark reticulations are somewhat radiating. Length $7 \mathrm{~cm}$.

"Shell with a rather strong layer of lime, elliptical in outline; posterior sinus moderate. Length of shell 30 ; breadth $19 \mathrm{~mm}$.

"Mayaguez, Porto Rico."

The following points are based upon the Brazil specimen, and will serve as supplementary to the description of the former authors in anatomical details.

\section{External Characters.}

Body form. The body (Pl. X, fig. 4I), is soft, plump and smooth, the head and caudal regions being rather contracted, the remainder of the body but little distorted. The total length of the specimen is $40 \mathrm{~mm}$., its width and height being $20 \mathrm{~mm}$. 
Color. The general color is a pale yellowish gray, sprinkled above and on the sides with minute dark brown spots. The dorsal surface of the mantle, covering the shell, is pale grayish, with fine slightly elongate markings of dark brown arranged in inconspicuous radiate lines around the minute opening into the shell cavity. These radiate bands of dark color branch irregularly above the periphery of the shell and merge into the general mottling of the body. The sides of the body are marked with a few (eight to ten), irregularly scattered, larger, dark brown flecks, the largest of which is not over $1.0 \mathrm{~mm}$. in diameter. The inner surface of the parapodial lobes is marked with irregular dark brown maculations, alternating with lighter areas. The foot is light brown throughout. These notes were all made from the specimens while in formalin. On being transferred to alcohol, the darker colors gradually became much paler and disappeared more or less completely throughout.

Foot. The foot is very narrow, being strongly contracted, especially midway of its length, there being reduced to $2.0 \mathrm{~mm}$. in width, but broadening in front to $7.0 \mathrm{~mm}$., and behind to 4.0 mm., terminating in a short, bluntly pointed tail. The anterior end of the foot is broad and blunt with rounded outer angles.

Parapodia. The parapodial lobes are $29 \mathrm{~mm}$. in length, occupying nearly three-fourths of the entire length of the animal. They are rather low and not at all prominent, being but $10.0 \mathrm{~mm}$. in extreme height. The lobes are fleshy, their margins thin and slightly undulating, being slightly rugose locally, a condition probably due to contraction. The anterior ends of the lobes are widely separated, the interval being $6.5 \mathrm{~mm}$., which is lessened at the posterior end to $0.5 \mathrm{~mm}$. though the lobes are distinct and not completely joined behind the siphon.

Mantle. The mantle area is distended and plump, the minute central opening into the shell cavity is borne upon a low papilla, which is rendered more conspicuous by the radiate pigmentation above described. On the right side the mantle extends in a thin-edged semitranslucent flap over the gill cavity. Posteriorly its right margin is deeply notched, the edges being elevated and rolled together, forming the prominent excurrent siphon, which extends backward and upward between the edges of the parapodia to a height of $3.0 \mathrm{~mm}$. 
Shell. The shell (Pl. X, fig. 40), is very thin and membranaceous, the calcareous portion, small in amount, having been broken and detached, was nearly all in small fragments in the shell cavity. The outline of the intact membranaceous portion is elliptical, with a moderate posterior sinus, as described by Dall and Simpson. In length it measures $14.7 \mathrm{~mm}$. and in maximum width $9.8 \mathrm{~mm}$., though the membranaceous condition renders the actual curvature a matter of some doubt.

Pallial cavity. The pallial cavity is roomy, the branchial plume, of the usual Tethy's type, is nearly semicircular in outline, and extends transversely beneath the shell, its left margin reaching well to the left side, the right tip projecting slightly from beneath the mantle margin.

Anal and renal opening. The anal opening is pocket like, and situated upon the rear wall of the siphon tube, near its base. In front of it lies the small inconspicuous renal opening near the base of the branchia.

Hypobranchial gland. The external opening of the Organ of Bohadsch, or hypobranchial gland, lies upon the summit of a low thickened elevation, just below the anterior end of the base of the branchia, and $2.0 \mathrm{~mm}$. distant from it. Upon the ventral surface of the anterior end of the base of the branchia is situated the osphradium, in the form of an oval yellowish depression. Through the transparent body wall of this region many of the nerves from the parieto-visceral ganglion complex may be traced for varying distances.

Reproductive openings. The genital opening lies just in front of the anterior edge of the mantle, and is marked by an increased pigmentation which is carried backward along the body wall toward the opening of the Organ of Bohadsch. The female portion of the opening is oblique and slitlike, the portion lying above it is prolonged forward as a deep conspicuous groove along the side of the body and head to the opening of the penis, close to the right anterior tentacle, upon the side of the head.

Tentacles. The anterior tentacles are strongly contracted, broadly auriform, with a well developed external groove. Their contracted condition precluded any even approximate measurements. The posterior tentacles, or rhinophores, are also strongly contracted, extending but $1.5 \mathrm{~mm}$. above the surrounding sur- 
face. They are composed of the usual rolled plate with an external, auriform slit. The bases are wide apart being separated by $3.0 \mathrm{~mm}$. distance.

\section{Internal Anatomy.}

The animal was opened along the median line of the foot by a longitudinal incision, in order to disturb the viscera as little as possible. The peritoneum is colorless, the liver light chocolate, the grey windings of the intestine inclosing it in spiral turns.

\section{Alimentary System.}

Pharyngeal bulb. The pharyngeal bulb is nearly spherical and slightly elongate, the radula sack projecting from its ventral surface as a prominent, rounded eminence. The salivary glands are long, slender and strap shaped, their relations being similar to Tethys dactylomela and other Aplysiidae. A pair of oblong lateral laminae, placed obliquely, the mandibular plates, (Pl. III, fig. I5), guard the entrance of the pharyngeal bulb, being separated above and below by a narrow interval. The extreme width of a mandible is approximately two-thirds of its greatest length, the actual measurements in the individual at hand being $3.00 \mathrm{~mm}$. in length by $1.9 \mathrm{~mm}$. in width. The borders of the mandibles are rounded. Each lamina is made up of a countless number of flexible, nearly straight rodlets with slightly dilated blunt tips (P1. III, fig. I6), having a maximum length of $0.09 \mathrm{~mm}$. and a diameter of $0.006 \mathrm{~mm}$., the length decreasing toward the posterior border of the lamina, the diameter remaining the same, the rodlet being somewhat flattened antero-posteriorly. The bases of the rodlets are supported by a homogenous horny cuticula of considerable thickness.

Radula. The radula is of a deep amber color in its anterior older portion, becoming much lighter posteriorly. It measures $5.0 \mathrm{~mm}$. in greatest length by $4.8 \mathrm{~mm}$. in width at its posterior end, tapering, at first gradually, then more rapidly for the last two-fifths of its length to a rounded anterior end. The anterior rows of teeth are incomplete, being worn away and broken by use. The teeth are arranged in 38 rows, the last 15 of which are inclosed in the radula sheath. The number of teeth in each 
row increases from $16: 1: 16$ in the oldest complete row to $22: 1: 22$ in the thirtieth. The dental formula of this individual may be expressed then as 38xi6-22:I:I6-22. The rhachis bears a single, massive tooth (P1. IV, fig. 23 ; P1. V, fig. $26, m$ ), its base, trapezoidal in form, measuring $0.27 \mathrm{~mm}$. in width at its posterior end and $0.132 \mathrm{~mm}$. in length, varying but slightly from these dimensions throughout the length of the radula. The posterior margin is slightly emarginate, the anterior one deeply so, the curve being carried up on the anterior face of the hook as a broad, deep groove. The anterior end is prolonged upward and backward in a strong hook, terminating in a stout, triangular, median cusp, upon either side of which are borne two smaller cusps typically. The larger of these, next to the median one, is from one-half to two-thirds the length of the latter; the outer ones are very much smaller and are more variable in both form and size.

With the exception of the outermost three to five teeth, the lateral teeth are strongly hooked and of similar form, decreasing gradually in size toward the outer borders of the radula (Pl. IV, figs. 23-25). Each lateral tooth (P1. IV, figs. 23-25; P1. V, figs. 26-30), consists of a stout oblong base obliquely placed, from the dilated anterior end of which arises a stout hook, terminating in a triangular cusp. The sides of this cusp bear four to ten denticles, quite small near the tip and, in general, increasing in size toward the base, though irregularities in this are not infrequent. Upon the inner side of each tooth, at the base of the hook, the series of denticles is terminated usually by a very large and broad denticle, while upon the outer flank of the main cusp a series of two or three smaller cusps is borne. In the radula of Tethys dactylomcla there is but one external cusp in this position, which is usually itself denticulate, but in $T$. cervina the margins are uniformly smooth (cf. P1. I, figs. I-5, and P1. IV and V, figs. 23-30). Indications of a fourth lateral cusp at the extreme end of this series are frequently found. The first ten laterals are approximately equal in size ( $\mathrm{Pl}$. IV, figs. $23-24, I-I O)$, the remaining ones decrease toward the outer border of the radula ( $\mathrm{Pl}$. IV, fig. 25), the hook finally becomes rudimentary and disappears altogether, the outermost three to five teeth being reduced to oblong flattened plates (Pl. V, fig. 28). The teeth of this species 
are in general about two-thirds the size of those of Tethys dactylomela.

The visceral mass nearly fills the body cavity of the animal. It is made up of the esophagus, the three divisions of the stomach, and the intestine, the latter inclosing in its windings the liver and the ovotestis.

Esophagus and stomach. The esophagus is short and rather thin walled, dilating into the very ample first stomach, or ingluvies (Pl. VI, fig. 3I, ingl.), a thin walled sack, densely packed with fragments of algae. The whole alimentary canal is spirally twisted from left to right, clockwise. The ingluvies occupies about one turn of this spiral, the second, or grinding stomach (P1. VI, fig. 3I, m. st.), together with the third gastric division completing about one-half of the second turn. The anterior end of the ingluvies dilates rather suddenly from the esophageal tube, the posterior end tapering more gently to the broad band like circular constriction in the canal, marking externally the limits of the thick walled, muscular, second, or grinding stomach (Pl. VI, fig. $31, m$. st.). This portion is about $4.0 \mathrm{~mm}$. in length by $5.0 \mathrm{~mm}$. in diameter at its anterior end, tapering somewhat posteriorly. Its inner surface bears a number of strong horny teeth, arranged in five somewhat irregular rows, the anterior ones of which contain the smaller teeth, the succeeding ones increasingly larger, and the last two the largest. The tips of this gastric armature meet in the center of the lumen in the contracted condition, thus making a most effective gastric mill. In general the form of these teeth is the same throughout, being that of a four sided pyramid, the base a rhomb in outline with one of the acute angles directed forward. In the largest teeth of the posterior rows (P1. III, fig. 2I ), the crest is either single, rounded and bluntly pointed, or wedge shaped, being prolonged into a transverse ridge. In most cases this ridge shows three distinct summits, separated from each other by shallow depressions, which are continued downward upon the anterior face in two deep grooves, while the posterior face is more uniformly convex. The base frequently presents a transverse median depression upon its ventral surface, corresponding in position to the region of greatest elevation above (P1. III, fig. 2I). The smaller teeth, found in the two anterior rows, have a single groove upon the anterior face, carried up to 
the cusp, which is single, and may present the form of a point (P1. III, figs. 18, I9), or of a transverse wall with a concave front face (Pl. III, fig. 20). At the anterior margin of each of these smaller teeth rises a lower median cusp, which is connected by a lower sloping ridge with the posterior higher main one (Pl. III, figs. 18, I9). All these teeth are borne upon thickened disks of epithelium with elevated margins and concave central portions, corresponding to the convex bases of the teeth.

The third stomach (Pl. VI, fig. $3 \mathrm{I}, 3$ st.), is nearly as thin walled as the first one, and is about one-fourth as long, being 6.0 $\mathrm{mm}$. in length upon its greater curvature. It increases in diameter from the posterior border of the second stomach for a short distance, then tapers as it becomes imbedded in the posterior visceral mass. The inner wall of the third stomach bears a circular band of small flattened horny teeth, approaching close to the anterior margin of the stomach on the side of the lesser curvature, and arching backward from this region around the greater curvature, there reaching a distance of $4.0 \mathrm{~mm}$. from the anterior margin. The tooth bearing zone is $2.0 \mathrm{~mm}$. in width throughout its whole extent. The teeth are much more highly developed than in Tethys dactylomela, are curved and conical in shape (P1. III, fig. 22), and are much more irregularly arranged than in the second stomach, small and large teeth being intermingled. Behind this tooth bearing zone a few small and slender teeth of similar shape are irregularly scattered.

Intestine. The intestine is twisted in a slightly more complicated way than the gastric region just described, the greater part describing a wide loop upon the left side and upper surface, the terminal portion then returning to the simple spiral form (P1. VI, fig. 3I, int.). Within the coils of the intestine are inclosed the liver and the ovotestis, the outer surface of the former showing throughout its whole extent, though so deeply imbedded in the liver as to everywhere present a smooth surface. It is a simple, thin-walled tube save at the most anterior portion, where it is dilated somewhat, and receives a slender diverticulum, the "hepatic coecum" of Mazzarelli and Zuccardi (Pl. VI, fig. 3 I $h$. $c \propto$.). Upon opening the intestine at its anterior end a large cavity in the substance of the liver is disclosed (P1. VI, fig. 32), into which open three large principal ducts and several smaller 
ones, which ramify throughout the liver, conveying its secretion to the central biliary cavity. Into the posterior side of this chamber opens the hepatic coecum (Pl. VI, fig. 32, h. cox.), a narrow curved cylindrical tube, at first imbedded in the liver, but appearing at its surface for the distal third of its length. It is $9.0 \mathrm{~mm}$. in length, the diameter varying from $1.0 \mathrm{~mm}$. to 1.25 $\mathrm{mm}$. It is traversed by two longitudinal folds, arising from opposite sides, the one higher than the other, which meet and overlap, thus dividing the lumen into two practically separate, longitudinal portions, united at the blind, distal end. At the opening of the coecum into the bile chamber, the anterior one of these communicates freely with the latter, its walls being grooved and folded in prolongation of similar folds and grooves in the wall of the bile chamber. The posterior half of the coecum communicates as a deep groove with the intestine, one of the median, longitudinal folds in the wall of the coecum being continued across the opening of the bile chamber and down into the intestine (Pl. VI, fig. $32, l . r$. ), there gradually merging with its wall.

\section{The Central Nervous System.}

The central nervous system (Pl. VII, fig. 34) is made up of three pairs of ganglia resting upon the posterior end of the pharyngeal bulb, and, with their commissures, encircling the commencement of the esophagus. These are the cerebral, the pedal and the pleural ganglia, each pair united by commissures of varying length, while the ganglia of each side are united in a triangular grouping by the cerebro-pedal, the cerebro-pleural, and the pleuro-pedal connectives. Close to these ganglia, and to be included with them in the central nervous system, are the buccal ganglia, situated on the ventral side of the esophagus, and forming with their cerebral connections, the cerebro-buccal connectives, another ring around the anterior end of the alimentary canal. These structures will be taken up briefly in the following description. On plate VII is figured a dorsal view of the whole central nervous system of Tethys cervina, excepting the buccal ganglia, together with the origins of the nerves taken up in the following pages. As in the similar figure of the preceding species of Tethys, given on Plate II, the nerves are numbered in the 
order of their appearance from in front and above downward and backward. All abbreviations in the following description refer to fig. 34, Plate VII, unless otherwise indicated.

Cerebral ganglia. The cerebral (cer. g.) ganglia are completely fused together into a large quadrilateral mass, all traces of their primitive separation into right and left moities having disappeared. The nodulated dorsal surface of the mass is highly arched, the ventral slightly concave. In width the complex measured $1.5 \mathrm{~mm}$., in length $0.9 \mathrm{~mm}$. and in thickness $0.7 \mathrm{~mm}$. A slender, sub-esophageal, cerebral commissure passes below the esophagus, connecting the halves of the ganglionic mass together ventrally. In fig. $34, \mathrm{Pl}$. VII, s. c. com., it is seen inclosed in the same sheath of connective tissue as the pedal commissure and lying at its anterior margin.

Cerebral nerves. From the cerebral ganglia arise six pairs of nerves and three connectives, the origins of which are the same for each side.

The first cerebral nerve ( $c . I)$ arises from the anterior outer face of the ganglion, and courses forward to its distribution to the skin and the muscles of the mouth region.

The second cerebral nerve $(c .2)$ arises immediately behind the first, and is much larger. It curves forward along the pharyngeal bulb, giving off, midway of its length, a strong outer branch to the anterior tentacle, in which it terminates in a small ganglion. The main trunk breaks up into a number of divisions, which are distributed to the muscles and integument of the mouth region.

The third cerebral nerve (c. 3 ) arises from the upper dorsal border of the ganglion, and is distributed mainly to the rhinophore, in which it terminates in a small ganglion. It also gives off two or three slender branches, the first and largest of which forms, apparently, an anastomosis with the optic nerve. It is not a true fusion, however, the two nerves being merely united in a common, epineural sheath for a short distance. The distribution of this and the other slender branches of the third nerve is to the integument in the neighborhood of the eye and rhinophore. Upon the right side a true anastomosis occurs with a branch of the second pedal nerve, as shown at $x$. in the figure and to be described further on. 
The fourth, or optic nerve $(c .4)$ is slender, long and unbranched. It arises from the dorsal margin of the ganglion and passes outward and upward to the eye. No special optic ganglion can be made out at its base without serial sections.

The fifth cerebral nerve (c. 5) arises from the postero-lateral face of the ganglion, immediately above the origin of the cerebrobuccal connectives. It is a rather slender nerve, passing forward and ramifying to the muscles of the mouth region. That of the right side sends, in addition, a branch to the penis.

The sixth cerebral, or auditory nerve, is closely associated with the cerebro-pedal connectives and is not visible in dorsal view. It arises close to the base of the connective, and follows it to the upper face of the pedal ganglion where it terminates in the otocyst, being throughout its course inclosed in the connective tissue sheath of the cerebro-pedal connective (c. p. con.).

Three sets of connectives arise from the cerebral ganglia, the cerebro-buccal, the cerebro-pleural and the cerebro-pedal. The first named pair is the longest, arising from the outer ventral margins of the ganglia, and encircling the anterior end of the esophagus to unite with the buccal ganglia beneath. They are not visible in fig. 34. The cerebro-pedal connectives ( $c . p$. con.), pass obliquely outward and backward from their origins upon the postero-ventral margin of the cerebral ganglia to the pedal ganglia (ped. g.). They are short and thick, and are inclosed in a strong connective tissue sheath with the cerebro-pleural connectives $(c . p l$. con.), which are of nearly equal diameter, but less long.

Pedal ganglia. The pedal ganglia ( $p e d . g$.$) , are rounded$ flattened structures, measuring $1.4 \mathrm{~mm}$. in diameter and $0.6 \mathrm{~mm}$. in maximum thickness. They are connected below the esophagus by a strong commissure ( $p$. com.), I.o mm. long and $0.15 \mathrm{~mm}$. wide. A much longer and quite slender parapedal commissure (p. p. com.), arising from the lower posterior margin of each ganglion also unites the two. Upon the upper margin of the pedal ganglia are received the cerebro-pedal connectives and just behind them the very short plcuro-pedal ones. From each ganglion ten nerves are given off. These will be described for the right side, any difference which may exist upon the opposite one being noted. The nerves are taken in order and numbered in the 
series from the upper anterior margin of the ganglion, downward and backward. For the nerves originating along the outer margin of the ganglion this presents no difficulties, but those nerves which arise from the median portion of the ventro-anterior face are of necessity more arbitrarily assigned their position in the series as indicated.

Pedal nerves. The first nerve $(I)$, is a very slender one, arising from the upper ventro-anterior face of the pedal ganglion, just below and external to the entrance of the cerebro-pedal connective, and very close to the origin of the second nerve. It passes outward and forward to the integument in the eye region.

The second nerve (2), is similar in size to the first nerve, arises quite close to it, and in some specimens may possibly be found to branch from a common trunk with it. It courses outward and upward, dividing into two branches near the proximal end of the penis. The dorsal one of these branches passes to the dorsal retractor of the penis sheath, the ventral subdivision gives off a twig which anastomoses with a branch of the third cerebral nerve, another to the ventral retractor of the penis sheath, and then courses forward below the penis to its distal end, giving off several minute branches to it. The extreme ramifications of this portion of the nerve are to the anterior end of the penis sheath and to the muscles and integument surrounding it. Upon the left side this nerve is distributed to the muscles and integument of the body wall from the eye forward.

In Tethys dactylomela these two nerves, numbers one and two of $T$. cervina, are represented by but one nerve, described as the first on page 27 , and so figured in Pl. II, p. $I$, but with the same distribution as the first and second here described.

The third pedal nerve (3) arises from the upper external margin of the ganglion and bifurcates almost immediately. The anterior one of these branches divides in turn almost at once, one branch, $3 a$, forming an anastomosis with the first pleural nerve $(p l . I)$, being like it distributed to the dorsal peritoneum and musculature back to the heart region, the other, $3 b$, passing directly backward to a similar distribution. The posterior main branch $(3 c)$ is much longer and is shown in detail in fig. 35 of P1. VIII. It curves backward, sends off a branch (fig. $35,3 b$ ), to the right lateral retractor muscle of the head, and to the body wall 
above it, another (fig. 35, 3c), to the Organ of Bohadsch, or hypobranchial gland, and finally (fig. $35,3 f$ ), unites with the first nerve from the right parietal ganglion, thus forming a parieto-pedal connective. From the above mentioned branch (fig. $35,3 b$ ), to the lateral retractor of the head a branch is given off which courses backward along the body wall, passes beneath the right margin of the Organ of Bohadsch, and well beyond the latter forms an anastomosis at an acute angle with the recurrent branch (fig. 35, 2c) of the second nerve (fig. 35, l. v. 2), of the left visceral ganglion, which also sends a branch to the Organ of Bohadsch, as will be described below. In Tethys dactylomela the third pedal nerve is represented by two separate nerves, the second and third of the description on page 28 , they corresponding in their distribution to the third nerve alone of $T$. cervina.

The fourth pedal nerve (4) is long and slender, arising from the outer margin of the ganglion and passing backward to the parapodium of the same side.

The fifth pedal nerve (5) is a strong one from the median lateral margin of the ganglion. Close to its origin it gives off a slender branch ( $5 a)$ which might possibly be considered a separate nerve, though its distribution is the same as that of the main nerve, to the parapodium. In $T$. dactylomela a similar branch is given off from the fifth nerve, but its origin is further removed from the base of that nerve. Its distribution is the same as that here indicated.

The sixth, or posterior pedal nerve (6) is the longest of the nerves from the pedal ganglion. It arises from the mid-lateral margin of the ganglion, curves backward, unbranched for over one-half of its course, and is distributed to the posterior portion of the foot.

The seventh pedal nerve ( 7$)$ arises upon the lower portion of the ventro-anterior face of the ganglion, below the origin of the first and second nerves. Like these and the ninth is is closely imbedded in the connective tissue surrounding the pharyngeal bulb and may be dissected out with some difficulty. A branch of the seventh forms an anastomosis with the ninth, and both are distributed to the muscles and integument of the side of the head. The nerves of both sides are alike in origin and distribution.

The eighth, or median pedal nerve $(8)$ is a strong trunk 
arising from the outer lower margin of the ganglion and is distributed to the middle region of the foot. Upon the left side its origin is slightly more removed from that of the tenth.

The ninth pedal nerve (9) arises from the ventral portion of the lower anterior face of the ganglion. It is quite slender and forms an anastomosis with a branch of the seventh. Its distribution has been given above in connection with that of the latter nerve, and is similar on both sides.

The tenth, or anterior pedal nerve $(I O)$, is a large trunk from the outer lower margin of the ganglion. It doubles forward in four main divisions beneath the pharyngeal bulb and is distributed to the anterior portion of the foot.

The order, arrangement and distribution of the pedal nerves is the same for the two species of Tethys here studied, but they disagree markedly with the accounts given by other authors, notably Von Ihering ('77) and Mazzarelli ('93), for the Mediterranean forms. Until I am able to secure material for a detailed comparison of all the species concerned I cannot explain this lack of agreement. Von Ihering ('77) describes and figures but six nerves from each ganglion. Mazzarelli ('93) describes and figures seven paired pedal nerves and one unpaired one upon the right side, and two unpaired ones upon the left, their order and distribution not agreeing with the Brazilian forms, while Lacaze-Duthiers ('87) found but six in all.

Pleural ganglia. The pleural ganglia ( $p l . g$.$) , are situated$ just above, and in contact with the upper surface of the pedal ganglia, with which they are connected by the very short pleuropedal connectives. They are about one-third the size of the pedal ganglia, and are spheroidal in outline, measuring $0.5 \mathrm{~mm}$. in greatest diameter. They are made up of large conspicuous cells, which give their surface a knobbed appearance. Contrary to the descriptions and figures of Von Ihering ('77), and Mazzarelli ('93), I find that the pleural ganglia give rise to the following nerves.

Pleural nerves. From the left pleural ganglion arise two nerves. The first $(p l . I)$, is a slender nerve from the superior face of the ganglion. It passes outward and downward, receives an anastomosing branch from the third pedal nerve and ramifies 
to the peritoneum and the muscles of the dorsal body wall, just above and behind the region of the central nervous system.

The second pleural nerve ( $p l .2)$, arises just exterior to the origin of the pleuro-visceral connective. It passes backward as a long slender unbranched trunk in the dorsal peritoncum, to the region of the pericardium, in the anterior wall of which it ramifies among the muscles.

From the right pleural ganglion but one nerve $(p l . I)$, is given off. It corresponds to the first one of the left side and has a similar distribution. It also receives an anastomosing branch, $3 a$, from the third pedal nerve of the right side.

From the median posterior face of the ganglia arise the long and strong connectives, which pass backward to the ganglion complex upon the visceral loop, situated immediately below the anterior boundary of the pericardium. The left of these connectives ( $p l . v$. con.), is slightly longer than its fellow, measuring I $4.0 \mathrm{~mm}$., as compared with $12.0 \mathrm{~mm}$. for that of the right side. The right of these ( $p l$. par. con.), is the pleuro-parictal connective, the left the pleuro-visceral one. Their peripheral relations will be taken up further on.

Buccal ganglia. The buccal ganglia are oval in outline, each measuring $0.45 \mathrm{~mm}$. in length by $0.42 \mathrm{~mm}$. in width, and are connected by a broad commissure $0.18 \mathrm{~mm}$. in length, so that the two ganglia are distinctly separated from each other, though enveloped in a common connective tissue sheath. From the anterior median face is given off a strong unpaired nerve as in Tethys dactylomela, soon bifurcating to the muscles of the rotella. From the outer side of each ganglion four nerves are given off, in addition to the cerebro-buccal commissures. These nerves are distributed to the pharyngeal bulb, the salivary glands and the esophagus, but their ramifications were not worked out in detail.

Parieto-visceral ganglia. The parieto-visceral ganglion group (Pl. VIII, fig. 35, par. v. g.), is situated beneath the dorsal wall of the body, slightly to the right of the median line and directly below the anterior border of the pericardium. The composition of the group as made up of a right and left portion, fused in the median plane, can be readily made out, but any further division into component ganglia is not indicated in surface view. The double nature of the group is marked only at the 
anterior end by the entrance of the respective connectives, and by a slight groove upon the anterior face. The nerve cells of these ganglia are of the usual gigantic type found in Opisthobranchs generally, and cause the surface of the ganglia to present a series of irregular protuberances.

Parictal nerves. From the right or parietal ganglion arise two nerves.

I. The vulvar nerve (P1. VIII, fig. 35 ; Pl. X, fig. 42, r. p. I), is a delicate trunk from the right side, soon bifurcating into (a), a branch (figs. $35,42, r . p . I a$ ) coursing forward and anastomosing with a branch of the third pedal nerve (Pl. VIII, fig. $35,3 f$ ), forming the pedo-parietal connective before described, and (b), the vulvar nerve proper (Pl. VIII, fig. 35 ; Pl. X, fig. $42, r$. p. $I b$ ), which passes to the anterior end of the large hermaphroditic duct and to the integument surrounding it.

2. The second, or osphradio-ctenidial nerve (P1. VIII, fig. 35; Pl. $\mathrm{X}$, fig. $42, r . p .2$ ), is a very strong trunk, in diameter quite reaching that of the pleuro-parietal connective. It arises from the upper right side of the parietal ganglion, passes outward and backward in a curve to the right, thence upward to the anterior base of the ctenidium, where it unites with the large ganglion of the osphradium (P1. VIII, fig. 35 ; Pl. X, fig. 42, osp. g.), lying immediately below the integument, and visible through it. The osphradium is visible externally as a depressed oval area of a light yellowish color, situated upon the ventral face of the anterior portion of the base of the ctenidium. It is $0.4 \mathrm{~mm}$. in length by o.I mm. in width. From this osphradial ganglion arise two rather strong nerves, one (Pl. VIII, fig. 35 ; Pl. X, fig. 42, osp. g. I), passing forward, its several branches being distributed among the large gland cells of the anterior and lateral margins of the mantle. The other nerve from the osphradial ganglion passes a short distance to the left and terminates in a smaller branchial ganglion (Pl. X, fig. 42, ct. g.) at the right of the pericardium. From this ganglion a main branchial nerve (P1. X, fig. $42, c t . n$.), passes backward to the ctenidium, and several very delicate nerves are also given off to the pericardial wall and are lost among its fibres.

Visceral nerves. The left, or visceral ganglion is equal in size to the right parietal one. At its anterior, more pointed end it 
receives the distal end of the left pleuro-visceral connective. From its posterior portion it gives origin to the following four nerves.

I. From near the posterior median line arises a slender nerve (Pl. X, fig. 42, l.v. I), which immediately bifurcates to the Vesicle of Swammerdam, or spermatotheca, and its duct, a slender branch being also continued to the adjacent peritoneum.

2. A large nerve (P1. VIII, fig. $35, l . v .2)$, given off from the posterior right side of the ganglion, passes obliquely backward to the right, crossing the large hermaphroditic duct midway of its length, to the posterior end of the body. It gives off a number of slender branches to the dorsal peritoneum, and a larger one, $2 a$, to the liver, separating from the main nerve near its origin, but continued with it in a common epineural sheath for some distance. A little beyond the middle of its course the second nerve gives off a moderately strong recurrent branch to the right, $2 c$, and then passes straight backward, $2 b$, bifurcating to the anal portion of the intestine, and to the siphon. From the recurrent nerve, $2 c$, a long, posterior branch, $2 d$, is given off, which is distributed to the peritoneum in the median posterior region near the rectum; the main nerve, curving forward, sends one or two very delicate branches to the peritoneum, a stronger one, $2 e$, to the posterior face of the Organ of Bohadsch, passes beneath the right margin of the latter gland, and forms an anastomosis with the terminal branch of the third pedal nerve, $3 e$, which, it will be remembered, sends a branch to the anterior face of the Organ of Bohadsch, and one uniting with the vulvar nerve from the right parietal ganglion. By this arrangement the hypobranchial gland receives its nerve supply not only from the right pedal ganglion, but also from the left visceral one as well. It would be an interesting physiological problem to determine the relative influence of these two nerves with such different origins upon the secretory activity of the gland. Mazzarelli ('9o) has made a comparative study of the morphology of the gland of Bohadsch in a number of Aplysiidae, and has represented diagramatically the innervation in seven species. In all of these the nerve supply is found to be from the right pedal ganglion, but in none of them is any mention made of such relations as are here described for the two Brazilian species. In figs. 36 and 37 of Plate IX I have reproduced Mazzarelli's figures I 7 and 19 of Tav. I for Tethys punctata 
and Tethy's depilans as typical of his results. In figs. 38 and 39 of the same plate I have made similar diagrams showing the innervation for Tethys dactylomela and Tethys cervina, according to my dissections. Vayssière ('85) describes and figures for Tethys depilans a branch of the "nerf genital," which originates from the left visceral ganglion (not from the right, as quoted by Mazzarelli, p. 8), and passes to the "glande opaline," or gland of Bohadsch, as in the forms here described. He does not find, however, the innervation from the pedal ganglion also. Mazzarelli disputes the accuracy of the observations of Vayssière, holding that the nerve supply is from the pedal ganglion alone. In Tethy's dactylomela and Tethys corvina we have seen that both ganglia in question send nerves to the Organ of Bohadsch, so in these forms both authors would be partly right, and it would not be a matter of great surprise to find, upon a reexamination of the Mediterranean Aplysiidae that in them also the double innervation actually exists.

3. The third nerve (Pl. VIII, fig. 35 ; Pl. X, fig. 42, l.v. 3), arises from the posterior margin of the left visceral ganglion and courses backward, giving off a slender branch to the liver, crosses the large hermaphroditic duct near its origin, sending a delicate branch to it, swells into the small genital ganglion, (Pl. VIII, fig. $35, g . g$.), lying at the base of the adnexed genital mass, and thence passes backward parallel to the small hermaphroditic duct for nearly one-half the length of the latter. To this duct it sends a branch (P1. VIII, fig. 35, v. $3 a$ ), which passes backward along its surface to the ovotestis, sending a few delicate branches to the duct on the way. The main trunk (P1. VIII, fig. 35, v. $3 b$ ), turns abruptly to the right, leaving the hermaphroditic duct and, passing backward, ramifies in the dorsal body wall in front of the anal portion of the alimentary canal.

4. The fourth nerve (Pl. VIII, fig. 35 ; Pl. X, fig. 42, l.v. 4), equal in size to the second and third, arises at the posterior end of the ganglion, close to the base of the third nerve, diverges to the left, sending a branch to the liver, and courses obliquely across below the pericardium to its posterior wall. A strong branch (PI. VIII, fig. 35, 4a), is sent off about midway of this course which ramifies to the ventricle and the pericardial wall, the main trunk, (PI. VIII, fig. 35, $4 b$ ), curving dorsally in the posterior 
wall of the pericardium, bifurcates to the kidney, the dorsal pericardial wall and the auricle near the entrance of the branchial vein.

In Tethys dactylomela and in the Mediterranean Aplysiidae studied by Mazzarelli ('93, Monog. p. I08) the third and fourth nerves, here described as separate for Tethys cervina, are united in one trunk for some distance from their origin.

\section{The Reproductive System.}

The ovotestis (PI. VI, fig. 33, ov. t.) is an irregular lobulate organ, situated at the posterior end of the visceral mass, closely united to the liver in front, and inclosed in the last turns of the intestine. From its median antero-dorsal face the small hermaphroditic duct (Pl. VI, fig. 33, sm. h. d.) arises, a white nearly straight tube, $9.0 \mathrm{~mm}$. in length, gradually increasing in diameter from $0.3 \mathrm{~mm}$. as it emerges from the ovotestis, to $0.8 \mathrm{~mm}$. near the adnexed genital mass. The adnexed genital mass is a flattened, elliptical complex, made up of the nidamental and albumen glands and the fertilization chamber, inclosed in the loops of the genital duct, (fig. 33, sp. p., c. p.), and is situated immediately behind and below the right posterior border of the pericardium. It is $2.0 \mathrm{~mm}$. in length, $1.3 \mathrm{~mm}$. in greatest width, and $1.0 \mathrm{~mm}$. in thickness. Its position is in almost direct prolongation of the large hermaphroditic duct, which extends forward along the right body wall to the external opening. At the left of its basal end the spermatocyst (Pl. VI, fig. 33, sp. c.) projects transversely as a free pear-shaped sack, its length, I.o mm., being one-half the length of the adnexed genital mass, while its diameter is nearly $0.5 \mathrm{~mm}$. Its duct (P1. VI, fig. 33, $d$. C.), the "duct of Cuvier," opens into the proximal end of the copulatory duct (Pl. VI, fig. 33, cop. d.). The stout large hermaphroditic duct is $4.5 \mathrm{~mm}$. in length, one-half that of the small hermaphroditic duct, its diameter $1.0 \mathrm{~mm}$. being practically the same throughout. It is made up of two channels, separated by deep folds of the dorsal and ventral walls, which overlap in the median line thus forming the ovo-spermatic duct (P1. VI, fig. 33, ov. sp.d.) and the copulatory duct (P1. VI, fig. 33,cop.d.). At its distal end it is slightly enlarged and receives the long slender duct of the vesicle of Swammerdam, the spermatotheca, (Pl. VI, fig. 33, spth.), which enters from the left side and above. This duct is $3.0 \mathrm{~mm}$. long 
and o.I mm. in diameter. The spermatotheca is thin walled, spherical and I.o mm. in diameter. A very slightly developed system of folds in the wall of the large hermaphroditic duct, close to and above its external opening, probably functions as a vulvar gland.

The spermatic portion of the duct is continued forward beyond the external opening as a deep groove along the side of the animal, downward and forward, to the penis opening, situated as usual on the right side of the head, just below the anterior tentacle. The penis is inclosed in an evertible, muscular sack, the posterior end of which is attached to the foot and the lower body wall by two groups of retractor muscles, a dorsal and a ventral set. The spermatic groove is continued along the inner wall of this sheath to its base, where the penis proper is attached, and is thence continued forward along the side of that organ to its tip. In its retracted condition the penis sack measures $7.0 \mathrm{~mm}$. Its inner wall is thrown into a series of longitudinal folds, between two of which the spermatic groove is inclosed. This and the adjacent folds are sprinkled with brown pigment.

The proximal end of the sheath is occupied by the retracted penis, a slightly flattened, conical, muscular organ, $0.6 \mathrm{~mm}$. in diameter at the base, and ca. $2.5 \mathrm{~mm}$. long in its retracted condition. Along its whole length extends a deep furrow, the spermatic groove, continuous at its base with the groove upon the inner surface of its sheath. No trace can be made out of any armature upon any portion of the penis or its sheath, nor is there any specialized glandular area present.

\section{The Organ of Bohadsch.}

The organ of Bohadsch, or hypobranchial gland, is spherical, somewhat flattened in form, of a whitish color, and has a diameter of $4.0 \mathrm{~mm}$. In general aspect it presents the appearance of a close bunch of grapes, its surface being nodular in form, corresponding to the very large gland cells of which it is constituted. The gland opens externally by a single large duct, the orifice with tumid margins being situated upon a conspicuous elevation below the ctenidium and behind the reproductive opening.

Large gland cells similar in form to those of the hypobranchial gland are also found scattered in the mantle margin, 
and doubtless contribute to the well known characteristic defensive secretion of these animals.

Circulatory, Excretory and Respiratory Systems.

The circulatory, excretory and respiratory systems of Tethys cervina, so far as studied, were not found to differ markedly from those of other species, and matters of familiar knowledge, and hence they will not be entered upon in this place.

Leland Stanford Junior Zoological Museum, Invertebrate Series No. I44. 


\section{Tribe III. Pleurobranchoidea.}

Dorsal region covered by a large shield-like mantle, or notaeum. Shell external, internal or absent. Head distinct, with two pairs of tentacles. A single ctenidium on the right side, between the mantle and foot. Foot without parapodia. Genital duct diaulic, the male and female apertures contiguous. Visceral commissure short.

\section{Family PLEUROBRANCHIDAE.}

Mantle fleshy, stiffened by spicules, concealing wholly or partly the delicate haliotiform shell, if developed at all. Anterior tentacles united to form a frontal veil, posterior tentacles, or rhinophores, auriculate. Foot flattened, large. Radula multiserial, with no rhachidian teeth. Mandibles well developed, composed of many oblong plates arranged in tesselated pattern.

\section{Genus PLEUROBRANCHUS Cuvier, 1805.}

Pleurobranchus, Cuvier. Mémoire sur la Phyllidie et sur le Pleurobranche. Annales du Museum d'Histoire $\mathrm{Na}$ turelle, V, I805, p. 266-276, P1. I8, Figs. I-6.

Berthella, Blainville. Manuel de Malacologie. I825, p. 469, 627, P1. XLIII, Fig. I.

Pleurobranchus, Pilsbry. Tryon's Manual of Conchology, XVI, I896, p. I9I.

Pleurobranchus, Vayssière. Monographie des Pleurobranchidés. Ann. des Sciences Naturelles, Zoologie. Ser. 8, T. VIII, I898, p. 279.

Pleurobranchus, Bergh. Malacologische Untersuchungen, IV. I, 3, in Semper's Reisen im Archipel der Philippinen, VII, I898, p. II7.

Body elliptical, mantle more or less developed, its borders free, the anterior border more or less emarginate; shell internal, calcareous or subcalcareous. Rhachis of ctenidium smooth. Male and female genital openings contiguous, or almost united. Mandibles made up of flattened, closely set elements. 
Pleurobranchus agassizii Sp. Nov.

Plates XI and XII, Figs. 43-57.

Three small specimens of a Pleurobranchus were taken by Mr. Greeley at Riacho Doce, Alagoas. They were killed in formalin and afterward transferred to alcohol. The coloration of the animals in life was not noted; the color of the preserved specimens is a rather uniform pale, pinkish yellow. In two of the specimens a fine light brown mottling seemed to divide the dorsum into very minute polygonal areas, but even this trace of color gradually disappeared on their being transferred to alcohol.

\section{External Characters.}

Size. The three individuals measured 10 , I I and $8 \mathrm{~mm}$. in total length, by $6,6.5$ and $5.0 \mathrm{~mm}$. in width respectively. In each case the foot is somewhat contracted, the mantle but slightly so, the measurements in life probably exceeding the above somewhat. The length of the foot is $6.5,6.0$ and $5.5 \mathrm{~mm}$., with corresponding widths of $4.0,4.0$ and $3.0 \mathrm{~mm}$. in each case.

Body form. The body is arched, slightly depressed, oblong; the mantle broad, extending far beyond the foot throughout its entire circumference, though the strongly contracted posterior end of the foot, the rhinophores, and the frontal veil probably extend well beyond the mantle margin in the living animal. The mantle margin is very slightly emarginate above the tail. The surface of the dorsum is smooth, save for slight, irregular nodosities formed by unequal contraction. The mantle margin is moderately thick and very wide, being $2.0 \mathrm{~mm}$. in width, its free edge being smooth.

Shell. The white calcareous shell (P1. XI, fig. 43) shows plainly through the mantle in all the specimens. It is placed well forward, its anterior margin being above the head region, while the posterior portion covers the anterior two-thirds of the posterior visceral mass. In outline it is oblong, nearly linear, the lateral margins being nearly parallel. The anterior margin is more gently rounded than the posterior one, the spire very small, oblique, the whole shell being made up of about two turns, the outermost one very broad and flat, and forming almost the whole area of the shell. The lines of growth are plainly marked; the 
inner and outer surfaces of the shell are quite smooth. The length of the shell varies in the three specimens from $4.2 \mathrm{~mm}$. to $5.5 \mathrm{~mm}$., its width from $2.5 \mathrm{~mm}$. to $3.0 \mathrm{~mm}$.

Foot. The foot is smooth, truncately rounded in front, more pointed behind. No well marked pedal gland is visible at its posterior end. The lateral margins of the foot are continuous, undulating, the anterior margin bilabiate, the lower lip much thicker than the upper, which bears a median notch. The dorsal surface of the foot margin is smooth, with no visible pigmentation, if any existed during life.

Head. The frontal veil is large, trapezoidal, its anterior, free margin smooth, nearly straight, the outer angles very slightly rounded, the external margin deeply auriculate. The width of the frontal veil in the three specimens is $4.0,4.0$ and $3.0 \mathrm{~mm}$. respectively, the length being $1.5 \mathrm{~mm}$. in all. The rhinophores (Pl. XII, fig. 57) are very large cylindro-conical organs, their bases contiguous, but not fused. Each is made up of a loosely rolled plate, the margins external, the lower one overlapping the upper. The margins are prolonged at the base into a considerable flap, which is free. Just above and external to the base the very large eyes shine conspicuously through the integument.

Ctenidium. The branchial plume lies on the right side in the roomy space between foot and mantle, completely concealed by the latter. It measures one-half the total length of the body, being $5.0 \mathrm{~mm}$. long in the largest specimen, while in the smallest one it is but $2.0 \mathrm{~mm}$., i. e. one-fourth the body length. The posterior half of the plume is free from the body wall; the rhachis entirely smooth. The plume is bipinnate, bearing about twelve pinnules on each side, arranged alternately. The anal opening is situated above the posterior end of the base of the branchial plume.

\section{InTERnAL AnATOMy.}

Mandibles. The labial armature is made up of a pair of oblong mandibles of a light amber color in their anterior portion, becoming paler behind, borne upon the sides of the buccal opening. Their greatest length is $1.215 \mathrm{~mm}$., their width $0.66 \mathrm{~mm}$., being nearly twice as long as wide. The oblique anterior border is slightly narrower than the more rounded posterior one, the dor- 
sal border is rounded, the ventral one is straight (Pl. XII, fig. 56). Each mandible is made up of closely set chitinous elements, arranged in some 72 transverse rows, each row containing about 35 platelets. The anterior portion of the platelets of each row overlaps the interspaces between the posterior portions of those in the preceding series, thus giving a close, tesselated appearance to the whole mandibular plate. The individual elements of the mandible are somewhat trapezoidal in form (Pl. XI, figs. 4448). The anterior portion is prolonged above into a flattened hook, directed obliquely forward and upward, pointed at the tip, and bearing laterally three to six strong denticles. Immediately behind the denticles upon each side is borne a stout truncated lateral process, which is in contact with the corresponding process of the adjacent plate of either side. The lateral processes of a platelet are not, however, exactly opposite to each other, the dorsal one being slightly behind its fellow of the opposite side as a rule, thus causing a slight obliquity in the row of platelets across the mandible (P1. XI, fig. 46). Toward the dorsal margin the platelets become progressively thinner, until at the margin itself they become flattened and scale like, the anterior hook and the lateral processes are lost, and the whole takes on a simple lozenge shape. The body of a typical platelet is thick, truncate posteriorly, and fits closely in with its fellows. A deep, narrow, median slit (Pl. XI, figs. 45, 46) bifurcates the ventral surface of the body of the platelet, extending backward nearly or fully one-half of its length, and is slightly dilated posteriorly. It does not extend through to the dorsal surface, but may be readily seen from above by a slight change of focus. This groove is well marked in all except the very youngest platelets, its location in these latter being overlapped by a granular mass, identified by Vayssière as the remnants of the nucleus of the cell which generated the platelet.

The dimensions of these elements varies from the anterior to the posterior ends of each mandible, and from end to end of each transverse row. The length of a typical older platelet is $0.022 \mathrm{~mm}$., its thickness $0.015 \mathrm{~mm}$., and its width, inclusive of the lateral processes, $0.017 \mathrm{~mm}$. At the posterior end of the mandible the length of a similarly situated platelet is $0.035 \mathrm{~mm}$, and its width o.org $\mathrm{mm}$. 
Radula. The radula is nearly colorless, about one and onehalf times as long as broad. The rhachis is narrow and naked, the lateral teeth are unciform, strongly hooked, and arranged in 48 rows, with from 42 to 50 teeth in each half row. The dental formula may hence be expressed as 42-50:0:42-50x48. The innermost tooth in each row (PI. XI, fig. 52) is somewhat smaller than its neighbors, the remaining teeth being approximately of the same size, with the exception of the outermost ones, which decrease gradually in size, the last ones of the series becoming flattened and almost rudimentary (Pl. XI, fig. 49). The body of each tooth (P1. XI, figs. 50-52) is oblong, flattened, slightly oblique, its posterior end truncate, in some cases emarginate or notched. The anterior end is rounded, the inner margin expanded into a flattened wing, which is overlapped by the next inner tooth, the outer margin being nearly straight. Viewed from below (P1. XI, fig. 53) the bases are of a somewhat oval outline, becoming more linear toward the ends of the rows. A typical tooth, such as the one shown in side view in Pl. XI, fig. 50, taken from the middle of the $22 \mathrm{~d}$ row, measures $0.025 \mathrm{~mm}$. in total length of base, the height of the hook above the bottom of the base is $0.014 \mathrm{~mm}$. The outermost tooth, such as is shown in fig. 49, of Pl. XI, taken from the IIth row, is $0.01 \mathrm{~mm}$. in base length, its total height being $0.006 \mathrm{~mm}$.

Viscera. The very poor preservation of the viscera precluded any satisfactory study of their structure and relations, their hard and brittle condition resisting all attempts at softening.

\section{Nervous System.}

Central ganglia. The central nervous system is enveloped in a closely fitting connective tissue capsule, very difficult to remove, which also binds it closely to the buccal mass. The cerebro-pleural complex (P1. XII, fig. 55) is closely fused, and the two sides are in such close contact in the median line that no commissures connecting them may be made out. No distinct line of demarcation can be made out between the cerebral and pleural moieties of the complex upon either side, nor is there any grouping of the nerve cells to correspond to such a division. The separation into two distinct ganglia as shown by Von Ihering ('77) for Pl. meckeli (fig. 8, Taf. II), does not here 
obtain, the two ganglia being united into a single flattened mass, circular in outline, and having a diameter of $0.36 \mathrm{~mm}$. The pedal ganglia are slightly smaller than the cerebro-pleural ones, being $0.3 \mathrm{~mm}$. in diameter, and having the same flattened, spherical form. The eyes are very large, nearly spherical structures, o.I $5 \mathrm{~mm}$. in diameter, and borne upon very short optic nerves.

Connectives. The cerebro-pedal and pleuro-pedal connectives (Pl. XII, fig. 55, c. p. con., pl. p. con.) are extremely short and can only be seen after carefully dissecting away the capsule and displacing the ganglia by gentle pressure upon the cover glass.

Otocysts. The otocysts, not represented in fig. 55 of Pl. XII, are spherical structures, $0.06 \mathrm{~mm}$. in diameter. They are situated at the upper inner border of the inner face of the pedal ganglia, close to the cerebro-pedal connectives, and contain a large number of minute otoconia.

\section{Reproductive System.}

The glans penis is extruded in all three specimens. It is short and bluntly conical, and is surrounded at its base by a conspicuous fold of integument, which is continuous all around save at the posterior side, where its ends overlap with a deep fissure between them. Just within this fissure, and close to the posterior portion of the base of the glans penis is the female opening (P1. $\mathrm{XI}$, fig. 54,v). The exact relations of this opening with that of the duct of the nidamental-albumen gland could not be made out satisfactorily. They are very close together, the gland duct seeming to have a common external opening with the vagina, but the condition of the material made this and other points in the structure of the reproductive system uncertain. In sections the glans penis is circular, and there is no indication of an anterior wing-like appendage, such as is given by Vayssière as a characteristic of his subgenus Pleurobranchus s. str. (Monog. '98, p. 307).

\section{Systematic Position.}

There can be no doulbt but that this species is distinct from the three Antillean forms described by Mörch ('63), especially in the light of the careful anatomical description which Bergh 
('97, '98b) has given of these forms. Its lack of agreement with Pleurobranchus patagonicus d'Orbigny, the only recorded species from the east coast of South America, is equally clear from Bergh's study of the anatomy of that species ('98a). Nor does it agree satisfactorily with the Antillean Pleurobranchus lacteus of Dall and Simpson ('99, p. 367) in external characters nor in shell. An anatomical study of the latter species is much to be desired, however, before certainty can be assured. In the meantime I must consider the present form a new species and have much pleasure in dedicating it to Professor Alexander Agassiz of Harvard University.

Type No. 145, Invertebrate Series, Leland Stanford Junior University Zoological Museum. 


\section{SUBoRdER NUDIBRANCHIATA.}

Naked hermaphroditic opisthobranchiate Mollusca, generally of symmetrical, slug-like form; without a shcll in the adult state. Ctenidium and osphradium absent; symmetrical accessory respiratory appendages usually developed from the dorsal integument, rarely from the sides. Central nervous system concentrated. Radula usually strong, the teeth uni- or multiserial. Kidney not compact.

\section{Tribe I. Doridoidea.}

Genital duct triaulic, liver completely inclosed in the visceral mass, female duct bifurcated. Anal aperture postero-median upon the dorsum, surrounded by the branchial rosette, or rarely between the perinotacum and the foot.

\section{Family DORIDIDAE.}

Branchial plumes in an arc or circle, usually joined together at their bases, usually retractile into a common cavity. Rhinophores always with perfoliate clavus. Pharyngeal bulb never suctorial.

\section{Subfamily DISCODORIDINAE.}

Body not hard, depressed; the dorsum minutely granuligerous. Mantle margin rather wide; tentacles digitiform; branchial plumes usually tri- or quadripinnate; foot rather wide.

Labial armature made up of minute, closely set rods. Rhachis of radula naked, the pleurae multidentate, the teeth hooked.

Penis usually unarmed.

Three specimens of Dorididae were found in the collection, all of them being apparently new species. 
Genus DISCODORIS, Bergh, 1877.

Discodoris, Bergh. Jahrbücher der deutschen Malakozoologischen Gesellschaft, IV, I877, p. 61. - Malacologische Untersuchungen, XII, I877, p. 5I8. -Mal. Unters. XV, I884, p. 658. - Mal. Unters. Supplement Heft I, I880, p. 47 : II, I88I, p. I08. -Mal. Unters. XVII, I89o, p. 895. - System der Nudibranchiaten Gasteropoden. I892, p. I02. -Challenger Reports, X, I884, p. 92. -Die Opisthobranchiata der Siboga Expedition. I905, p. 98 .

Body rather soft, rounded or oval in outline; branchial aperture slightly crenulate, stellate or bilabiate; the anterior margin of the foot bilabiate, the upper lip more or less notched.

Prostate gland large.

\section{Discodoris branneri Sp. Nov.}

Plate XII, figs. 58-65.

One specimen of this form was taken at Riacho Doce, Alagoas, and was preserved in formalin, followed by alcohol. The rhinophores and branchiae are completely retracted, the whole specimen being slightly contracted and rolled up. No notes accompanied it save that of locality alone.

\section{External Characters.}

Form. Color. The body is depressed, linear oblong with bluntly rounded anterior and posterior ends. The dorsum is minutely villous, being everywhere covered with minute conical papillae. The mantle edge is thin and broad, extending far beyond the margin of the foot, and is fully one-half the width of the latter in the preserved specimen. The general ground color of the dorsum is pinkish, with thickly scattered irregular blotches of brown everywhere over its surface. Along the sides of the dorsum is a longitudinal row of five or six larger black spots about equidistant from each other.

Foot. The foot is smooth, almost linear, its anterior and posterior ends bluntly rounded. The anterior margin of the foot is thickened, and deeply bilabiate, the upper lip bilobed by 
a deep median notch. Its length is $24.0 \mathrm{~mm}$., the width $12.0 \mathrm{~mm}$. The ground color of the foot is pinkish, thickly set with irregular brownish blotches, apparently arranged at random, i. e. producing no definite color pattern. The largest of these blotches may reach a diameter of $1.0 \mathrm{~mm}$., but the majority are much smaller.

Head. The head is retracted and bears two tapering conical oral tentacles, $2.5 \mathrm{~mm}$. long, and with a basal diameter of I.o mm.

Rhinophores. The rhinophores are completely retracted within their sheaths, the margins of which are low and closely set with short slender papillae. The clavus of the rhinophore is stout, club shaped, and lamellate.

Branchiae. The branchiae are situated as usual upon the posterior mid-dorsal region, surrounding the anal papilla and the renal opening. They are six in number, tripinnate, and retractile within a deep branchial pocket, the margin of which is thin and slightly prominent.

Total length of the specimen $32.0 \mathrm{~mm}$., its width $12.0 \mathrm{~mm}$.

\section{Internal Anatomy.}

The dorsal wall of the body cavity is rather firm and thick, its peritoneal lining colorless, save for a pinkish tint, which is possessed by all the viscera in common.

\section{Alimentary System.}

The alimentary canal is of the general type of the cryptobranchiate Dorids. The pharyngeal bulb is conical, truncate in front, $3.5 \mathrm{~mm}$. long, by $2.5 \mathrm{~mm}$. wide, and $3.0 \mathrm{~mm}$. in height, the radula sheath projecting behind and below as a rounded eminence. The mouth opening is of an inverted $\mathrm{T}$ shape, the labial disc being covered by a firm transparent cuticle.

Labial armature. Externally the opening is guarded on either side by a somewhat triangular, yellow plate, the apex of which is directed backward (PI. XII, fig. 58). The anterior border of each of these labial plates is slightly convex, ca. $0.8 \mathrm{I} \mathrm{mm}$. long, the upper border is straight, $0.72 \mathrm{~mm}$. long, and is separated from its fellow on the opposite side by a distance of from 0.05 to $0.06 \mathrm{~mm}$. The posterior border is very slightly concave, $1.08 \mathrm{~mm}$. in length, while the lower angle is rounded. 
These mandibular plates are made up of slender closely set blunt rodlets, longest in front and decreasing in length toward the posterior border. Those of the anterior portion range up to $0.096 \mathrm{~mm}$. in length (P1. XII, fig. 59), and decrease regularly toward the posterior portion, where they are very short (P1. XII, fig. 60), the average diameter of ca. $0.005 \mathrm{~mm}$. remaining nearly the same throughout, the tips of the rodlets being slightly dilated to nearly the same extent also.

Radula. The radula is broad and short, deeply grooved longitudinally in the median line, the teeth of one sort, uniform in shape, strongly hooked, and arranged in 26 rows of from 45 to 48 teeth in each half row, the rhachis being destitute of teeth. The dental formula may hence be expressed as 45-48:0:45-48x26. The outermost two or three teeth of each row (P1. XII, fig. 62) are slightly smaller than the remaining teeth of the row, the base of the outermost being about one-third the length of that of the others, the remaining teeth being practically of the same size until the innermost two are reached, which are again somewhat smaller. The average height of a typical tooth (P1. XII, fig. 63) is $0.186 \mathrm{~mm}$., the length of the base $0.15 \mathrm{~mm}$. The general tint of the radula is a faint yellow, deepening posteriorly, while the anterior portion is colorless or nearly so.

Blood gland. Overlying the buccal mass is the blood gland, divided into two lobes, the largest being thick and rounded, about $2.0 \mathrm{~mm}$. in diameter, and is situated in front of, and in contact with the central nervous system. The posterior lobe, immediately behind the anterior one, is much smaller, triangular in form, its base being directed forward, and has a length of $1.5 \mathrm{~mm}$. and a breadth of $0.5 \mathrm{~mm}$. at the broadest end.

Salivary glands. The salivary glands are long and strap-like, the anterior portion, $\mathbf{I} .0 \mathrm{~mm}$. in width, being coiled upon the posterior face of the pharyngeal bulb. Each narrows to $0.5 \mathrm{~mm}$. in width as it passes through the nerve collar, and extends backward, below the viscera ventrally, for about one-half the total length of the animal.

Esophagus, stomach and intestine. The esophagus is short and wide, ca. $3.0 \mathrm{~mm}$. long by $1.5 \mathrm{~mm}$. in diameter, passing directly downward and backward to the stomach, into which it dilates. The latter organ lies in a deep notch in the anterior face of the 
posterior visceral mass. It describes a $C$ shaped loop upon itself, the pyloric end lying almost directly above the anterior portion. The anterior half of the intestine is large and dilated, being about I $1.0 \mathrm{~mm}$. long by $2.0 \mathrm{~mm}$. in diameter. It courses obliquely upward and backward in a deep groove in the upper right side of the visceral mass, constricts suddenly to $0.5 \mathrm{~mm}$. in diameter, and continues for about $11.0 \mathrm{~mm}$. to the anal opening, situated at the summit of the anal papilla, in the center of the branchial circle.

Liver. The liver is of the usual Dorid form, bluntly conical, the apex lying posteriorly beneath the branchiae, the anterior end divided by a deep median groove into right and left lobes, between which the stomach is inclosed. The total length of the liver is I $2.0 \mathrm{~mm}$., its maximum diameter $6.5 \mathrm{~mm}$. The dorsal surface of the organ is divided by two transverse sulci into three nearly equal lobules, their surface being diversified by an irregular system of complicated ridges and shallow grooves.

\section{Reproductive System.}

Hermaphroditic gland and duct. The hermaphroditic gland is relatively inconspicuous and thin, the specimen evidently not having been taken during its breeding season. It can be distinguished with difficulty from the upper surface of the liver which it closely covers. From the anterior border of its right lobe it gives rise to the long, narrow, whitish hermaphroditic duct (Pl. XII, fig. $65, h . d$.) which courses forward and downward for a distance of ca. $3.5 \mathrm{~mm}$., dilating into the long white hermaphroditic ampulla (P1. XII, fig. 65, h. amp.). This latter organ is of considerable size, making up a large portion of the anterior genital mass. It is $10.0 \mathrm{~mm}$. in length by $1.0 \mathrm{~mm}$. in diameter, and is coiled in three to four close loops upon the posterior and outer face of the anterior genital mass. At its anterior end it divides at once into the spermatic duct (P1. XII, fig. $65, s p . d$.) and the oviduct (P1. XII, fig. 65, ov. d.). The former is very short, passing almost at once into the apex of the heart-shaped pinkish prostate gland (Pl. XII, fig. 65, pr. g.), which occupies the posterior inner face of the anterior genital mass. From a deep median groove in its posterior face arises the slender vas deferens (Pl. $\mathrm{XII}$, fig. $65, v . d$.). The total length of the prostate gland is 4.0 
mm., its greatest breadth $3.0 \mathrm{~mm}$. and thickness $2.0 \mathrm{~mm}$. Its surface is very finely lobulated.

$V$ as deferens and penis. The vas deferens courses straight forward and outward along the inner and anterior faces of the complex to the penis. Throughout its whole length it preserves a uniform diameter of $0.5 \mathrm{~mm}$., dilating suddenly at its outer end into the penis. The penis is somewhat contracted and nearly spherical in form, about $2.25 \mathrm{~mm}$. in diameter, the large conical glans (P1. XII, fig. 65, p.) projecting externally. The latter is bluntly conical, its apex truncate, $2.0 \mathrm{~mm}$. in length, $1.0 \mathrm{~mm}$. in diameter at the base, and tapering to $0.5 \mathrm{~mm}$. at the apex. The glans bears an armature of minute hooks, set in longitudinal rows, about $I 7$ in number near the distal end of the glans and increasing to nearly Ioo toward the base. The individual hooks (Pl. XII, fig. 64, $a, b$ ) are rather stout, the largest occurring near the base of the glans, and measuring 0.02 to $0.027 \mathrm{~mm}$. in height, their basal dimensions being nearly the same.

Vagina and duct. The vagina and vaginal duct lie upon the upper anterior border of the anterior genital complex (P1. XII, fig. $65, v a g$.$) , and are of about equal length. The distal vaginal$ portion is conical, thick walled, with a series of longitudinal ridges upon its external surface, separated by shallow grooves, united at intervals transversely, giving the surface a somewhat lobulated appearance, which is due to internal glandular structures. In sections through the vagina and its duct the wall is seen to be made up of two conspicuous layers, an outer muscular one, consisting mainly of fibres arranged in a circular direction, and of nearly uniform thickness, throughout the whole length of the vagina and its duct, varying but slightly from about $0.045 \mathrm{~mm}$. An inconspicuous submucous layer of connective tissue bears the innermost coat, the mucous layer, which is made up of a layer of columnar epithelial cells, distended with secretion products. This mucous layer is thrown into closely crowded leaflike longitudinal folds, about twenty in number in the proximal portion of the vagina, and increasing to some fifty or more in the distal extremity. These folds range in height from $0.09 \mathrm{~mm}$. to $0.24 \mathrm{~mm}$. in the proximal and distal portions respectively. The narrow central lumen, left free from the folds, is filled with a coagulated mucous-like secretion. 
The vaginal duct is whitish, muscular, of nearly uniform diameter, and $4.0 \mathrm{~mm}$. in length. It describes a loop (P1. XII, fig. 65), returning upon itself and opening into the spermatotheca (P1. XII, 65, spth.), which is a conspicuous dark spherical structure, $2.0 \mathrm{~mm}$. in diameter, lying in the mid-dorsal region of the anterior genital complex. Upon its dorso-anterior face is the common opening of the vaginal and the uterine ducts, concealed by the overlapping proximal end of the vagina. The uterine duct (Pl. XII, fig. $65, u . d$.) is slightly the more slender of the two, and passes obliquely forward along the inner face of the nidamental gland, beneath the sack like spermatocyst, which is doubled above it. Near the anterior end of the nidamental gland the uterine duct receives the short slender duct of the spermatocyst (PI. XII, fig. $65, s p . c$.), an elongated pear-shaped organ of a whitish color, $1.5 \mathrm{~mm}$. in length by $1.0 \mathrm{~mm}$. in diameter, and closely packed with spermatozoa. Its slender duct is slightly less than one-half the length of the cyst itself.

Nidamental gland. The uterine duct passes into the anterior end of the nidamental gland (Pl. XII, fig. 65, n. a. c.), immediately after receiving the duct of the spermatocyst, and at a point not far from the entrance of the oviduct, which joins the anterior end of the hermaphroditic ampulla to the nidamental gland. In most Dorididae the greater portion of the anterior genital complex is made up usually of the nidamental and the albumen glands. In this individual the two glands in question form but a very small portion of the whole, being but $2.0 \mathrm{~mm}$. in extreme length by $\mathrm{I} .2 \mathrm{~mm}$. in width and $\mathrm{I} .0 \mathrm{~mm}$. in thickness. This proportion may possibly be due to absence of secretory activity in a non-breeding season, or to non-maturity. The surface of the nidamental gland is finely sculptured with minute ridges and depressions, is pinkish in color, and opens externally, immediately below and behind the opening of the vagina, by means of a broad duct (P1. XII, fig. $65, n . d$.), $1.5 \mathrm{~mm}$. in length. The albumen gland is included in the windings of the nidamental gland, being exposed as a small oval area, r.o $\mathrm{mm}$. in length by $0.3 \mathrm{~mm}$. in width, upon the upper face of the larger gland. At the anterior border of this area is found the entrance of the uterine duct.

The systematic position of this species presents some difficulties due mainly to the well-developed penis armature, a 
character not present in the genus Discodoris. In this respect it resembles Carminodoris, from which, however, it differs strongly in other features, notably in the granular, almost velvety notxum. For the present $I$ deem it best to consider it a species of Discodoris until the study of further material may warrant a different disposition, rather than to create for it a separate genus based upon this character alone.

Some thirty or more species of Discodoris have been described, mostly inhabiting the Pacific and Indian oceans. But five of these, $D$. notha Bergh, $D$. muta Bergh, D. indecora Bergh, $D$. tristis Bergh and D. edvardsi Vayssière are from the Atlantic, the first four from the Antilles, the Azores and the Cape Verd Islands, the last from the Morocco coast. From all these the present species may be distinguished readily.

I take great pleasure in dedicating this new species to my esteemed colleague, Professor J. C. Branner, the originator and leader of the Branner-Agassiz expedition.

Type No. I46 Invertebrate Series, Leland Stanford Junior University Zoological Museum. 
Discodoris voniheringi Sp. Nov.

Plates XIII, XIV, XV; figs. 66-76.

One specimen of this new species was taken at Riacho Doce, Alagoas, July 20, I899, by Mr. Greeley. No color notes accompanied the specimen, which was killed in formalin, afterward followed by alcohol.

\section{External Characters}

Form. The general body form is depressed, elongate, elliptical, the ends equally rounded, the mantle margins rather wide and thin, projecting far beyond the edge of the foot, the submarginal space nearly equalling the width of the foot itself.

Color. The ground color of the dorsum is pinkish gray, sprinkled everywhere with minute dark brown, or black spots. The under surface of the mantle and the sides of the body are a lighter pinkish, thickly sprinkled with minute dark spots, giving the surface a dusty appearance. Upon the under surface of the mantle on either side is borne a longitudinal series of three to four large round brownish blotches about midway between the mantle edge and the sides of the body. The largest of these spots reaches a diameter of $2.0 \mathrm{~mm}$. Posteriorly this series is continued around above the top of the foot by a series of six or seven much smaller spots more irregularly disposed.

Dorsum. The dorsum is rather firm, tuberculate, being covered everywhere with low tubercules of varying size, inflated at their tips and much thicker than the slender cylindro-conical processes covering the dorsum of the preceeding species. The largest of these tubercules reach a diameter of $1.0 \mathrm{~mm}$., and occupy the summits of slight elevations of the dorsal integument, having smaller and lower tubercules irregularly grouped around them.

Foot. The foot is smooth, rounded in front, its anterior margin deeply bilabiate, the upper lip projecting beyond the lower, and deeply notched to a depth of $0.5 \mathrm{~mm}$. The sides of the foot are nearly parallel, gradually converging posteriorly to the bluntly rounded tail, which does not project beyond the 
mantle edge. The edges of the foot are thin and crenulate. Its color is in general the same as that of the under surface of the mantle.

Head. The head is inconspicuous, the mouth a vertical slit, bearing upon either side long slender finger-like oral tentacles, I. $5 \mathrm{~mm}$. in length, their tips blunt and curving forward.

Rhinophores. The rhinophores are brownish black, deeply retractile within conspicuous sheaths, with high tuberculate margins, the tubercules being of the same type as those of the general dorsal area. The sheaths reach a height of $1.0 \mathrm{~mm}$., the whole slightly retracted rhinophore has a height of $2.5 \mathrm{~mm}$. The clavus is of the usual club shape, perfoliate, with ca. 25 leaves on each side. The dark pigment is especially concentrated on the strong stalk of the rhinophore, where it forms a circular band, immediately below the clavus.

Branchiae. The branchiae are six in number, bipinnate, completely retractile into the branchial pocket, which bears a conspicuous lobulate margin, the low divisions of which carry tubercules similar to those of the dorsum. The anal and renal openings are situated as usual within the circle of the branchiae. The reproductive openings in the specimen were very small and inconspicuous.

Dimensions. Total length of the whole animal $20.0 \mathrm{~mm}$., its width $14.5 \mathrm{~mm}$., and maximum height $5.0 \mathrm{~mm}$. Length of the foot $16.5 \mathrm{~mm}$., its width $6.0 \mathrm{~mm}$; greatest width of the mantle margin $6.0 \mathrm{~mm}$.

\section{Internal Anatomy.}

Blood Glands. The dorsal integument is rather soft and not thick. The pseudo-peritoneum is colorless, save in the region of the central nervous system where it is thickly sprinkled with minute, dark brown spots. The phagocytic blood glands, two in number lie directly in contact with the central nervous system; the anterior larger one is elliptical in outline and rather thick, measuring $1.5 \mathrm{~mm}$. in length by $1.0 \mathrm{~mm}$. in width and $0.2 \mathrm{~mm}$. in thickness, and is dark gray in color, being sprinkled with minute black spots. Its dorsal surface is arched, the ventral concave, while the general contour is smooth throughout. It lies directly in front of the cerebral ganglia upon the pharyngeal bulb. The 
posterior lobe is very much smaller and thinner, and lies transversely, its anterior border in contact with the central nervous system. It is somewhat reniform in shape, measuring $0.7 \mathrm{~mm}$. in transverse by $0.3 \mathrm{~mm}$. in longitudinal diameter.

\section{Alimentary System.}

Labial armature. The oral tube is short and conical, I.o $\mathrm{mm}$. in length, bearing a colorless cuticula. The labial armature is small, consisting of a median plate, $0.735 \mathrm{~mm}$. in length by $0.135 \mathrm{~mm}$. in greatest width, and of two triangular lateral plates, $0.63 \mathrm{~mm}$. in greatest length by $0.3 \mathrm{~mm}$. in width (Pl. XIII, fig. 66). The median plate is elongate, spear-shaped, and is made up of closely set granular thickenings of the cuticle of varying size. Its median portion is marked by a narrow line in which the thickenings are much less numerous and are smaller than on either side. In the densest regions these granulations may assume the aspect of very short blunt rodlets measuring up to $0.002 \mathrm{~mm}$. in diameter, and approximately the same in height.

The median plate is set off from the lateral ones by a narrow strip of cuticle, nearly destitute of such elevations. The lateral plates are approximately right angled triangles in general outlines, the apex being directed backward, the perpendicular side parallel to the median plate. The granular thickenings forming these lateral plates are of the same general type as those of the median one, are very dense in the central portions and merge off gradually toward the periphery into the thickened cuticula surrounding them.

Radula. The pharyngeal bulb is large and strong, $3.0 \mathrm{~mm}$. in length by $2.0 \mathrm{~mm}$. in height, in form truncately conical, the radula sheath projecting very slightly behind and below. The radula is broad, short, and deeply grooved, colorless in front, but becoming straw colored posteriorly. The teeth are in twenty-six rows, the rhachis of the radula is naked, and the pleural teeth vary in number from forty-six in the anterior half rows, to fifty in the posterior ones. The dental formula may be expressed 46-50:0:46-50x26. The teeth are all simple hooks in form, the majority except the outermost and innermost in each row, being of the same size and shape (Pl. XIII, figs. 67, 68; P1. XV, fig. 75). The base of a typical average tooth measures $0.082 \mathrm{~mm}$., the height 
$0.099 \mathrm{~mm}$. The outermost tooth in each row is much smaller than the average, the base being much shorter, often nearly rudimentary, and the hook much more slender, as is shown in the slightly oblique view in fig. 69 of Pl. XIII. The next two teeth adjacent to the outermost, are progressively larger and form a transition to the remainder in the row. In like manner the innermost tooth of each row (Pl. XV, fig. 76 ) is much smaller than its fellows, the succeeding ones increasing in size, the typical dimensions being reached in the fifth or sixth tooth of each series. In front view all of the teeth of the radula are inclined toward the median line by a strong curve at their bases, the effect of which is partly nullified by a curve in the reverse direction in the middle and upper portion of the shaft (P1. XIII, figs. 67, 68).

Visceral complex. The esophagus begins with a large dilation immediately behind the pharyngeal bulb. It recurves upon itself, narrows, passes through the commissural loop of the central nervous system, and, after a short course, opens into the stomach. The posterior visceral mass is bluntly conical, $8.0 \mathrm{~mm}$. long by $5.5 \mathrm{~mm}$. in maximum diameter, its lateral and lower surfaces convex, the upper one slightly flattened. The upper anterior margin is deeply notched for the reception of the stomach, the pyloric flexure of which is uppermost, passing gradually backward into the wide intestine, which courses along the dorsal surface of the liver to the anus. At the left of the pylorus lies the sack-like gall cyst of the liver, the greatest diameter of which, $1.4 \mathrm{~mm}$., is nearly equal to that of the pylorus.

\section{Reproductive System.}

Hermaphroditic gland and duct. The hermaphroditic gland lies as usual upon the upper and anterior portion of the liver. The slight development of the reproductive cells rendered this gland relatively inconspicuous in the specimen. The hermaphroditic duct is short and slender, passing forward from the right anterior lobe of the hermaphroditic gland, and, after a course of ca. $1.5 \mathrm{~mm}$., dilates into the long thick convoluted hermaphroditic ampulla (P1. XIV, figs. $73,74, h$. amp.). This is closely coiled in a number of loops upon the posterior and lower border of the anterior genital complex, and makes up fully one-third the bulk of the latter. Its approximate length is $7.0 \mathrm{~mm}$., with a fairly 
uniform diameter of $0.7 \mathrm{~mm}$. It is grayish white in color, and is densely packed with spermatozoa.

The wall of the hermaphroditic ampulla consists of a onelayered low epithelium, resting upon a thin subepithelial layer of connective tissue, which is in turn enveloped by a thin noncontinuous layer of circularly disposed smooth muscle fibres. A loose connective tissue adventitia, not distinctly separated from the muscularis, forms the outermost layer. In places the whole wall is so reduced in thickness that it seems to be composed of the epithelium alone.

At the rounded posterior end of the nidamental gland the distal end of the hermaphroditic duct passes into the connective tissue along its anterior border, opening into a rather large cavity, $0.08 \mathrm{~mm}$. in diameter, which is continued forward in the substance of the gland for some distance. Immediately after entering the nidamental-albumen gland complex the slender spermatic duct ( $\mathrm{Pl}$. $\mathrm{XIV}$, figs. $73,74, s p . d$.) is given off, which, after its emergence from the gland, passes almost immediately into the substance of the prostate gland. These relations were made out in serial sections only, owing to the minuteness of the structures involved. It is of interest to note that the dense mass of spermatozoa, with which the hermaphroditic ampulla was filled, did not extend into the spermatic duct at all, but were confined to the extension of the ampulla into the nidamental-albumen gland complex.

Prostate gland. The prostate gland envelopes a $U$ shaped loop of the vas deferens (P1. XIV, figs. 73 and $74, p r . g$. ). It is $2.0 \mathrm{~mm}$. in length, $1.0 \mathrm{~mm}$. wide, somewhat prismatic in form, approximately triangular in cross section, its surface smooth and marked off into small lobules. Its posterior inner margin is curved, its inner and ventral surface convex, while its anterior distal portion is prolonged into two pointed lobes which inclose a portion of the spermatotheca. It is enveloped by a very delicate capsule of connective tissue covering the closely packed lobules of the gland. The lumen is a more or less $U$ shaped cavity, the walls of which are formed by a single layer of cubical to columnar, ciliated cells, passing over at the upper extremities of the $U$ into the ciliated columnar epithelium of the vas deferens, and the spermatic duct respectively. Into this cavity open at intervals the very short branched tubular glands which make up the bulk of 
the organ. The gland cells are large and clear, with large, deeply staining nuclei, the reticular cytoplasm being distended with a clear albuminous secretion, staining with difficulty. The poor fixation of the single specimen available precluded any satisfactory cytological study of the gland.

$V$ as deferens and penis. From the distal end of the prostate gland passes the vas deferens (P1. XIV, figs. $73,74, v . d$.) a slender tube, ca. $3.0 \mathrm{~mm}$. long, which courses with but few loopings outward and forward, terminating in the penis into which it rather suddenly dilates (P1. XIV, figs. $73,74, p$.$) . It is lined with a$ single layer of slender columnar epithelium, surrounded by a thin layer of smooth muscle cells and a connective tissue adventitia. Toward the distal end the muscular elements become much increased, the wall of the praeputium being made up almost entirely of them. The penis was strongly retracted and curved upon itself, as was also the whole organ. It is bluntly cylindrical in shape, slightly tapering and is entirely destitute of any armature.

Vagina. The vagina (P1. XIV, figs. $73,74, v a g$. ) is small and conical in general form, its length in the slightly contracted condition being $1.0 \mathrm{~mm}$., with a maximum diameter of $0.5 \mathrm{~mm}$. Its slender duct (P1. XIV, fig. 74, vag. d.) passes directly inward to the central region of the dorsal face of the anterior genital complex where it opens into the spermatotheca (Pl. XIV, fig. 74, spth.). In cross section about midway of its length it has a diameter of $0.097 \mathrm{~mm}$., of which $0.052 \mathrm{~mm}$. is occupied by the lumen. The lining is formed by a single layer of cubical epithelium bearing long cilia, in the distal portion elevated into long ridges, which become lower and disappear in the proximal portion. The muscular coat is strongly developed, and consists of a circular and a longitudinal layer, enclosed externally by a connective tissue adventitia.

Spermatotheca and spermatocyst. The oblong flattened spermatotheca lies in the center of the dorsal face of the anterior genital complex (Pl. XIV, figs. 73, 74, spth.). It is of a light amber color, is slightly flattened dorso-ventrally, measuring 0.435 $\mathrm{mm}$. in its antero-posterior diameter by $0.3 \mathrm{I} 5 \mathrm{~mm}$. dorso-ventrally, with an extreme length of $0.46 \mathrm{~mm}$. It is lined by a high columnar epithelium, apparently ciliated, but the preservation of the specimen renders this point uncertain. A connective tissue cap- 
sule of considerable thickness, intermingled with smooth muscle fibres, surrounds the organ. The vaginal and uterine ducts are united in a common entrance into the spermatotheca. In fig. $7 \mathrm{I}$ of P1. XIII is shown a reconstruction from sections with the relations of these ducts and of the adjacent organs. The vaginal duct, vag. d., is shown in its proximal portion only, uniting with the uterine duct, $u$. $d$., at their common entrance into the spermatotheca, spth. The uterine duct describes two $\mathrm{S}$ shaped loops close together, receives the slender duct of the spermatocyst, $s p c$., and opens into the nidamental gland at its anterior end, and some distance from the anterior margin of the albumen gland. The spermatocyst is of an elongate pear shape, doubled upon itself, its greatest diameter being $0.19 \mathrm{~mm}$., and its length $0.330 \mathrm{~mm}$. It lies immediately in front of and external to the spermatotheca (P1. XIV, figs. 73 and $74, s p c$.).

Nidamental-albumen gland complex. The nidamental-albumen gland is rather small in proportion to the remainder of the anterior genital complex. It is ovoid in outline, the broader end being directed forward and outward. The upper surface is nearly plane, the under surface slightly convex. The surface is marked as usual by parallel convolutions, which are however, not very conspicuous, being quite faint on the central dorsal region occupied by the albumen gland. The duct of the nidamental gland appears upon the ventro-anterior surface (P1. XIV, fig. 73, $n . d$. ), is large, and slightly flattened dorso-ventrally. In cross section (P1. XIII, fig. 70) its limen is seen to be large, the dorsal ventral and anterior walls being thin, and of nearly equal thickness. The posterior wall bears two strong parallel longitudinal ridges, $d$, and $v$, projecting into the lumen and forming a deep groove between them. At the distal end of the duct these two ridges coalesce, the deep furrow becoming reduced to a shallow groove upon the crest of a single ridge. As the duct approaches the gland proper, this groove widens out, the ventral ridge decreases and disappears, while the dorsal ridge merges into the roof of the lumen of the gland.

Upon the external surface there is but little indication of the division into nidamental and albumen glands, such as is usually seen in other Dorididae, but in sections the structural difference is clearly apparent. In P1. XIII, fig. 7I the boundary 
of the gland is approximately marked by the dotted oval line. It occupies the median posterior portion of the complex. The distal end of the hermaphroditic ampulla, $h$. $a$., enters the connective tissue stroma of the gland at its posterior end, giving off the slender spermatic duct, $s p$. $d$., almost at right angles, and then dilates into a broad cavity, $2.5 \mathrm{~mm}$. in length and $0.1 \mathrm{~mm}$. in diameter. Its wall is practically identical in structure with that of the hermaphroditic ampulla, and, like the latter organ, it is packed full of spermatoza. It is probably to be regarded as a fertilization chamber, since it is here that the ova first come in contact with the spermatozoa from a different individual. Just beyond the middle third of the gland complex this cavity bends sharply at right angles, dilates somewhat, thence passes again in a course parallel with the long axis of the gland, narrowing rapidly to the exit of the uterine duct, $u$. $d$., from the anterior end. Just as the above mentioned dilation begins to narrow, a more slender duct, $0.24 \mathrm{~mm}$. in diameter, is given off at an acute angle, running sharply backward and ventrally, and opening into the cavity of the albumen gland at its anterior end. This cavity is irregularly pear-shaped in form, the broad end being turned forward and outward, its tip extending nearly to the proximal end of the gland complex. It is lined by a low cubical epithelium, with large spherical nuclei. Into it open on all sides at intervals the secretory alveoli of the albumen gland, which may be either single, or, as is usually the case, branched into a small number of divisions. The cells of the secretory alveoli are columnar, ca. $0.006 \mathrm{~mm}$. in average height, with large conspicuous nuclei, but their preservation did not permit making out any further details of their structure. Dorsal to the entrance of the branch of the hermaphroditic duct into the cavity of the albumen gland, a somewhat broader duct passes forward into the cavity of the nidamental gland proper. This large cavity occupies the ventral portion of the nidamental gland throughout its whole extent, and receives the short blind glandular diverticula which form the mucous secretion. In general the cavity is undivided, save for a few irregular ramifications along its posterior and outer border into which secretory alveoli open. The lumen of the duct is lined with small cubical cells with large nuclei; in the posterior half of the gland these cubical cells are replaced by tall slender columnar 
ones much similar to those of the terminal alveoli of the gland. An examination of fig. 72 of Pl. XIV may aid in a clearer perception of the relations of the above described cavities. It represents the principal ducts of the gland complex in side view, as reconstructed from serial sections, the glandular alveoli and other subordinate ramifications being left out for the sake of clearness. The dotted line represents the contour of the gland complex as seen from the front side. At the posterior end of the complex the large hermaphroditic ampulla, $h$. amp., enters, gives off the slender spermatic duct, $s p$. $d$., which emerges from the gland as seen in fig. 74 of Pl. XIV, the duct passing forward, dilating into the fertilization chamber, $f$. ch., which makes a sharp, knee like turn upward, then narrowing rapidly, gives off the slender duct, $x$, to the albumen gland, and receives the uterine duct, $u . d$, at the distal end of the gland complex. The duct $x$, corresponding doubtless to the oviduct in other Dorids, passes backward, and to the right, and opens into the cavity of the albumen gland, $l$. alb., triangular in this side view, and terminating posteriorly in a blind blunt prolongation. At its antero-dorsal end this cavity passes into the duct connecting it with the cavity of the nidamental gland, alb. $d$., and opening into the extreme anterior end of the latter at the exit of the nidamental duct. The ventrally placed large cavity, $l$. nid., into which the alveoli of the nidamental gland pour their mucous secretion, extends backward to the posterior end of the gland complex. Its dorsal surface is concave, the ventral convex in the anterior half of the organ, posteriorly becoming flatter, and finally the concavity is shifted to the ventral side, the dorsal face being arched. From the anterior end of the cavity the broad nidamental duct, $n . d$., arises and emerges from the gland complex. In the figure the space between these ducts and cavities and the bounding dotted line is to be thought of as filled with the closely packed glandular diverticula arising from the cavities of the nidamental and albumen glands respectively.

The architecture of these two glands appears to be simpler in this species than in most other Dorididae. From fig. 72 of $\mathrm{Pl}$. $\mathrm{XIV}$ the path taken by the eggs in traversing the different ducts from the hermaphroditic ampulla to the nidamental duct, can be readily followed. No trace of a second duct from the 
albumen gland to the duct of the nidamental gland, such as that described by Pohl ('95) for Polycera could be found.

The circulatory, respiratory, excretory and nervous systems of this species presented no marked differences from other Discodoridinae.

The above species, which is clearly different from any hitherto described, I dedicate to Professor Hermann Von Ihering, the able Director of the Museu Paulista, Sao Paulo, Brazil, and the pioneer in the study of the Opisthobranchiata of that country.

Type No. I47, Invertebrate Series, Leland Stanford Junior University Zoological Museum. 


\section{Subfamily DIAULULINAE.}

Body neither hard nor soft; depressed or subdepressed; notaeum usually minutely villous, often silky; tentacles digitiform; branchial aperture rounded, crenulate, branchial leaves tripinnate; anterior margin of foot bilabiate, the upper lip notched. Labial armature none. Rhachis of radula naked. Pleurae multidentate, usually hooked. Penis usually unarmed.

Genus PELTODORIS, Bergh, 1879.

Peltodoris, Bergh. "Ueber die Gattung Peltodoris," Mittheilungen aus der Zoologischen Station zu Neapel, II, 2, I879, p. 222. -Malacol. Untersuchungen, Sup. Heft I, I880, p. 4I. -Neue Nacktschnecken der Südsee, IV, Jour. Mus. Godeffroy, XIV, I878. -Malacol. Unters., XVI, II, I889, p. 8I 5.

Body subdepressed, the circumference oval, subrigid, minutely granular above. Tentacles digitiform. Branchial aperture rounded, the branchiae of few leaves, usually tripinnate.

Labial armature none. Rhachis of radula naked, pleurae multidentate, the teeth hooked.

Prostate gland large. Penis and vagina unarmed.

The genus Peltodoris was established by Bergh in 1879 for the reception of the type species $P$. atromaculata Bergh, from the Mediterranean, and for a second species, P. crucis (Oersted), from the Antilles. The genus is much similar to Discodoris, differing in the less soft body, and especially in the unarmed labial disc. Whether such a slight difference is sufficient to establish a distinct genus or not may be a matter of doubt.

In this genus are placed the following species:

I. Peltodoris atromaculata Bergh. Bay of Naples. Bergh 1. c.

2. Peltodoris crucis (Oersted).

Antilles, St. Thomas, (Riise). Sainte Croix, (Oersted). Journ. de Conchyliologie, III, 3, I863.

3. Peltodoris manritiana Bergh.

Mauritius Isl. Bergh, Mal. Unters. XVI, 2, p. 815.

4. Peltodoris angulata Eliot.

East Africa. Eliot, Proc. Zool. Soc. London, 1903.

5. Peltodoris aurea Eliot.

East Africa. Eliot 1. c. 
6. Peltodoris rubescens Bergh.

Malay Archipelago. Bergh, Siboga Exp. 1905.

To this list is to be added the following new species, taken by Mr. Greeley at Riacho Doce, Alagoas, July 28, I 899.

Peltodoris greeleyi Sp. Nov.

Plate XV, figs. 77-82.

But one specimen is in the collection, no notes save that of locality and date accompanying it. The animal was rolled up in a loose coil, and was apparently not much shrunken by the preserving fluid.

\section{External Characters.}

Color and form. The color of the alcoholic specimen is very pale yellowish pink everywhere, there being no special markings. The dorsum is villous, quite velvety to the touch and quite similar to Diaulula in this respect. It is equally rounded in front and behind, the general body shape being oblong elliptical, with the wide, rather fleshy mantle edges projecting well beyond the foot.

Branchiae and rhinophores. The thirteen branchial plumes are short, simply pinnate and arranged in a complete circle about the anus, which occupies the summit of a low papilla, the minute pore-like renal opening being situated as usual, a little to the front and right. The branchiae were completely retracted within the branchial pocket, the thin margin of which is prominent, minutely villous, and slightly inrolled. The antero-posterior diameter of the opening is $2.8 \mathrm{~mm}$., the transverse slightly less. The margins of the sheath of the deeply retracted rhinophores are similarly villous. The clavus of the rhinophores is club shaped and perfoliate, with sixteen leaves on either side. The tentacles are short, conical and dorso-ventrally flattened.

Foot. The foot is broad and muscular, contracted, the anterior end rounded and bilabiate, the upper slightly notched.

Dimensions. The approximate length of the partly rolled up specimen is $18.0 \mathrm{~mm}$., with a maximum width of $10.0 \mathrm{~mm}$.

Internal ANATOMy.

Integument. The dorsal integument is thin, strengthened everywhere with minute spicules. Around the base of each papilla of the velvety surface of the dorsum is arranged a radial 
series of short, rod like spicules which are continued up into the papilla to its summit. The minute papilla, which lend to the surface of the dorsum its velvety appearance, are supported by a large number of spicules, distinguishable into two classes. In the axial portion of each papilla are found four to eight stout, blunt, cylindrical spicules at right angles to the general body surface. Placed obliquely around these in a radiate manner, their central tips forming a close ring at the summit of the papilla, are a variable number of more slender, pointed spicules of the type generally found throughout the thickness of the integument (Pl. XV, fig. 77). The average length of the central spicules is $0.07 \mathrm{~mm}$., their diameter $0.006 \mathrm{~mm}$., while the oblique spicules average o.II $\mathrm{mm}$. in length and $0.004 \mathrm{~mm}$. in diameter.

The pseudo-peritoneum is colorless throughout, all the viscera being covered with a delicate sheet of connective tissue. Loosely attached to the dorsal surface of the central nervous system is the bilobed blood gland, very thin and flat, its anterior lobe being much smaller than the posterior one.

\section{Alimentary System.}

The oral tube is short, broad and muscular, $1.25 \mathrm{~mm}$. long by $1.75 \mathrm{~mm}$. wide, partly everted through the mouth opening. No trace of a specialized labial armature was present other than the simple cuticular thickening.

Radula. The pharyngeal bulb is a nearly spherical mass, 2.I mm. in diameter, the radula sheath forming but a slight prominence upon the lower, posterior surface. The radula is broad, short and deeply grooved. The teeth are in 49 rows, of which the first, the oldest, are more or less worn away and incomplete. The rhachis is naked, the pleurae, 60 in number on each side, are strongly hooked, and of a similar shape throughout. The bases are moderately thick and heavy, the hooks blunt and flattened (Pl. XV, figs. 78, 8I). The shaft and hook of each tooth lie in the same plane, the tip of the hook not being directed toward one side as is usually the case. The dimensions of a typical tooth are: length of base $0.082 \mathrm{~mm}$., height of hook $0.049 \mathrm{~mm}$., width of base $0.005 \mathrm{~mm}$. The outermost tooth of each row is smaller than the remaining ones ( $\mathrm{Pl}$. XV, fig. 79), as are also the innermost pleurae (Pl. XV, fig. 80). The 
dental formula for the whole radula may be expressed as $60: 0: 60 \times 49$.

Visceral complex. The salivary glands are short and broad, $2.5 \mathrm{~mm}$. in length, scarcely extending beyond the circumesophageal ring of the central nervous system. The esophagus is short and wide, passing downward and backward into the large stomach, which lies in the usual V shaped groove in the upper anterior border of the liver. The stomach is broadly wedge shaped above, $4.5 \mathrm{~mm}$. in length, $3.0 \mathrm{~mm}$. wide and $2.25 \mathrm{~mm}$. in depth, presenting a somewhat triangular cross section. The esophagus enters at its lower anterior border, the intestine arising from the upper posterior end and passing backward to the anus, lying in a groove in the upper surface of the liver throughout its course. The latter organ presents the form of a blunt cone, the anterior end deeply notched for the reception of the stomach, and facetted by the pressure of the anterior genital complex. The cavity of the liver opens widely into that of the stomach on the ventral median line, immediately behind the opening of the esophagus. No bile cyst is present.

\section{Reproductive System.}

Hermaphroditic gland and duct. The surface of the liver is covered everywhere save on the central portion of the gastric groove, the anterior face and the antero-ventral surface by the ramifications of the hermaphroditic gland. Its duct arises by the union of a number of delicate tubules from the lobules of the mid-dorsal face, immediately behind the stomach. It courses forward and downward, between the right surface of the stomach and the anterior lobe of the liver, for a distance of $3.5 \mathrm{~mm}$. and dilates into the white hermaphroditic ampulla on the lower surface of the anterior genital mass (P1. XV, fig. 82, h.a.).

Anterior genital complex. The organs of this complex are very compact, convex upon the outer and inner surfaces, in lateral view oval, from above more pointed posteriorly than in front. The extreme length of the complex is $4.6 \mathrm{~mm}$., its width $2.5 \mathrm{~mm}$., and height $3.5 \mathrm{~mm}$. Its inner face bears a shallow broad groove, deepening toward the upper margin. Anterior to this groove and forming a large part of its anterior wall is a smooth, light brown surface, the wall of the spermatotheca (Pl. 
$\mathrm{XV}$, fig. 82, spth.). Below, wedged in between the spermatotheca in front and the albumen gland behind, appears the surface of the glistening white hermaphroditic ampulla. Encircling the spermatotheca and this ampulla is a lobulated mass, the prostate gland (P1. XV, fig. 82, pr.). Posterior to the hermaphroditic ampulla and the spermatotheca, the inner face of the anterior genital mass is made up principally of the albumen gland, finely convoluted and of a light yellow color, surrounded above, behind and below by the thicker convolutions of the pinkish nidamental gland. The lower posterior border of the complex is occupied by a broad convolution of the nidamental gland, which is of a reddish hue, markedly distinct from the remainder of the mass. In the figure 82 of Plate XV, the nidamental and albumen glands have been dissected away, and are not shown.

Hermaphroditic ampulla. The hermaphroditic duct dilates into its glistening white ampulla, midway of the inner face of the anterior genital complex. This ampulla is somewhat lunate in form, curving downward in a groove between the spermatotheca and the albumen gland, thence outward and upward upon the external face of the complex to a point immediately below and ir front of the spermatocyst, where it narrows suddenly, gives off the spermatic duct (P1. XV, fig. 82, sp. d.), and passes inward and upward into the nidamental gland.

Prostate gland and penis. The very short spermatic duct passes at once into the large lobulate prostate gland (P1. XV, fig. $82, p r$.), overlying and forming the whole of the front surface of the complex. From its superior surface is given off the relatively long vas defenens ( $\mathrm{Pl} . \mathrm{XV}$, fig. $82, v . d e f$.), which describes an irregular loop, free from the surface of the anterior genital mass, above its antero-median transverse groove, and passes downward and outward into the praeputium. The praeputium is $1.5 \mathrm{~mm}$. long by $1.0 \mathrm{~mm}$. in maximum width, tapering inward to the vas deferens. Within it is inclosed the retracted glans penis, cylindro-conical in form, its length $0.78 \mathrm{~mm}$., its greatest diameter $0.16 \mathrm{~mm}$., tapering gradually to a truncate tip with a terminal diameter of 0.009 mm., smooth and entirely unarmed. 
Vagina and duct. Parallel to the praeputium and a little behind it pass the more slender vagina and vaginal duct. Their combined length is much less than that of the vas deferens and the praeputium. The vaginal duct (P1. XV, fig. 82, vag. d.), passes inward between the prostate gland in front, and the spermatotheca, opening into the latter after a course of ca. $2.0 \mathrm{~mm}$. The spermatotheca (P1. XV, fig. 82, spth.) is ellipsoidal in form, $3.0 \mathrm{~mm}$. in length by $2.5 \mathrm{~mm}$. in width, and is covered almost entirely by the prostate gland and the adjacent organs, being exposed only for a small portion of its extent upon the inner face of the anterior genital complex. The uterine duct (P1. XV, fig. 82, $u$. $d$.) is given off very close to the entrance of the vaginal duct, passes directly outward, becoming visible upon the outer surface of the mass, curves backward beneath the spermatocyst, and opens into the cavity of the nidamental gland. It receives, not far from its origin, the short duct of the pear shaped spermatocyst, which lies upon the upper outer border of the median portion of the complex. In length it measures $1.0 \mathrm{~mm}$., in width $0.5 \mathrm{~mm}$.

Owing to the loss of this portion of the material, which was being dissected at the time of the earthquake of April I8, 1906, I am unable to give any further details as to the structure of the prostate, nidamental and albumen glands.

The anatomy of the other organs of this species do not depart markedly from the other members of the genus.

This species is named in memory of Dr. Arthur W. Greeley, the zoologist of the expedition, whose untimely death cut short a life full of promise in his profession.

Type No. 148, Invertebrate Series, Leland Stanford Junior University Zoological Museum. 
Tribe II. AeolidoideA.

Genital duct diaulic, the male and female openings contiguous. Liver ramified, extending into the latero-dorsal integumentary papillae. Pharyngeal bulb bearing a pair of lateral mandibles.

\section{Family AEOLIDIADAE.}

Body slug-like, dorso-lateral papillae spindle, or club shaped, each terminating in a cnidosac armed with nematocysts. Head bearing a pair of simple tentacles, and a pair of simple or perfoliate rhinophores, non-retractile into sheaths. Foot elongate, the anterior angles frequently prolonged into tentacles.

\section{Subfamily AEOLIDIANAE.}

Body somewhat depressed or subdepressed. Dorsal papillae more or less compressed.

Masticatory margin of mandibles smooth or nearly so. Radula uniserial, the teeth wide, pectinate.

Penis unarmed.

\section{Genus SPURILLA, Bergh, 1864.}

Spurilla, Bergh. Anatomiske Bidrag til Kundskab om Aeolidierne. K. Dansk. Vidensk. Selsk. Skr., 5te Raekke, Naturvid. og Math. Afh., VII, I864, p. 205, Tab. VB. -Bergh, Beitraege zur Kenntniss der Mollusken des Sargassomeeres. Verh. d. k. k. zool.-bot. Gesellschaft in Wien, XXI, r87r, p. r283. -Bergh, Beitraege zur Kenntniss der Aeolidiaden, IV, Verh. d. k. k. zool.-bot. Ges. in Wien, XXVI, I877, p. 758-761. -Trinchese, S. Anatomia e Fisiologia della Spurilla neapolitana. Memorie dell'Accademia delle Scienze dell'Istituto di Bologna, T. IX, Ser. III, I878, p. 405-430. -Bergh, Beitraege etc., VII, 1. c. XXXII, I882, p. I2-I9. -Bergh, Beitraege etc., VIII, 1. c. XXXV, I885, p. 2627. - Vayssière, A. Recherches zool. et anat. sur les Mollusques Opistobranches du Golfe de Marseille, II. Annales du Musée d'Histoire Naturelle de Marseille, Zoologie, III, I888, p. III. - Supplément, Ibid, VIII, I903, p. 86. 
Body somewhat elongate, not depressed. Rhinophores perfoliate. Anterior angles of foot not prominent. Cerata cylindroconical, arranged in groups, each of which is borne upon a slight, crescentic, dorso-lateral elevation of the integument.

Masticatory margin of mandibles long, minutely denticulate, or smooth.

Radula uniserial, the teeth pectinate, emarginate in the center.

This genus was proposed by Bergh in 1864 for the reception of Delle Chiaje's Eolis neapolitana as the type species. In $187 \mathrm{I}$ he transferred to this genus a second species, Sp. sargassicola (Kroyer), and in $x 882$ and 1885 , in the papers cited above, made further additions to the knowledge of the anatomy of the type species, which had been already extensively studied by Trinchese in I878. Vayssière added to this in his excellent researches upon the Opisthobranchs of the Gulf of Marseilles, in I903 recognizing a third distinct species, Sp. inornata (A. Costa). The Siboga collections contained a fourth species, which was described by Bergh in 1905 in his beautiful work upon the Opisthobranchiata of that expedition.

At the present time the list of species described as belonging to this genus is the following:

I. Spurilla neapolitana Delle Chiaje).

Mediterranean, Cape Verd Islands.

2. Spurilla sargassicola (Kroyer).

Sargasso Sea, Atlantic Ocean.

3. Spurilla inornata (A. Costa).

Mediterranean.

4. Spurilla orientalis Bergh.

Kei Island, Malay Archipelago.

All three of these species are closely related, the first two being held by Bergh to be questionably distinct. The following description deals with the first member of this genus thus far taken from the West Atlantic. After a careful comparison of its structure with that of $S p$. neapolitana, and with the description of the others, I am of the opinion that it represents a distinct species, though certainty in this regard can only be secured by the study of a series of specimens. 
Spurilla braziliana Sp. Nov.

Plates XVI, XVII, XVIII and XIX; Figs. 83-96.

But one specimen was taken by the expedition, the locality label reading "Riacho Doce, Alagoas, July 28, I 899." The preservation of the specimen was rather poor, it having been killed in a distorted position, with the head, tentacles and rhinophores strongly contracted, and the posterior portion of the body recurved dorsally. The cerata had nearly all fallen off, but were preserved in the bottle. The original color had entirely disappeared, nor were any notes taken as to the color, dimensions or appearance in life. The animal in the preserved condition had a uniform, pale pinkish coloration.

\section{External Characters.}

Dimensions. The total body length is circa $23.0 \mathrm{~mm}$., of which the length of the foot makes up I $8.5 \mathrm{~mm}$., the quite distorted head region the remainder.

Body form. The general body form is slender and somewhat compressed, tapering posteriorly to a short bluntly pointed tail, the general body form being similar to that of the other species of the genus. The mouth is everted and reflexed, the whole head region being strongly contracted. The oral tentacles in their contracted state are tapering, with blunt extremities, their basal diameter being $0.5 \mathrm{~mm}$, and approximate length $3.0 \mathrm{~mm}$.

Rhinophores. The strongly contracted rhinophores are perfoliate, the clavus bearing eight prominent leaves, which alternate on the posterior side with an equal number of lower ones that extend forward, half way around the clavus from the posterior median line.

Cerata. The cerata are lanceolate, flattened, and variously curved, in part due to the action of the preservative, but also often showing the $\mathrm{S}$ shaped curves common in Spurilla neapolitana. The smaller cerata are more rounded and conical in form. The cerata are arranged in eight groups along the dorso-lateral margins of the body (PI. XVII, figs. 90, 9I). Each of the first five of these groups is made up of two slightly curved rows of cerata, the upper ends of the rows approaching each other and uniting to form an arc like figure, borne upon a slight integumentary elevation. The anterior limb of each of these arcs contains more 
cerata than the posterior one, the number in both decreasing in each group from the first backward, until the posterior limb entirely disappears, the anterior row being alone represented in the groups from the sixth onward. In figs. 90 and $9 \mathrm{r}$ the bases of the cerata are outlined by small circles, indicating the relative size and positions of these groups. The number does not exactly correspond upon the two sides of the body for each group, but the difference is not marked, the total number for the right side being eighty, that for the left eighty-one. The distribution of the cerata in the anterior and posterior limbs of the groups is shown in the following tabulation.

\begin{tabular}{|c|c|c|c|c|}
\hline \multirow{2}{*}{ Cerata Group } & \multicolumn{2}{|c|}{ RIGHT SIDE } & \multicolumn{2}{|c|}{ LEFT SIDE } \\
\hline & $\begin{array}{c}\text { Anterior } \\
\text { Limb }\end{array}$ & $\begin{array}{c}\text { Posterior } \\
\text { Limb }\end{array}$ & $\begin{array}{c}\text { Anterior } \\
\text { Limb }\end{array}$ & $\begin{array}{l}\text { Posterior } \\
\text { Limb }\end{array}$ \\
\hline 1st group & 11 & 7 & 13 & 8 \\
\hline 2nd " & 10 & 7 & 10 & 6 \\
\hline 3 rd & 8 & 5 & 8 & 7 \\
\hline 4 th " & 7 & 4 & 9 & 5 \\
\hline 5 th & 6 & 3 & 6 & 2 \\
\hline 6th “" & 5 & & 4 & \\
\hline 7 th & 4 & & 2 & \\
\hline 8 th “ & 3 & & 1 & \\
\hline Totals & 54 & 26 & 53 & 28 \\
\hline
\end{tabular}

These figures may be expected to vary somewhat in individuals of different sizes, as they do also for the Mediterranean species.

The anterior limb of the first group begins in front of and below the bases of the rhinophores. The reproductive openings are situated close together, below the first arc of cerata on the right side; the anal opening is placed on a prominent tubular papilla, well up on the same side, and is included in the span of the second group. The opening is large, with slightly lobulated margins (Pl. XVI, fig. 88). The very minute renal opening is immediately in front of its base. 
Foot. The foot is rather narrow, tapering posteriorly into a short bluntly pointed tail. The anterior margin is thickened, with a distinct, median groove, its outer angles are short and pointed (PI. XVI, fig. 85). The total length of the foot is 18.5 $\mathrm{mm}$., the diameter of its anterior portion $3.5 \mathrm{~mm}$., narrowing to $3.0 \mathrm{~mm}$. about midway of its length.

Pharyngcal bulb. The pharyngeal bulb is nearly oval in outline, broadest on its upper posterior border, the sides sloping toward each other below. In front the dark brown hinge portion of the mandibles is thickened and conspicuous. Its maximum measurements are, length $3.0 \mathrm{~mm}$., breadth $1.8 \mathrm{~mm}$., and height I. $8 \mathrm{~mm}$., being fully one-third smaller than the pharyngeal bulb of specimens of Sp. ncapolitana of the same dimensions of the body.

Mandibles. The mandibles (P1. XVII, figs. 92, 93), are similar in general form to those of $S p$. ncapolitana, but decidedly smaller. They are elongate oval in outline, $3.0 \mathrm{~mm}$. in greatest length by $2.0 \mathrm{~mm}$. in greatest width. Each mandible is made up of three portions, the head, the body and the masticatory process. The head is massive, strongly arched in front and below, and bears the fulcrum, or hinge (P1. XVII, figs. 92, d., 93, e.), a strong dark yellow curved ridge, its concavity directed downward. In the left mandible the crest of this ridge is single (Pl. XVIII, fig. 95, c.), fitting into a groove between the diverging double crests of the corresponding ridge of its fellow of the opposite side (P1. XVIII, fig. 94, c.).

The body is elliptical, thin, and strongly arched in front, less so behind, its whole extent strongly marked by the lines of growth, parallel to the posterior border. Its inner face is concave, the outer convex. The masticatory process is made up of a triangular lamina, widest behind, attached to the ventral margin of the body of the mandible. Its posterior end is free from the mandible and is separated from it by a deep sinus (Pl. XVII, figs. 92, 93, c.). The ventral margin (P1. XVII, figs. $92,93, b$.) is much thickened and broader, and is prolonged forward, curving upward and backward to the posterior end of the fulcrum (P1. XVIII, figs. 94, 95, d.). It serves as the masticatory margin of the mandible, and shows no trace of the denticles characteristic of the other species of Spurilla. 
According to the descriptions and figures of Trinchese ('78) the single crest is found upon the fulcrum of the right mandible, the double crest upon the left one in Spurilla neapolitana, which is the reverse of the condition here described. In the preparations which I have made of the mandibles of Sp. neapolitana the relations of the single and double crests is the same as that which I have found in Sp. braziliana. I am at a loss to explain the contradiction in results.

Radula. The radula is uniserial, consisting of a series of eighteen strongly arched slightly emarginate pectinate plates of an amber color. These plates increase rapidly and regularly in size from before backward, and present a slightly convex anterior face. The first five plates have their central denticles worn and broken, the last five are still inclosed in the radula sheath where they are developed. The dimensions of the individual teeth range from a basal width of $0.27 \mathrm{~mm}$., and a height, measured from the middle of the base line to the top of the middle denticle, of $0.225 \mathrm{~mm}$., in the first plate, to a width of $0.425 \mathrm{~mm}$., and a height of $0.30 \mathrm{~mm}$. in the eighteenth plate. The relative proportions are well shown in Pl. XVI, figs. 83 and 84 , which illustrate the twelfth and the first plates of the radula respectively.

Each plate is slightly emarginate at its summit (P1. XVI, fig. 89 ), but none so much so as to give the bilobed appearance figured by Bergh ('64, '7r), Trinchese ('78) and Vayssière ('88, 'o3) for the other species of this genus. The denticles are slender and lanceolate, the lateral ones slightly curved, the remainder straight, increasing in length from the sides upward, and reaching a maximum height about the eighth or tenth from the center. The central denticle is low and broad, usually with a small denticle next to it on either side, the succeeding ones increasing in length rapidly. The number of denticles in the first plate is $49: 1: 49$; in the fifth $39: 1: 40$; in the twelfth $57: 1: 53$; in the fifteenth $61: 1: 63$; and in the eighteenth $49: 1: 47$, the increase in number thus being irregular. In a radula taken from an individual of Sp. neapolitana of the same body dimensions this increase in the number of denticles is much more regular, representative plates running as follows. First plate 18:I:I5; fifth plate $23: 1: 23$; tenth plate $34: 1: 34$; twelfth plate $32: 1: 35$; fifteenth plate $35: 1: 37$; eighteenth plate $52: 1: 44$; and in the twenty-sixth 
and last plate $54: \mathrm{I}: 5 \mathrm{I}$. In this radula the basal diameter of the plates varied from $00.09 \mathrm{~mm}$. in the first, to $0.55 \mathrm{~mm}$. in the twenty-sixth. In Sp. neapolitana the three central denticles are very small or rudimentary, while in the Brazil species the central denticle is valid and much larger (P1. XVI, fig. 89).

Salivary glands. The extremely long salivary glands are shown in figs. 86 and 87 of Pl. XVI. They have the same general appearance and relations as exhibited in the other species of Spurilla.

Central nervous system. The ganglia of the central nervous system are inclosed in a strong closely applied connective tissue capsule, from which in the specimen at hand the ganglia had in part shrunken away, the general preservation precluding any satisfactory detailed study of the cells and fibre tracts in sections, though the general relations could be readily made out. For comparison several specimens of $S p$. neapolitana were also dissected. In general there is no great difference between the two species, but some marked discrepancies were noted between the Neapolitan species and the figures given for it by Bergh ('77), and by Trinchese ('78), especially in respect to the origins of the nerves. In Bergh's fig. 4, Pl. XII, the nerves appear to be represented in a diagrammatic fashion, they being neither numbered, nor mentioned in the text, the author manifestly laying most stress upon the form and grouping of the ganglia. In the earlier paper of Trinchese, "Nuovo Ricerche sull' Organizzazione del Cervello degli Eolididei," Memorie dell'Accademia delle Scienze dell'Instituto di Bologna, I875, Serie III, T. V, he devotes his attention to certain peculiarities of the nerve cells as seen in preparations, cleared in glycerine and flattened under a cover glass, his figure of Tavola I giving but a faint idea of the actual form of the ganglia and the origins of their nerves. In his "Anatomia e Fisiologia della Spurilla neapolitana," cited above, this is corrected in the figures of Tavola XI, which present the best representations of the central nervous system of this Eolid yet published. In the figure of the same for $S p$. brasiliana, given on Pl. XIX, fig. 96, I have adopted the designations used by Trinchese for the nerves for the sake of ease of comparison, though I must disagree with him as to the actual origin and 
relations of some of these nerves in both the Brazilian and the Neapolitan forms.

In studying both species the central nervous system was carefully freed from its attacliments, stained in Paracarmine, and cleared in glycerine. To facilitate microscopic examination, and to avoid unnecessary displacement of the parts concerned, a piece of glass rod was drawn out in a flame to the approximate diameter of the esophagus of the animal. A short bit of this was passed through the circumesophageal loop of the central nervous system, and the whole mounted on a slide having a suitable depression ground in it. The preparation may then be rotated and examined from all sides, without danger of disturbing the relations of its parts. The use of the Zeiss binocular dissecting microscope enormously facilitates the recognition of the relations of the ganglia and their nerves.

The dorsal portion of the nerve collar is made up of the fused cerebro-pleural ganglia (P1. XIX, fig. 96, c. pl. g.), in contact along the median line, the cerebral portions being joined by the very short and broad cerebral commissure. The two ganglia are marked off from each other by a slight transverse constriction, dividing the complex into two approximately equal portions, the anterior, cerebral one being slightly larger than the posterior, pleural part. While in the main the nerve cells correspond in their distribution to these divisions, there is no middle region between the two entirely free from them. The length of the whole complex is $0.6 \mathrm{~mm}$., the transverse diameter of each cerebral portion $0.345 \mathrm{~mm}$., that of the pleural portion $0.315 \mathrm{~mm}$.

Lateral to the esophagus are situated the ellipsoidal pedal ganglia (Pl. XIX, fig. 96, ped.g.), connected to the cerebro-pleural complex by the very short cerebro-pedal and pleuro-pedal connectives. The maximum length of the pedal ganglia is $0.33 \mathrm{~mm}$., with an antero-posterior diameter of $0.2 \mathrm{I} \mathrm{mm}$., and a dorsoventral diameter of $0.225 \mathrm{~mm}$.

The ventral portion of the circumesophageal ring is made up of the commissures. These are three in number, two of which are united together in a common sheath, forming a broad band. In this band are included the broad pedal and the narrower subcerebral commissures (P1. XIX, fig. 96, ped. com.). Separate from this, but close to it is the slightly longer pleural commissure 
(Pl. XIX, fig. 96, pl. com.), taking its origin from the pleural portion of the cerebro-pleural complex. At a point about onefourth of its length from the left side it gives off a moderately strong, unpaired nerve, the N. genitalis (P1. XIX, fig. 96, $n . g$.). This is described and figured by Bergh as arising from the right side in Sp. neapolitana. In the Brazil species no ganglion cells were found at the origin of the nerve. To these three commissures should be added a fourth loop around the esophagus, which is separated from them by some distance. This is formed by the cerebro-buccal connectives and the buccal ganglia. These slender connectives (P1. XIX, fig. 96, cer. buc. con.) arise from the cerebral ganglia just below and in front of the eyes. The buccal ganglia themselves are quite similar to those of the Neapolitan species. They are oval in form, $0.24 \mathrm{~mm}$. long by $0.21 \mathrm{~mm}$. broad, and are united by a very short $(0.042 \mathrm{~mm}$.) and broad commissure. A pair of small gastro-esophageal ganglia are closely united to them.

From the antero-dorsal portion of the cerebral ganglia arise the short stout olfactory nerves (P1. XIX, fig. 96, olf. n.), which dilate into the very large elliptical olfactory ganglia at the base of the rhinophores. These nerves should, perhaps, be termed cerebro-olfactory connectives, the name olfactory nerves being reserved for the branches arising from the summit of the ganglia, which are distributed to the olfactory epithelium of the rhinophores.

The small optic ganglia, bearing the eyes (P1. XIX, fig. 96, e.), lie upon the dorso-lateral margin of the cerebral ganglia, in direct contact with them, and above the origin of the cerebropedal connectives. Immediately behind these are the approximately spherical otocysts (P1. XIX, fig. 96, ot.), $0.045 \mathrm{~mm}$. in diameter, containing many small otoconia of an ellipsoidal shape. In sections the otocysts are seen to lie upon and behind a group of small ganglion cells, outside the limits of the cerebro-pleural complex, and probably to be regarded as an otic ganglion, but the preservation of the material precluded any decision as to their exact relationships.

Plate XIX, fig. 96 shows the origin of the nerves from the central nervous system in Sp. braziliana, being much the same as that given by Trinchese for $S p$. neapolitana. Nerve VII 
is worthy of separate notice, however. I am unable to confirm Trinchese's figures as to its origin in either species. He shows it as arising from the lower outer margin of the pedal ganglion as a pedal nerve. According to my preparations and sections it is a nerve from the cerebro-pleural complex, its fibres penetrating the capsule of the pedal ganglion at the upper inner border of the latter, immediately above the connectives joining the pedal ganglion to the cerebro-pleural complex. The fibres do not enter the pedal ganglion, however, but course directly into the pleural portion of the cerebro-pleural group. A similar relation may also be suspected in Sp. inornata in the case of the nerve numbered 6, in fig. 36 of P1. III, in Vayssière's "Recherches sur les Mollusques Opistobranches du Golfe de Marseille, Supplément."

A decided asymmetry is to be noticed in the nerves of the pedal ganglia upon the two sides. Whether this has any special significance or not could not be determined by the dissection of but one specimen alone.

Counting the olfactory stalk as a nerve we have seven nerves given off from the cerebro-pleural complex, five of which arise from the cerebral portion, one from the intermediate zone between the cerebral and the pleural regions, and one from the pleural alone. As the optic and otic ganglia are sessile, they are not included in the above enumeration. From the pedal ganglion two large nerves arise, which are distributed to the sole of the foot. The peripheral distribution of the nerves was not worked out in detail, such an undertaking requiring much more material than was available.

\section{Reproductive System.}

The hermaphroditic gland is made up of eight spherical lobules, closely packed together and more or less flattened by mutual pressure. Six of these are paired, alternating more or less in position, while the seventh and eighth are unpaired. The glans penis is short and conical and entirely unarmed. The remaining organs of the reproductive system are not greatly different from those of the other species of Spurilla, all of which seem to show close similarity.

The general differences shown by this specimen in anatomical organization, especially as shown by the mandibles and radula, 
seem sufficient to authorize its recognition as a member of a species distinct from the European ones already described. The name Spurilla braziliana is here proposed for it.

Type No. I49, Invertebrate Series, Leland Stanford Junior University Zoological Museum. 


\section{LITERATURE.}

Adams, Arthur.

I854. Monographs of Actæon and Solidula. Proceedings Zool. Soc. London, I854, p. 58-62.

Bergh, Rudolph.

I864. Anatomiske Bidrag til Kundskab om Æolidierne. K. Danske Vidensk. Selsk. Skr., 5te Raekke, Naturvid. og Math. Afh. VII, p. I37-3I4, Tab. I-IX.

I87I. Beitraege zur Kenntniss der Mollusken des Sargassomeeres. Verh. d. k. k. Zool.-Bot. Gesellschaft in Wien, XXI, p. I273-I308, Taf. XI-XIII.

I877a. Kritische Untersuchungen der Ehrenberg'schen Doriden. Jahrb. d. Deutschen Malakozoologischen Gesellschaft, IV, p. 45-76.

I877b. Beitraege zur Kenntniss der Eolidiaden, IV. Verh. d. k. k. Zool.-Bot. Ges. in IVien, XXVI, p. 737-764, Taf. IX-XII.

I877c. Malacologische Untersuchungen, XII, in Semper, Reisen im Archipel der Philippinen, II Theil, Wissenschaftliche Untersuchungen, Band II, p. 495-546, Taf. LVII-LXI.

I878a. Neue Nacktschnecken der Südsee, IV. Journal Museum Godeffroy, H. XIV, p. I-50, Taf. I-V.

I878b. Malacologische Untersuchungen, XIII. 1. c., p. 5476or, Taf. LXII-LXV.

I879a. Beitraege zur Kenntniss der Eolidiaden, VI. Verh. d. k. k. Zool.-Bot. Ges. in Wien, I878, p. 553-584, Taf. VI-VIII.

1879b. Die Doriopsen des Atlantischen Meeres. Jahrb. d. Deutschen Malakozool. Ges. VI, p. 42-64.

I879c. Ueber die Gattung Peltodoris. Mittheilungen aus der Zoologischen Station zu Neapel, II, p. 222.

I880. Malacologische Untersuchungen, Stupplementheft I, 1. c., P. I- 78 , Taf. A-F.

I88I. Malacologische Untersuchungen, Supplementheft II, 1. c., p. 79-I28, Taf. G-L. 
I884a. Malacologische Untersuchungen, XV. 1. c., p. 647754, Taf. LXIX-LXXVI.

I884b. Report on the Nudibranchiata. Zoology, Challenger Expedition, X, P. I-I 54, Pl. I-XIV.

1889. Malacologische Untersuchungen, XVI, II, 1. c., p. 8I5-872, Taf. LXXXII-LXXXIV.

I890. Malacologische Untersuchungen, XVII, 1. c., p. 873991, Taf. LXXXV-LXXXIX.

1892. System der Nudibranchiaten Gasteropoden. Wiesbaden. Also as Heft XVIII, Malacologische Untersuchungen, 1. c., p. I-I74.

1894. Die Opisthobranchien. Bulletin Museum of Comparative Zoology, Harvard, XXV, No. IO, p. I25-233, Taf. I-XII.

1897. Die Pleurobranchiden, I, II. Malacologische Untersuchungen, IV, I, I, 2. 1. c., Band VII, p. I-5I, 53-II5, Taf. I-IV, V-VIII.

I898a. Die Opisthobranchier der Sammlung Plate, Zoolog. Jahrb. Supplement, Fauna Chilensis, p. 48I-582, T. 28-33.

I898b. Malacologische Untersuchungen, IV, I, 3, 1. c., p. I I7I58, Taf. IX-XII.

1905. Die Opisthobranchiata der Siboga Expedition. Leiden, p. I-248, Taf. I-XX.

dE Blainville, H. M. D.

I825. Manuel de Malacologie et de Conchyliologie. Paris. BoLot, E.

I886. Sur le Pontè de Doris. Comptes Rendus Acad. Sci. Paris, I02, 1. p. 829-831.

Cunningham, J. T.

1883. Notes on the Structure and Relations of the Kidney in Aplysia. Mitth. Zool. Station zu Neapel, IV, p. 420428, Pl. 30.

Cuvier, G.

I803. Mémoire sur la Genre Laplysia. Annales du Museum d'Histoire Naturelle, Paris, II, p. 287-3I4, Pl. I-IV.

1805. Mémoire sur la Phyllidie et sur le Pleurobranche. Annales du Museum d'Histoire Naturelle, Paris V, p. 266-276, P1. I8. 
DALL, W. H.

r889. Report on the Mollusca, Part II. Gastropoda and Scaphoda. Bulletin Museum Comp. Zool. Harvard, XVIII, p. I-492, P1. I-XL.

1891. Mollusks from the Vicinity of Pernambuco. Proceedings of the Washington Academy of Sciences, III, P. I39-I 47.

Dall, W. H. and Simpson, C. T.

190I. The Mollusca of Porto Rico. Bulletin U. S. Fish Commission, XX, Part I, p. 351-524, P1. 53-58.

Dobson, G. E.

I880. Notes on Aplysia dactylomela. Journal Linnæan Society, London, XV, p. I59-160.

Eliot, C.

I899. Notes on Tectibranchs and Naked Mollusks from Samoa. Proc. Philadelphia Acad. Sciences, I898, p. 512-523, P1. XIX.

Gourd, A. A.

1852. Mollusca and Shells. U. S. Exploring Expedition, XII. Philadelphia.

VON IHERING, H.

1877. Vergleichende Anatomie des Nervensystems und Phylogenie der Mollusken. Leipzig, p. I-290, Taf. I-VIII.

1886. Zur Kenntniss der Nudibranchien der Brazilianischen Küste. Jahrb. d. Deutschen Malakozoolog. Gesellsch., p. 223-240, Pl. IX.

1897. A Ilha de São Sebastiao. Revista Museu Paulista, II, p. I29-I70.

de Lacaze-Duthiers, H.

I887. Système Nerveux des Gasteropodes (type Aplysie). Comptes Rendus Acad. Sci. Paris, CV, p. 978.

LINNÈ, C.

I758. Systema Naturæ, Ioth ed., Holmiæ.

r766-68. Systema Naturæ, r2th ed.

r788-r795. Systema Naturæ, I3th ed. Cura J. F. Gmelin, Lipsiæ ( I790, Vol. I, Pars VI). 
Mazzarelli, Gius.

I889. Intorno all' Anatomia dell' Apparato riproduttore nelle Aplisie del Golfo di Napoli. Zoolog. Anzeiger, XII, p. 330-336.

I890a. Sul Valore fisiologico della Vescicola di Swammerdam delle Aplysix. Zoolog. Anzeiger, XIII, p. 39I-399.

I89ob. Ricerche sulla Morfologia della Glandola del Bohadsch nelle Aplysiidre. Mem. R. Accad. Sci. fis. e mat. Napoli, IV, (2), App. I.

I891. Ricerche sulla Morfologia e Fisiologia dell' Apparato riproduttore nelle Aplysiæ del Golfo di Napoli. Mem. R. Accad. Sci. fis. e mat. Napoli, IV, 2.

I893. Monografia delle Aplysiidæ del Golfo di Napoli. Mem. Soc. Ital. Sci. (dei XL), IX, Ser. 3a, No. 4, p. I-222, Tav. I-XIII.

Mörch, O. A. L.

I863. Contributions à la Faune malacologique des Antilles danoises. Journal de Conchyliologie, p. 2 I-43.

D'Orbigny, A.

I835-1843. Voyage dans 1'Amérique Méridionale. Paris, Vol. V, 1836.

Pelseneer, Paul.

I887. Recherches sur le système nerveux des Ptéropodes. Archives de Biologie, VII, p. 93-I29, P1. IV.

1904. Recherches sur divers Opisthobranches. Mem. Cour. Acad. Roy. de Belgique, LII, p. I-57, Pl. I-XXV.

1906. Mollusca. Part IV, Lankester's A Treatise on Zoology. London.

Pilsbry, H. A.

I895. On the Status of the Names Aplysia and Tethys. Proc. Acad. Nat. Sciences, Philadelphia, I895, p 347-350. 1896. Tryon's Manual of Conchology, Philadelphia, Vol. XVI.

Pohl, Hermann.

1905. Ueber den feineren Bau des Genitalsystems von Polycera quadrilineata. Zoologische Jahrbücher, Anat. Abteilung, Band XXI, p. 427-452, P1. 25-26.

RANG, S.

I828. Histoire Naturelle des Aplysiens. Paris. 
ROBERT, E.

I889. Sur l'Appareil reproducteur des Aplysies. Comptes Rendus Acad. Sci. Paris, CIX, p. 9I6.

Smith, E. A.

I872. Remarks on Several Species of Bullidæ. Annals and Magazine Nat. History, (4), IX, p. 344-355.

Trinchese, S.

1875. Nuovo Ricerche sull' Organizzazione del Cervello degli Eolididei. Memorie dell' Accad. Sci. delle Istituto di Bologna, Ser. III, T. V, p. I-8, Tav. I-III.

I878. Anatomia e Fisiologia della Spurilla neapolitana. Memorie dell' Accad. Sci. Istituto di Bologna, Ser. III, T. IX, p. 405-450, T. I-XII.

VAYSSIÈRE, A.

1885. Recherches zoologiques et anatomiques sur les Mollusques Opistobranches du Golfe de Marseille, I Tectibranches. Annales du Musée d' Histoire Naturelle de Marseille, Zoologie, Mémoire 3, p. I-I8I, Pl. I-6.

I888. Ibid, II, Nudibranches et Ascoglosses. 1. c., III, Mémoire 4, P. I-I6o, Pl. I-7.

I903. Ibid, Supplément. 1. c., VIII, Mémoire 3, p. 73-I08, Pl. II-III.

I898. Monographie de la Famille des Pleurobranchidés, I, Annales des Sciences Naturelles, Zoologie, (8), VIII, p. 209-402, Pl. I3-28.

I901. Ibid, II. 1. c., (8), XII, p. I-85, Pl. I-VI. Watson, R. B.

I886 Report on the Scaphopoda and Gasteropoda collected by H. M. S. Challenger. Zoology Challenger Expedition, XV, p. i-v, I-756, Pl. I-L, I-III.

ZUCCARDI, R.

I890. Intorno all' Anatomia dell' Apparato digerente nelle Aplysiæ del Golfo di Napoli. Boll. Soc. Nat. Napoli, IV, P. 5-I4, T. I-2. 


\section{EXPLANATION OF PLATES.}

All of the figures of Plates I-XIX were made by the aid of the Abbe Camera Lucida, and were redrawn in ink by Olive $H$. MacFarland. The line work of Plates II, VII and VIII was done by W. S. Atkinson. 


\section{Plate I.}

\section{Tethy's dactylomela (Rang).}

Fig. I. Median and first lateral teeth of each side of 49 th and 5 oth rows of radula. $\times 62$.

Fig. 2. 8th, 9th and Ioth lateral teeth of 49 th and 5 oth rows of radula. $x 62$.

Fig. 3. I8th, Igth and 29 th lateral teeth of 5 oth row of radula. x 62 .

Fig. 4. Outermost teeth, the 32 nd to $37^{\text {th }}$ laterals of $54^{\text {th }}$ row. $\times 62$.

Fig. 5. A single typical lateral tooth. $\mathrm{x}$ IIo.

Fig. 6. Side view of the outer face of $5^{\text {th }}$ laterals of the 49 th and 5 oth rows. $\times 62$.

Fig. 7. Labial armature in surface view. $a$, anterior; $p$, posterior margin. x 195. 

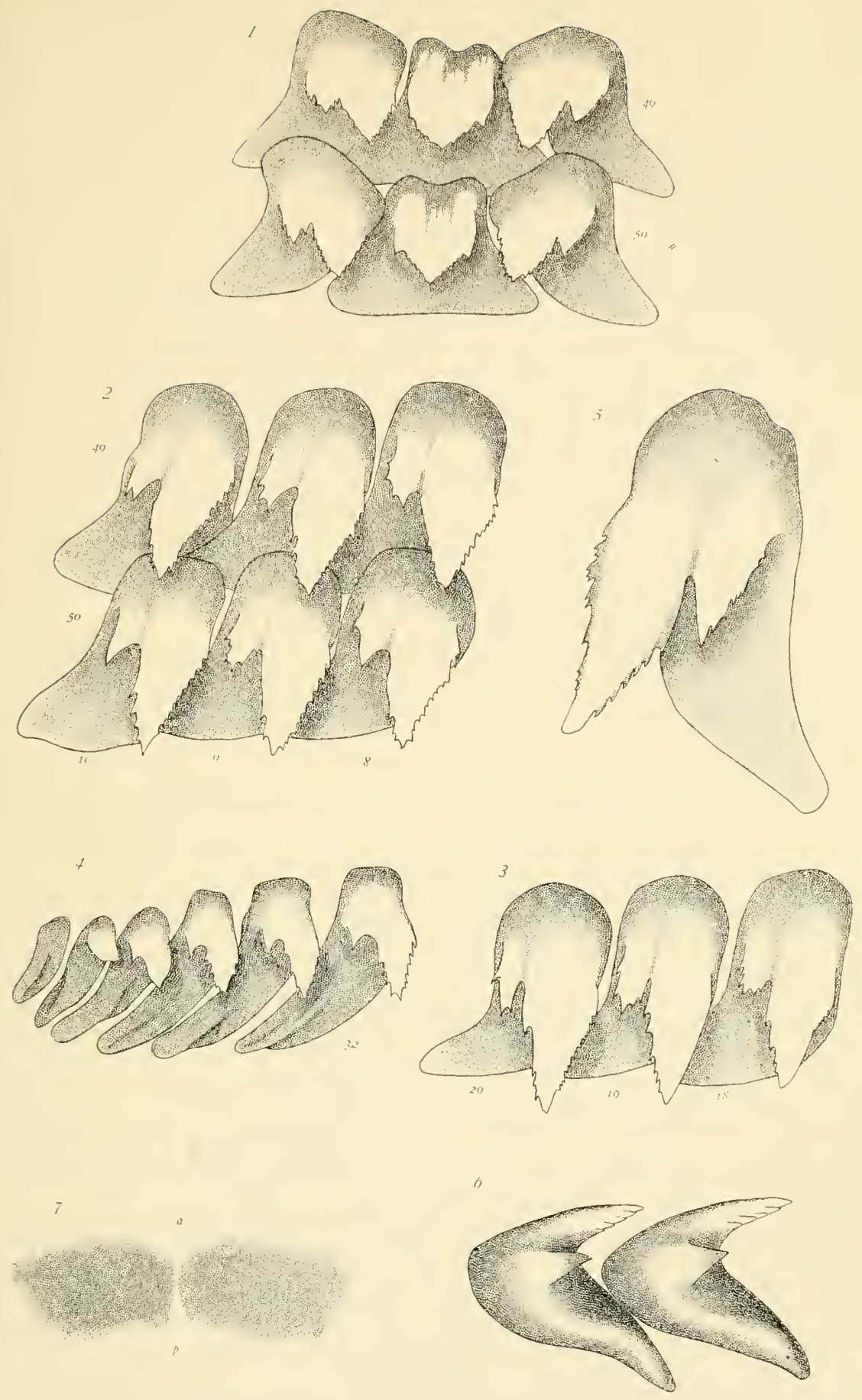



\section{Plate II.}

Fig. 8. Central nervous system of Tethys dactylomela (Rang). cer. g., cerebral ganglia; ped. g., pedal ganglia; pl. g., pleural ganglia; buc. g., buccal ganglia; c. p. con., cerebro-pedal connectives; $c$. pl. con., cerebro-pleural connectives; $c . b$. con., cerebro-buccal connectives; $p l$. par. con., right pleuro-parietal connective; $p l$. v. con., left pleuro-visceral connective; $p$. com., pedal commissure; p. p. com., parapedal commissure.

The nerves from each ganglion are numbered serially as described in the text, and are distinguished by the prefixed letter, $b ., c$., pl., or $p$., indicating their repective ganglia, buccal, cerebral, pleural or pedal. $\times$ I0.5. 

Figs. 9-I4, Tethys dactylomela (Rang).

Fig. 9. Buccal ganglia in situ, seen obliquely from below and the right side. es., cut end of esophagus; $s$. gl., right salivary gland, its severed distal end bent forward and to the right; buc. g., buccal ganglia; $c$. b. con., cerebrobuccal connective. The buccal nerves are numbered serially from $I$ to 6 . In this specimen the $5^{\text {th }}$ and 6 th nerves arose from a common trunk. $\times 8$.

Fig. Io. Buccal ganglia, ventro-posterior face. Lettering as in Fig. 9. $\times 8$.

Fig. II. Buccal ganglia, dorso-anterior face. Lettering as in Fig. 9. $\times 8$.

Fig. I2 Posterior margin of labial armature showing outlines of bases of the rodlets. $\times 223$.

Fig. 13. Two elements of the labial armature from anterior margin of plate. $\mathrm{x}$ I37.

Fig. 14. Parieto-visceral ganglion complex. r.p.g., right parietal ganglion; l. $v$. g., left visceral ganglion; $p l$. par. con., right pleuro-parietal connective; $p l$. $v$. con., left pleuro-visceral connective; $r . p$. I., Ist parietal, or vulvar nerve; $I a$., its branch forming an anastomosis with the branch of the $3^{\text {rd }}$ pedal nerve supplying the Organ of Bohadsch; $r . p .2$, second parietal, or osphradio-ctenidial nerve; $l . v . I$, first visceral nerve to vesicle of Swammerdam, the spermatocyst; $l$. $v .2$, second visceral nerve; l. v. $3 a$., and $l$. v. $3 b$., the two main branches of the third visceral nerve, in some specimens arising as distinct nerves, in others branching from a common trunk. $\mathrm{x} 8$.

Figs. 15-22, Tethys cervina Dall and Simpson.

Fig. I5. Outline of labial armature. $\times 8$.

Fig. 16. Rodlet from anterior portion of labial armature. $x$ I83.

Fig. 17. Surface view of Organ of Bohadsch, or hypobranchial gland. $a$., artery; $I$, nerve from right pedal ganglion; 2 , nerve from left visceral ganglion. $\times 6$. 

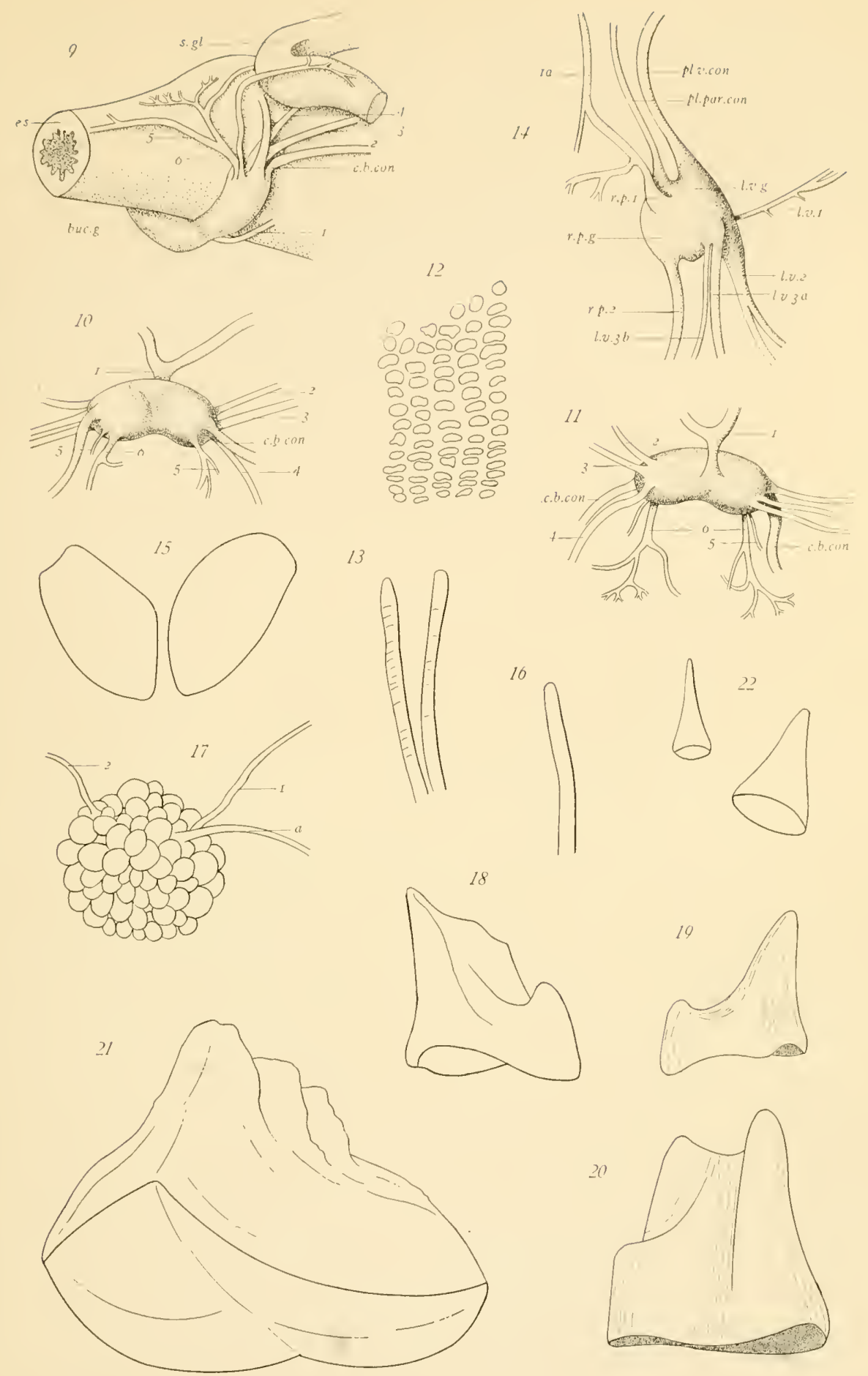

Fig. I8. Anterior smaller tooth of second triturating stomach, obliquely from in front. $\mathrm{x} 24$.

Fig. 19. Similar tooth in lateral view. $\times 24$.

Fig. 20. Larger tooth of posterior series, obliquely from in front. $\times 24$.

Fig. 2I. Largest tricuspid tooth of posterior series, obliquely from below, showing the convex basal surface with transverse median ventral groove. $\times 24$.

Fig. 22. Typical small, conical tooth from third triturating stomach. $\times 40$. 
Plate IV.

Tethys cervina Dall and Simpson

Fig. 23. Median and first three lateral teeth of twentieth and twenty-first rows of radula. $x 62$.

Fig. 24. Fourth to tenth lateral teeth of same rows of radula. x 62 .

Fig. 25. Eleventh to twenty-second (outermost) lateral teeth of same rows. The three figures of this plate represent the whole extent of two rows of teeth from the middle to the side of the radula. $\mathrm{x} 62$. 


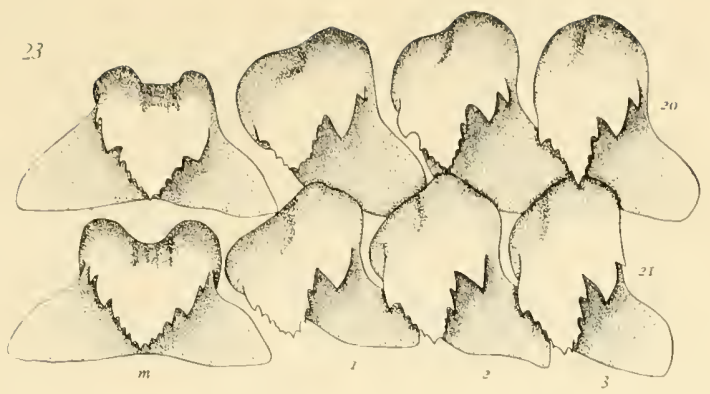

2.1

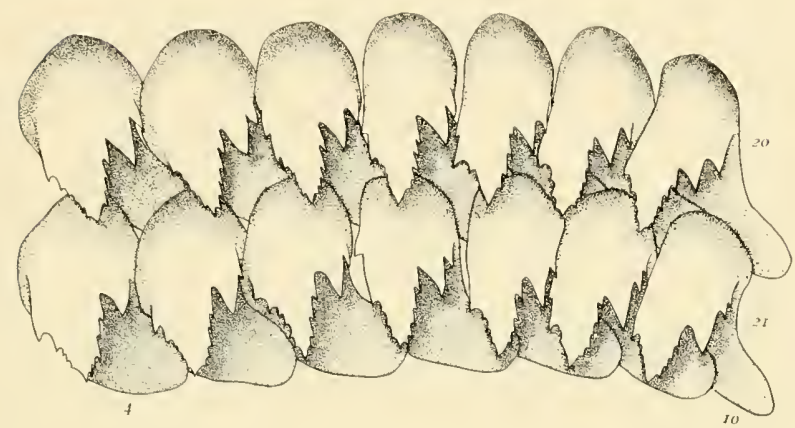

25

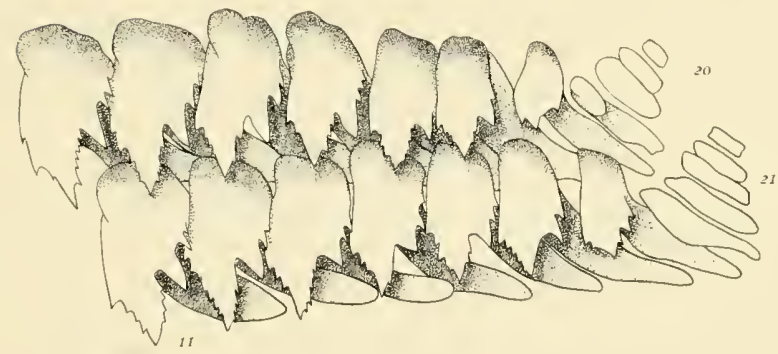





\section{Plate V.}

Tethys cervina Dall and Simpson.

Fig. 26. Median and first lateral teeth on either side, 24th and 25 th rows of radula. $\times 94$.

Fig. 27. Sixth, seventh and eighth lateral teeth, 24th and 25th rows of radula. $\times 94$.

Fig. 28. Seven outer lateral teeth of 29 th and 3 oth rows of radula. $x$ 94 .

Fig. 29. Detail of sixth lateral tooth of 20 th row of radula. $\mathrm{x}$ I80.

Fig. 30. Detail of I4th lateral tooth of 3oth row, from opposite side of radula. $x$ I 80 . 
26
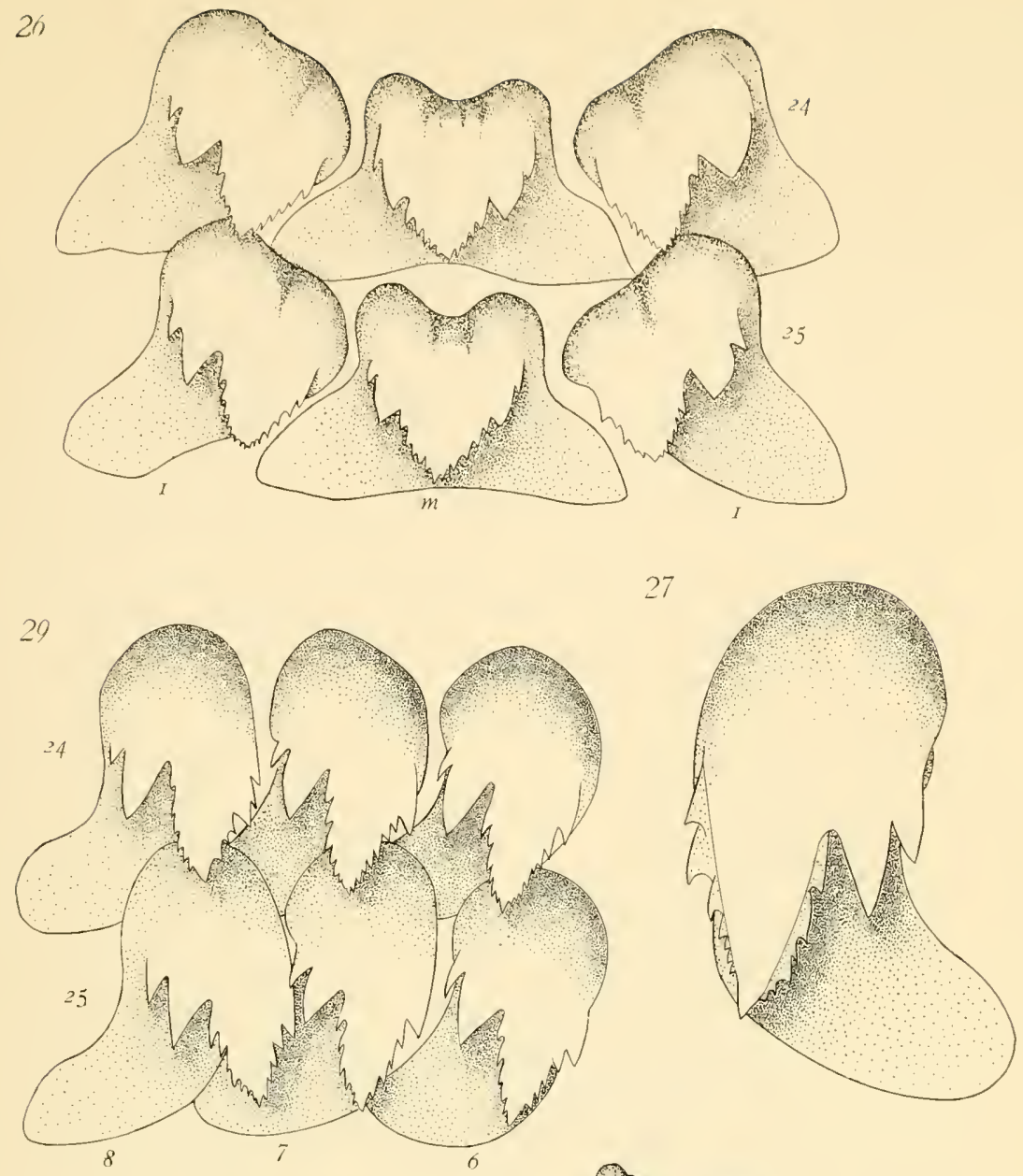

${ }^{25} \mathrm{He}_{\mathrm{H}} \mathrm{k}$
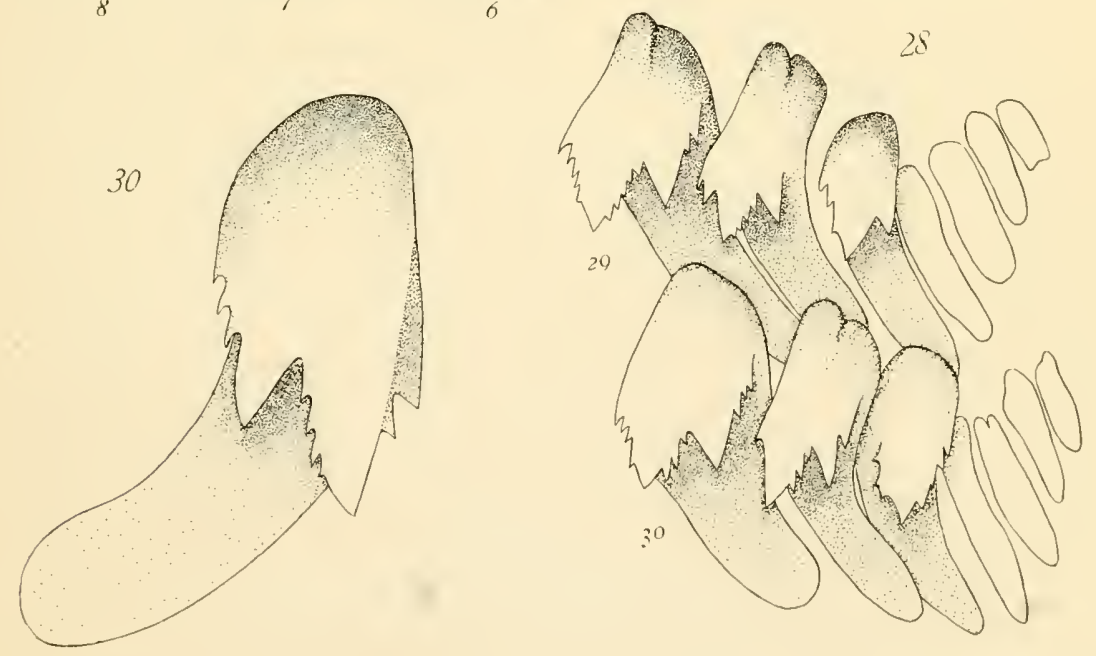




\section{Plate VI.}

Tethys cervina Dall and Simpson

Fig. 31. Alimentary canal from below. The convolutions of the intestine are shown in their natural position, the liver having been dissected away. $c$., lower end of the esophagus; ingl., ingluvies, or first stomach; $m$. st., muscular band of second, or grinding stomach; 3 st., third stomach; $h$. coc., hepatic coecum; int., intestine. $\times 3$.

Fig. 32. Relations of hepatic coecum and bile chamber. The wall of the lower portion of the third stomach and the first portion of the intestine have been cut away, showing the entrance of the large ducts of the liver in the opposite wall. The substance of the liver itself, which here almost entirely incloses the alimentary canal, has been dissected away. h. coe., hepatic coecum; $l$. $r$., the prolongation into the intestine as a longitudinal ridge of one of the folds in the wall of the hepatic coecum. $\times 5$.

Fig. 33. Reproductive system seen from below, the right border being above and to the left. ov. t., ovotestis; sm. $h . d$., small hermaphroditic duct; $s p . c$. , spermatocyst; $d . c$. , duct of Cuvier; $s p . p$., spiral portion of genital duct; $c$. p., convoluted portion of genital duct; ov. $s p$. d., ovospermatic duct; cop. d., copulatory duct; spth., spermatotheca; $d$. spth., its duct; in., flap of the integument, upon the external face of which lies the vulvar aperture; $g$. g., genital ganglion; $l$. $v$. 3., third nerve from left visceral ganglion. $\mathrm{x} 8$. 


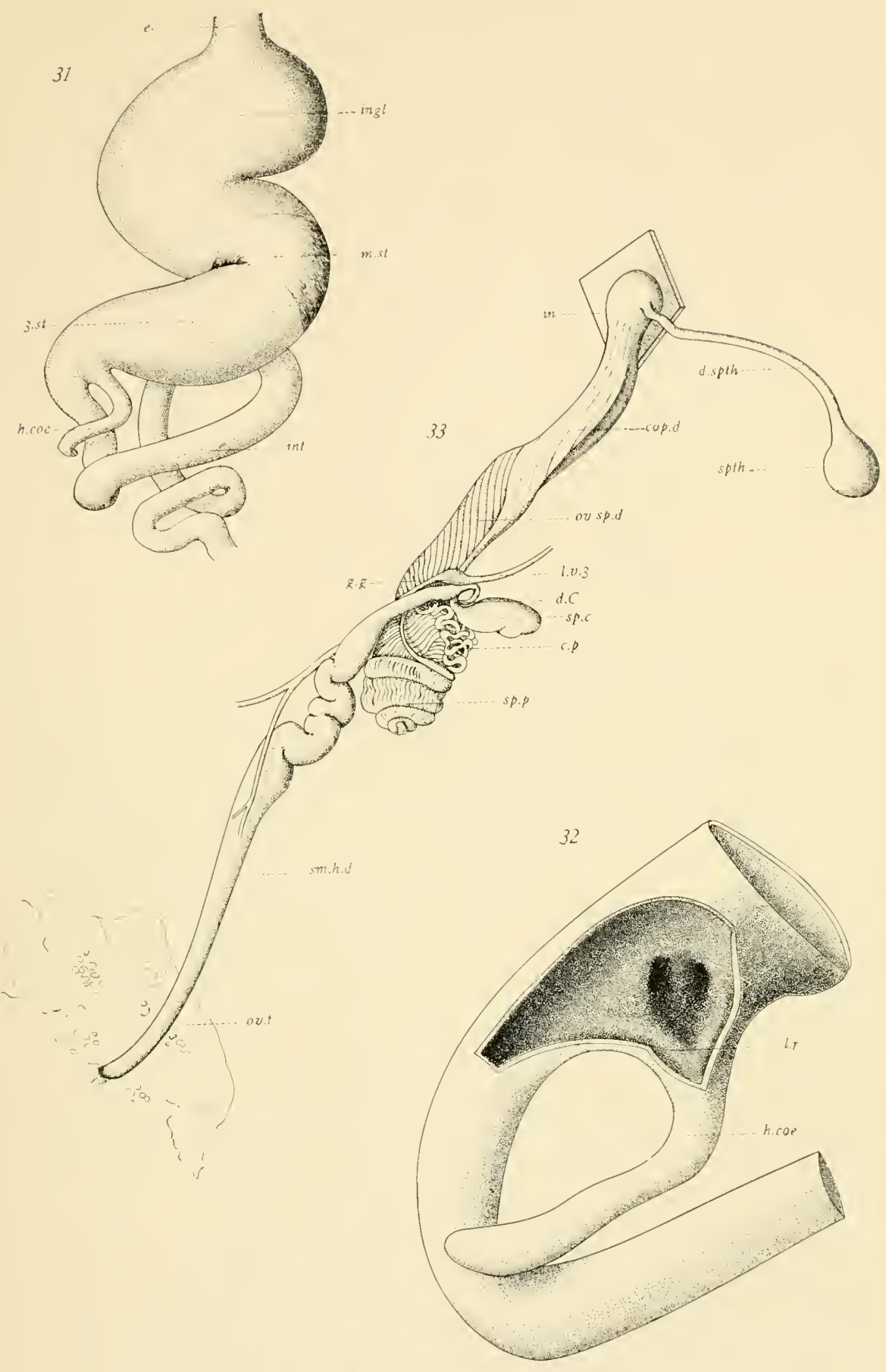




Plate VII.

Fig. 34. Central Nervous System of Tethy's cervina Dall and Simpson, in dorsal view. cer. $g$., cerebral ganglia; ped. g., pedal ganglia; pl. g., pleural ganglia; c. p. con., cerebro-pedal connective; $c$. $p l$. con., cerebro-pleural connective; pl. par. con., right pleuro-parietal connective; $p l . v$. con., left pleuro-visceral connective; $p$. com., pedal commissure; s. c. c., sub-cerebral commissure; $p$. p. com., parapedal commissure. The nerves are numbered serially in the order of their origin from each ganglion. Those of the pleural ganglia are designated pl. I, and $p l .2$; those of the cerebral ganglion by the prefix $c$ to their respective numbers, while the nerves of the pedal ganglia are designated by numerals alone. $x$ Anastomosis of a branch of the third cerebral nerve, $c .3$, of the right side with a branch of the second pedal, 2. $\epsilon$., eye. $\mathrm{x}$ I8. 

Fig. 35. Parieto-visceral ganglia and nerves of Tethys cervina Dall and Simpson. The contours of the Organ of Bohadsch, o. B., and the pericardial cavity, per. c., are indicated in dotted lines, that of the reproductive system in light lines and unshaded. The anterior end of the animal is directed toward the upper side of the plate, the right of the animal corresponds to the left of the plate, the preparation being drawn in ventral view. r. pl. par. con., right pleuro-parietal connective; l. p. $v$. con., left pleuro-visceral connective; par. v. g., the parieto-visceral ganglion complex, the ventral, or visceral moiety concealing the upper parietal portion; $r . p . l$., vulvar nerve of right parietal ganglion, bifurcating into $r a$., which anastomoses with a branch of the third pedal nerve, 3 ped., and $I b$., the vulvar nerve proper; $r . p .2$, osphradio-ctenidial nerve; osp. g., osphradial ganglion; $o . g$. $I$., nerve to mantle; $c t . g$., ctenidial ganglion; $l$. v. 2 ., second nerve of left visceral ganglion; $2 a$., its hepatic branch ; $2 b$., its main branch forking to siphon and anus; $2 c$., its recurrent branch to the peritoneum and the organ of Bojanus, anastomosing beyond the latter with a branch of the third pedal nerve; 3 ped., of the right side; $2 d$., its branch to the posterior peritoneum, etc.;.2e., the branch to the organ of Bojanus; $l$. v. 3 ., third nerve of left visceral ganglion, supplying $g . g$., the genital ganglion, and dividing into v. $3 a$., and $v .3 b$., to the small hermaphroditic duct and ovotestis, and to the dorsal body wall respectively, other delicate minor branches noted in the text not being represented. $l . v .4$., fourth nerve of left visceral ganglion, $4 a$. its branch to ventricle and pericardium, $4 b$. its branch to kidney, pericardium and auricle. 3 ped., main trunk of third pedal nerve of right side, bifurcating into $3 a$ and $3 b$. $3 a$ gives off $3 c$ to the organ of Bohadsch, and $3 f$, which anastomoses with a branch of the vulvar nerve, $I a$, and is distributed to the muscles of the body wall. $3 b$ sends off $3 d$ to the right retractor 


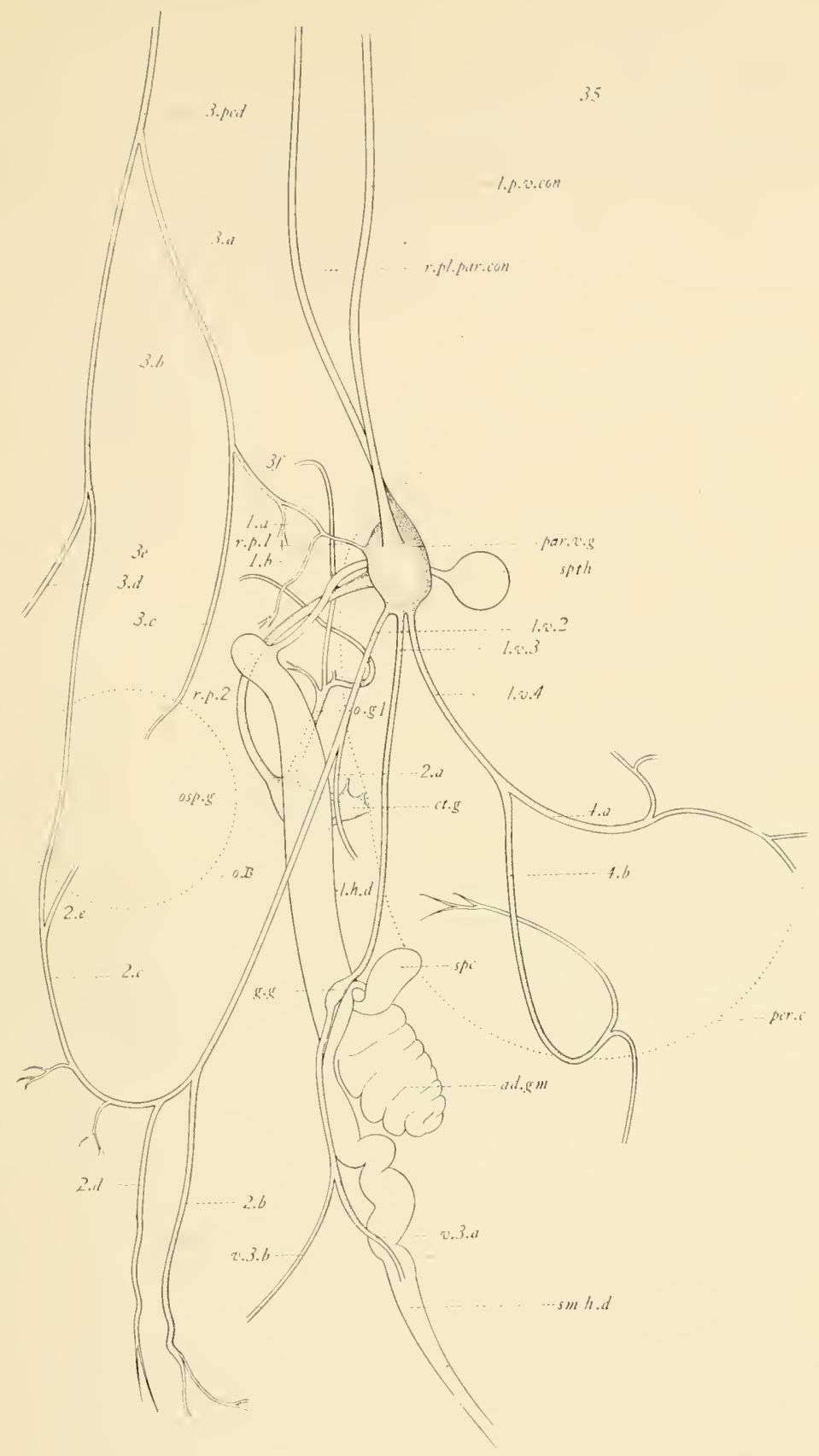



muscle of the head, and, as $3 e$, anastomoses with the recurrent branch of the second nerve of the left visceral ganglion, $2 c . s m . h$. d., small hermaphroditic duct; ad. g. m., adnexed genital mass; sp. c., spermatocyst; $l$. $h$. $d$., large hermaphroditic duct; spth., spermatotheca. $\times 8$. 


\section{Plate IX.}

Fig. 36. Diagram of Central Nervous System of Tethys punctata (Cuv.), seen from below, after Mazzarelli.

Fig. 37. Diagram of Central Nervous System of Tethys depilans (Linn), seen from below, after Mazzarelli.

Fig. 38. Diagram of Central Nervous System of Tethys dactylomela (Rang), seen from below.

Fig. 39. Diagram of Central Nervous System of Tethy's cervina Dall and Simpson, seen from below.

The following abbreviations apply to all the figures of this plate: c. g., cerebral ganglia; $p . g$. , pedal ganglia; $p l . g$., pleural ganglia; $l . v . g$. , left visceral ganglion, fused more or less completely with its fellow, the right parietal ganglion; $o$. B., organ of Bohadsch, or hypobranchial gland; $3 p$., third pedal nerve, $a$, its branch anastomosing with the right parietal ganglion, $b$, its branch to the organ of Bohadsch, $c$, its branch or branches to the muscles of the body wall, $m$, also in figs. 38 and 39 anastomosing with the recurrent branch, $2 c$, of the second nerve, $l$. $v .2$, from the left visceral ganglion; $2 a$, hepatic branch of second visceral nerve, $2 b$, its main trunk to siphon and anus. 
T. punctata (Cuz:)

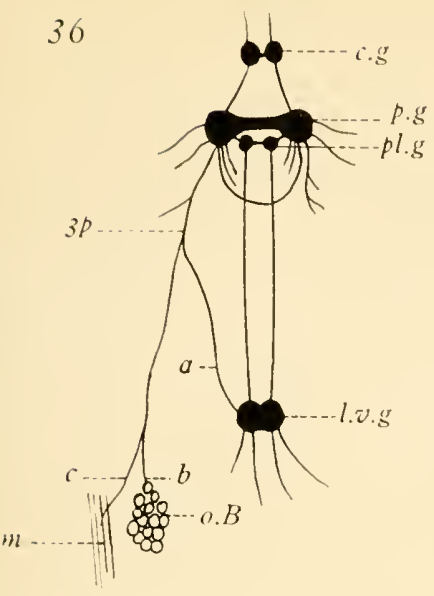

T. defilans (Linn.)

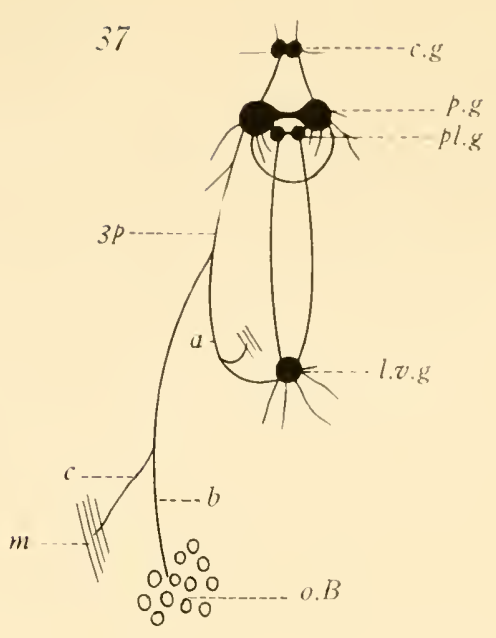

$T$ corina $D$ \& $S$

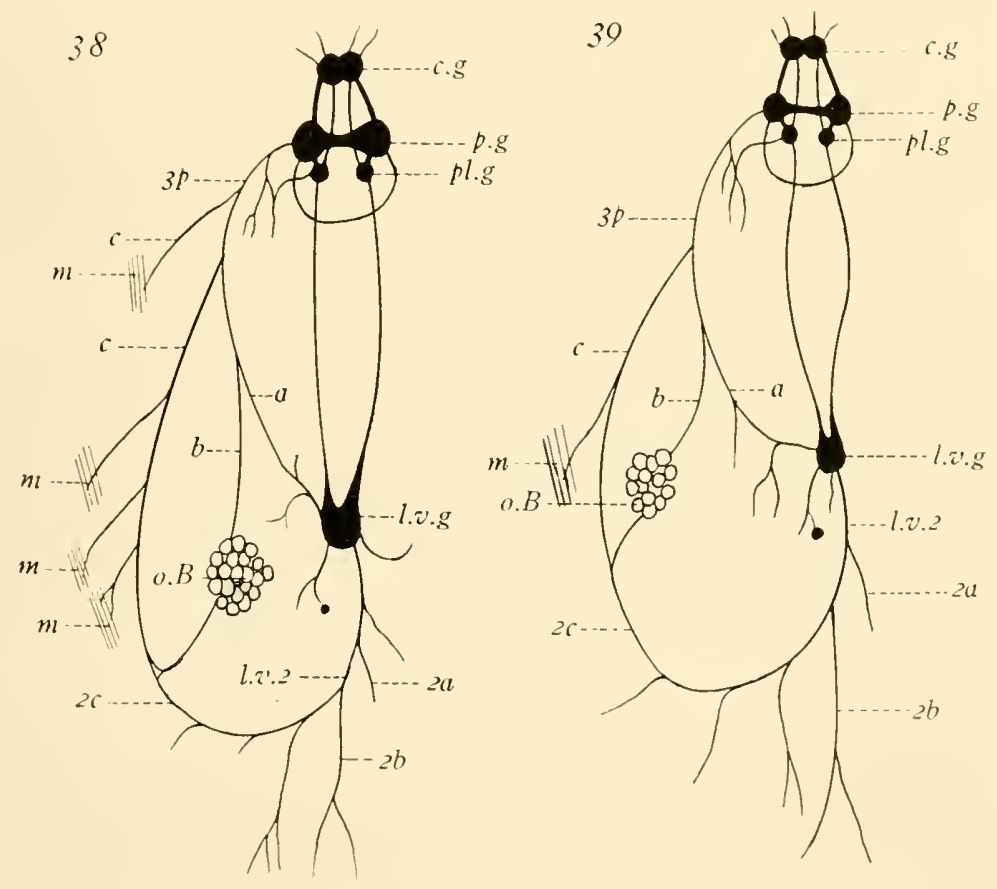





\section{Plate X.}

Tethys cervina Dall and Simpson.

Fig. 40. Dorsal view of shell. $\times 46$.

Fig. 4I. Outline sketch of preserved specimen in dorsal view, mainly intended to show the general proportions and the markings surrounding the mantle pore. Tentacles and rhinophores strongly contracted, the head itself less so. $\times 2$.

Fig. 42. Detail of parieto-visceral ganglion complex from above, the two fused ganglia being rotated into side view, and all the nerves being more or less displaced to show their mutual relations. pl. p. con., pleuro-parietal connective; $p l . v$. con., pleuro-visceral connective; $r . p . g$., right parietal ganglion; l.v. g., left visceral ganglion; $r$. p. $I$, vulvar nerve; $r$. p. Ia., its branch anastomosing with the third pedal nerve; $r . p . I b$., its branch to anterior end of large hermaphroditic duct; $r . p .2$, osphradio-ctenidial nerve; osp. $g$., osphradial ganglion together with a portion of the integument cut out from the body wall; ct. g., ctenidial ganglion; osp. g. I, nerve to anterior and lateral regions of the mantle; ct. $n$., main ctenidial nerve; $l$. $v$. $I$, nerve to vesicle of Swammerdam, or spermatocyst, and its duct; l. v. 2 , l. v. $3, l . v .4$, second, third and fourth nerves from the left visceral ganglion. $\mathrm{x} 20$. 


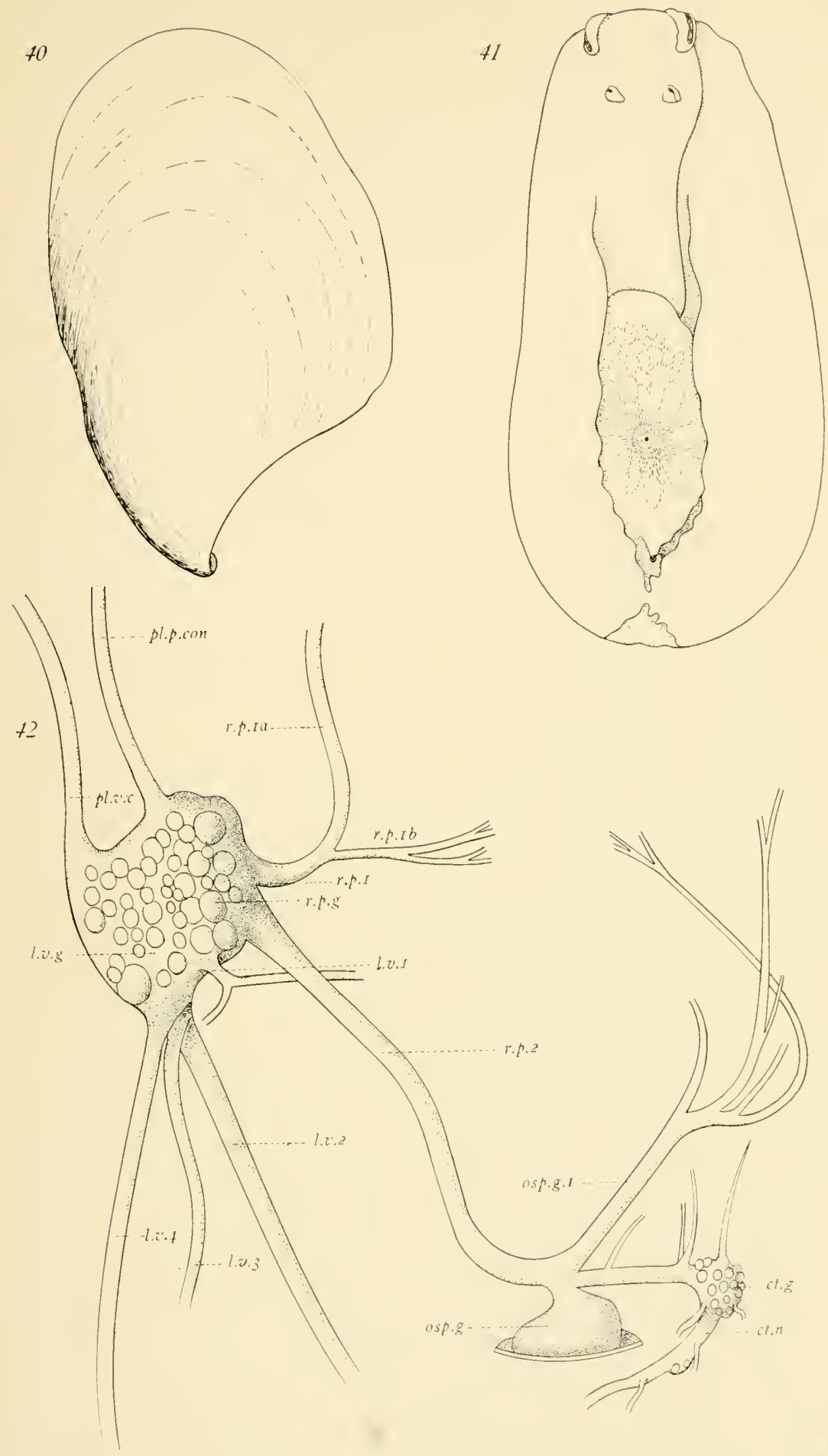




Plate XI.

Pleurobranchus agassizii MacFarland.

Fig. 43. Shell in dorsal view. $x+5$.

Fig. 44. Dorsal view of Ioth, IIth, and I2th elements of labial armature from 8 th to Ioth rows. $x 240$.

Fig. 45. Ventral view of elements of labial armature from near margin of 65 th and 66th rows. $\times 372$.

Fig. 46. Ventral view of bases of elements of labial armature from middle portion. At this focus the hook and denticles are not seen. $\times 240$.

Figs. 47,48 . Lateral views of isolated elements of labial armature. $\times 372$.

Fig. 49. Outermost lateral teeth of eleventh row of radula. $x 450$.

Fig. 50. Twenty-first and twenty-second lateral teeth of $22 \mathrm{~d}$ row of radula. $x 450$.

Fig. 5I. I6th, I7th, and I8th teeth of 19th row of radula, obliquely from above. $\mathrm{x} 450$.

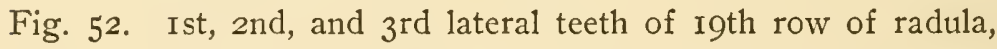
obliquely from above. $\mathrm{x} 450$.

Fig. 53. Ventral view of bases of 17 th to 2Ist lateral teeth of II th row of radula. $\times 450$.

Fig. 54. Lateral view of glans penis and vaginal opening from below. $v$., vaginal opening. $\mathrm{x}$ I2. 

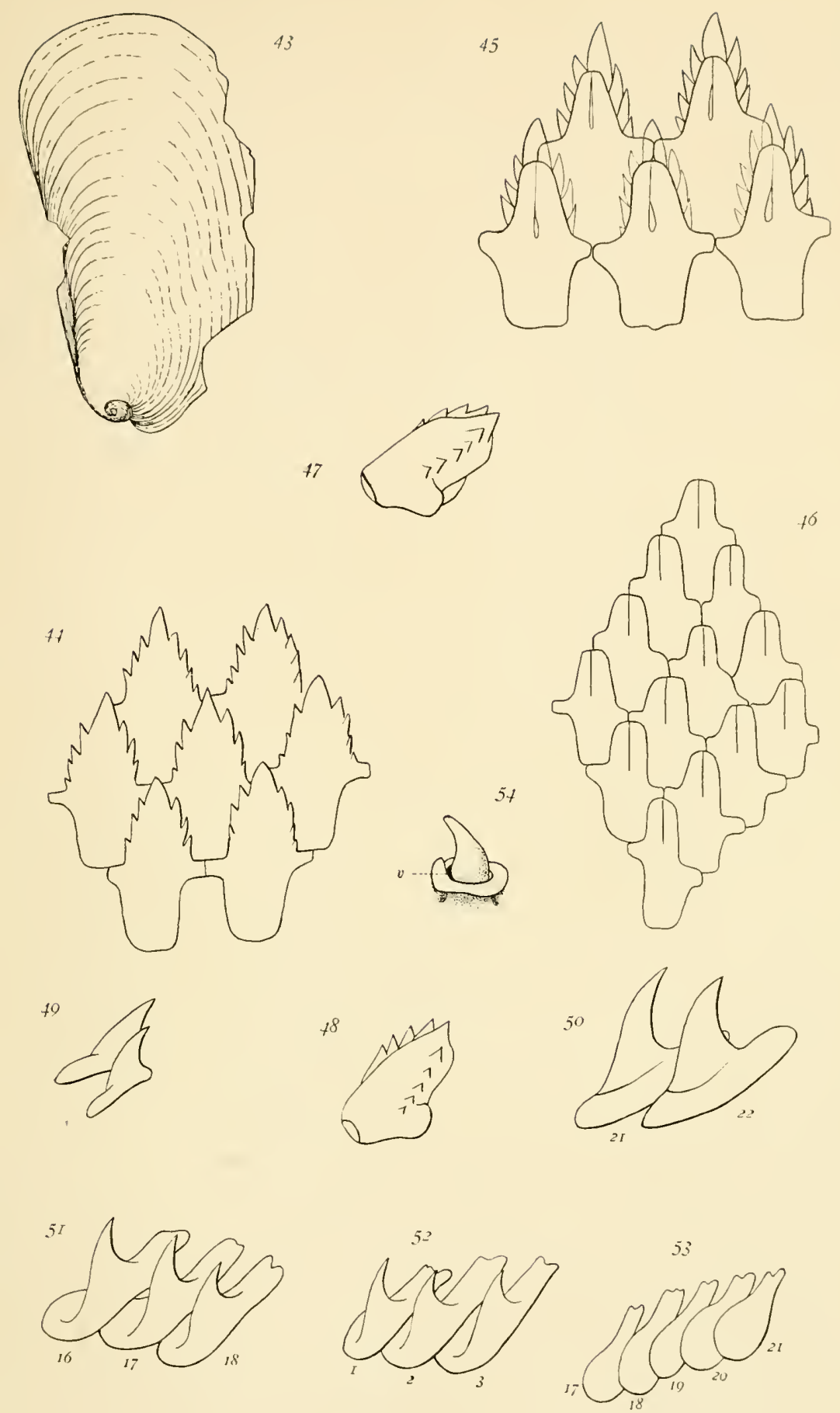

Figs. 55-57. Pleurobranchus agassizii MacFarland.

Fig. 55. Dorsal view of ganglia of Central Nervous System, the nerves and ventral commissures not being represented. $c$. pl. g., cerebro-pleural ganglion; $p . g$., pedal ganglion; $c$. $p$. con., cerebro-pleural connectives; $p l$. $p$. con., pleuro-pedal connectives; $e$., eye and optic ganglion. $\times 28$.

Fig. 56. Outline of mandibular armature. $d$., dorsal margin; $a$., anterior margin; $v$., ventral margin. $\times 28$.

Fig. 57. Ventro-lateral view of right rhinophore. $\mathrm{x}$ I2.

Figs. 58-65. Discodoris branneri MacFarland.

Fig. 58. Mandibular armature. x 30.

Fig. 59. Anterior rodlets of mandibular armature. $\times 2$ I 4 .

Fig. 6o. Posterior rodlets of mandibular armature. $x$ 2I4.

Fig. 61. Outermost lateral teeth of 16 th row of radula in side view. X I20.

Fig. 62. Outermost lateral teeth of 7 th row of radula, in side view. X I20.

Fig. 63. Typical lateral tooth from 5 th row, in side view of inner face. $\times 214$.

Fig. 64. Hooks of armature of glans penis, $a$, in side view; $b$, in front view. $\mathrm{x} 2 \mathrm{I} 4$.

Fig. 65. Reproductive organs from above, the parts slightly displaced so as to show their mutual relations. $h$. $d$., hermaphroditic duct; $h$. amp., hermaphroditic ampulla; $s p$. d., spermatic duct; ov. $d$. , oviduct; pr. g., prostate gland; $v . d$. , vas deferens; $p$., glans penis; $n . a$. $c$. , nidamental-albumen gland complex; $n$. $d$., duct of nidamental gland; $u$. $d$., uterine duct; $s p . c$., spermatocyst; spth., spermatotheca; vag., vagina, passing over proximally into the vaginal duct, its distal portion laid open by a triangular incision. $\mathrm{x}$ Io. 

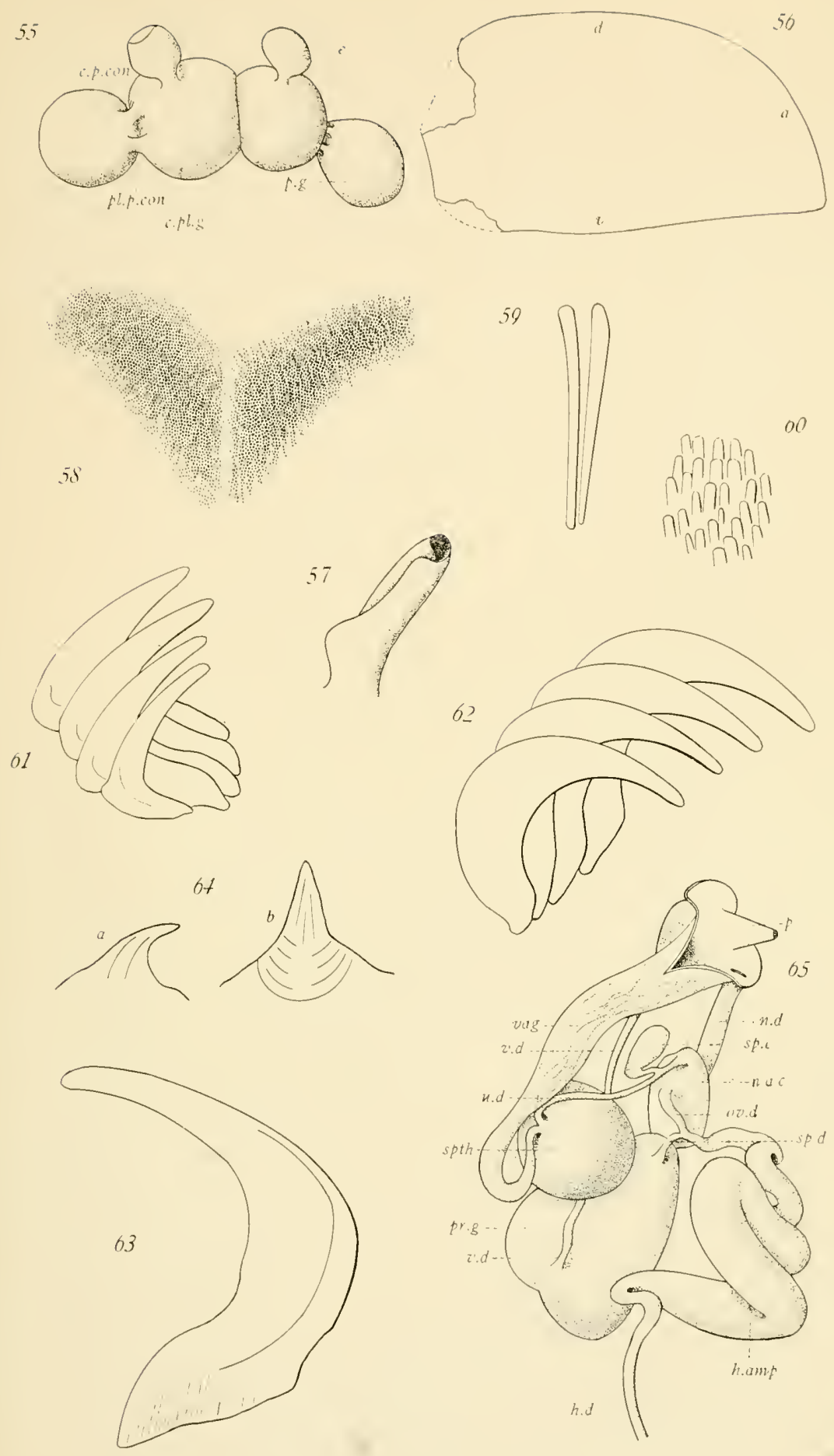




\section{Plate XIII.}

Discodoris voniheringi MacFarland.

Fig. 66. Labial armature. $a$, median; $b$, lateral plates; $c$, anterior border. $\times 37$.

Fig. 67. Front view of three typical lateral teeth of first row of radula. $x 212$.

Fig. 68. Front view of three typical lateral teeth from middle of first row of radula. $\mathrm{x} 2 \mathrm{I} 2$.

Fig. 69. Outermost lateral teeth of $x \mathrm{Ith}$ row of radula, obliquely from above. $\times 212$.

Fig. 70. Outline of cross-section of nidamental duct. $d$, dorsal; $v$, ventral ridge; $g$, groove between them. $\times 50$.

Fig. 71. Reconstruction from serial sections showing detailed relations of the ducts of the anterior genital mass. $h$. $a$., anterior end of hermaphroditic ampulla as it enters the nidamental-albumen gland complex; $s p$. $d$., spermatic duct emerging; $n . d$. ., nidamental duct; $s p t h$., spermatotheca; $u$. $d$., uterine duct; $s p . c$. , spermatocyst, with its duct, spc. $d$., leading into the uterine duct; vag. $d$., vaginal duct, cut off short to show the relations of the underlying organs. The dotted oval upon the surface of the nidamental gland indicates the approximate boundary of the albumen gland. 

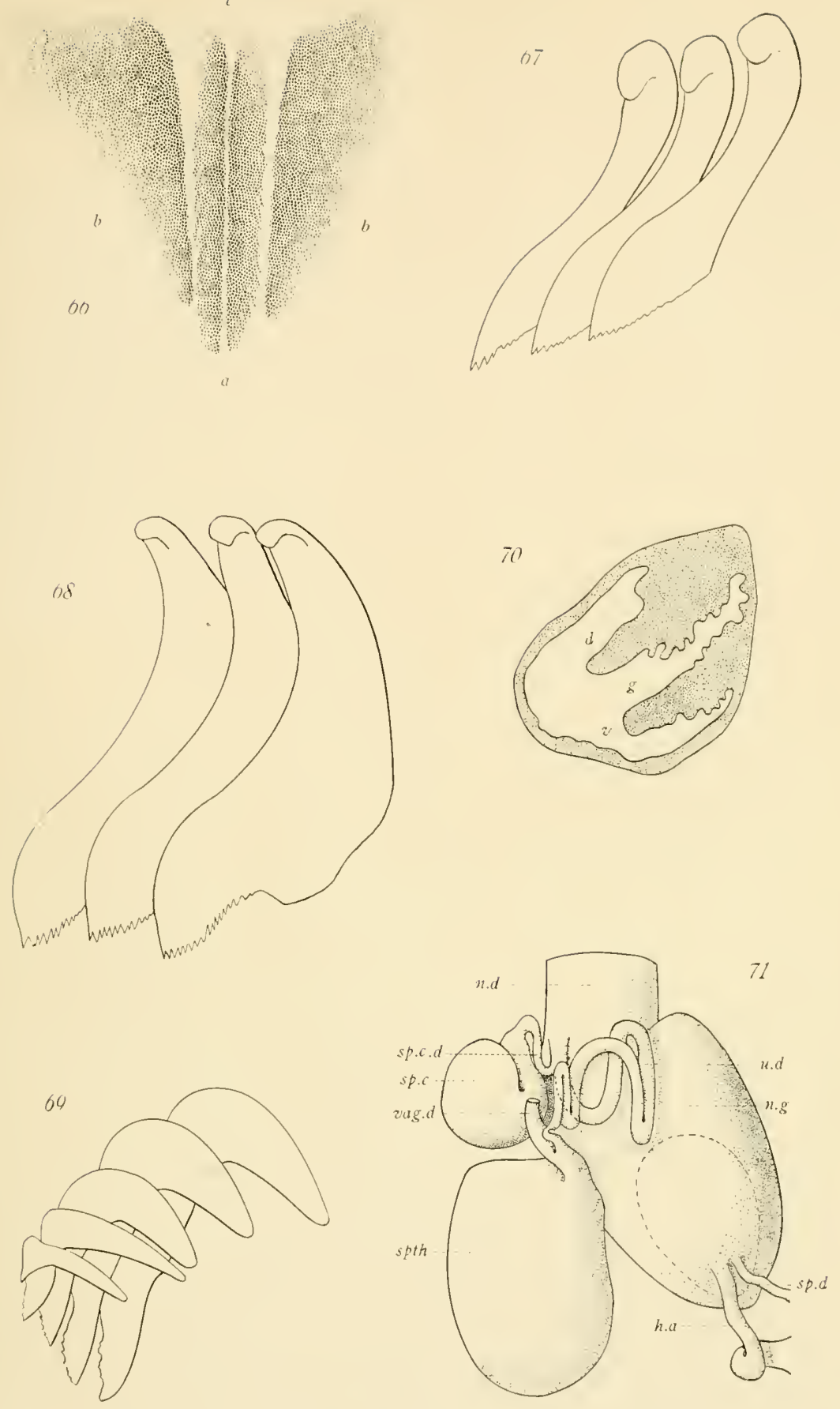




\section{Plate XIV.}

\section{Discodoris voniheringi MacFarland.}

Fig. 72. Reconstruction from serial sections showing the mutual relations of the principal ducts and cavities within the nidamental-albumen gland complex. The less important branches and all of the secretory alveoli of the glands have been omitted, and are to be thought of as filling the space between the ducts represented and the dotted line, which indicates the external contour of the gland complex, as seen in side view. h. amp., the distal end of the hermaphroditic ampulla as it enters the gland; $i . h . a$. , its intraglandular portion, dilating into $f$. ch., the fertilization chamber; $u$. $d$., uterine duct; l. alb., lumen of albumen gland; $x$., duct connecting intraglandular portion of hermaphroditic ampulla with the lumen of albumen gland; alb. $d$., albumen gland duct connecting the albumen gland with the lumen of the nidamental gland; $l$. nid., lumen of nidamental gland; $n$. $d$., nidamental duct, cut across as it leaves the gland. The cut end represents the thickness of the epithelial lining of the duct only. $\mathrm{x}$ I65.

Figs. 73 and 74. Ventral and dorsal views respectively of the reproductive complex. All connective tissue, nerves and blood vessels have been omitted for the sake of clearness. $h . d$., cut end of hermaphroditic duct; $h$. amp., hermaphroditic ampulla; sp. $d$., spermatic duct; $n . g$., nidamental-albumen gland complex; nid $d$., nidamental duct; vag., vagina; vag. $d$., vaginal duct; $u$. $d$., uterine duct; spth., spermatotheca; $s p c$. , spermatocyst; pr. $g$., prostate gland; $v . d$. , vas deferens; $p$. , penis; $p . o$. , external opening of præputium; $v$. $o$., external vaginal opening; $n . d . o$. , external opening of nidamental duct. × 36 . 

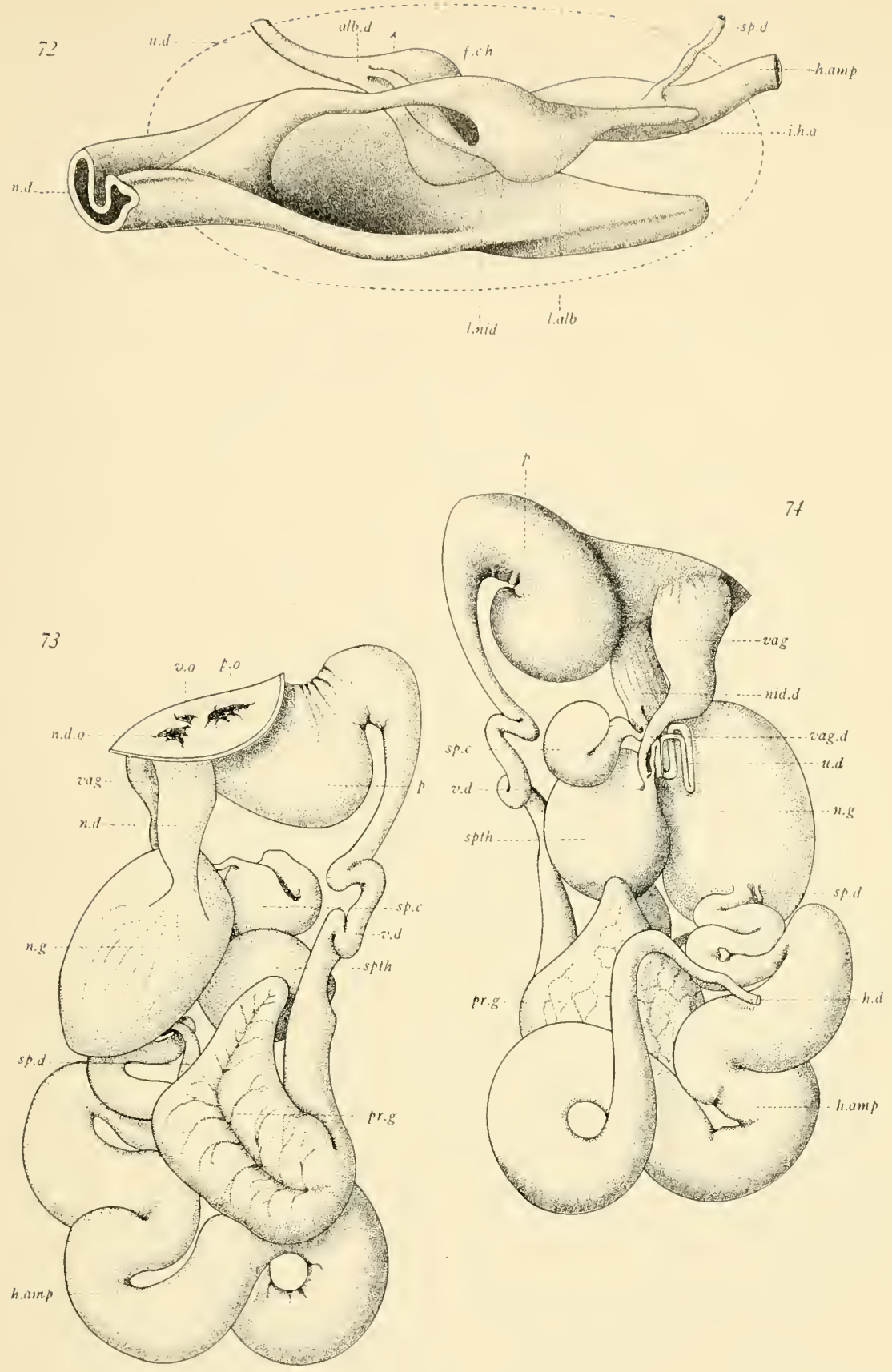



\section{Plate XV.}

Figs. 75-76. Discodoris voniheringi MacFarland.

Fig. 75. Side view of typical lateral tooth from near center of Ist row of radula. $\mathrm{x} 244$.

Fig. 76. Four lateral teeth from inner end of 16 th row, slightly displaced. $\times 244$.

Figs. 77-82. Peltodoris greeleyi MacFarland.

Fig. 77. Two typical spicules from dorsum. x 244 .

Fig. 78. Oblique view of base of typical lateral tooth of radula. x 282 .

Fig. 79. Outermost lateral teeth of 19 th and 2oth rows of radula. x 244 .

Fig. 80. Innermost lateral teeth of 17 th row of radula. $\times 244$.

Fig. 81. Typical lateral tooth of radula in side view. $\times 282$.

Fig. 82. Portion of anterior genital complex, the nidamental and albumen glands having been removed. $h . d$., anterior end of hermaphroditic duct; $h$. amp., hermaphroditic ampulla; $s p . d$., spermatic duct entering proximal end of large prostate gland, $p r . ; u$. $d$., uterine duct, receiving the duct of the spermatocyst, $s p c$., and cut off just before its entrance into the nidamental gland; spth., spermatotheca; vag. d., vaginal duct, its distal portion severed just before it dilates into the vagina; $v$. def., proximal portion of vas deferens. $\mathrm{x}$ IO. 

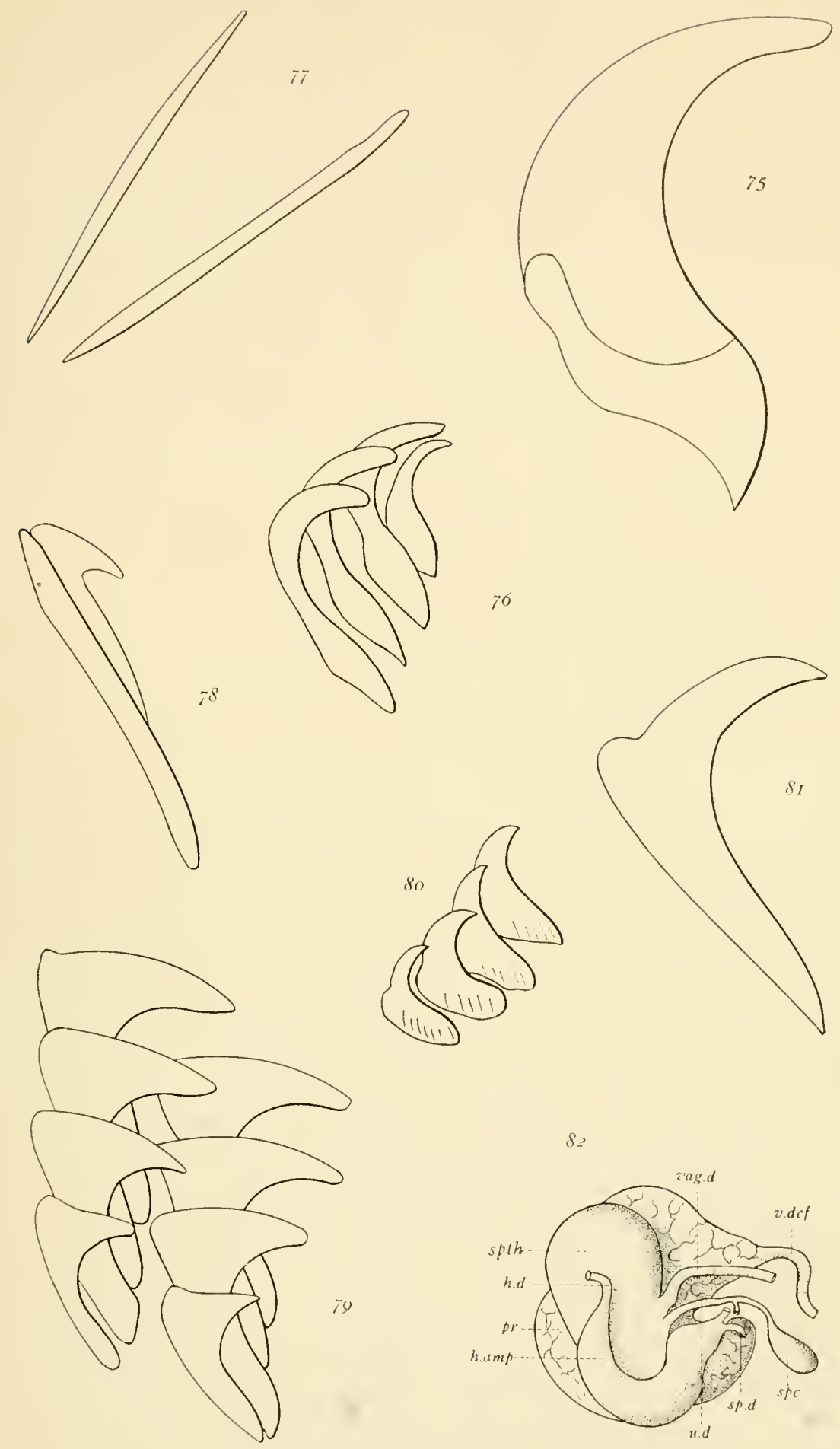

82

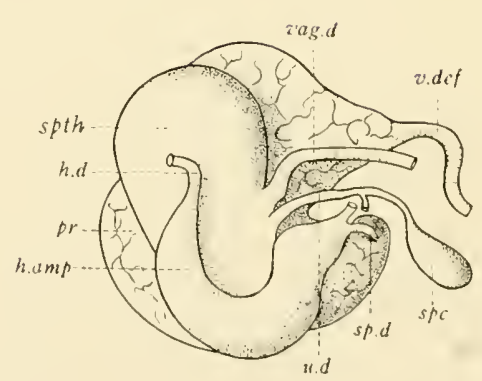






\section{Plate XVI.}

Spurilla braziliana MacFarland.

Fig. 83. Twelfth tooth of radula. $\mathrm{x}$ I 6 .

Fig. 84. First tooth of radula. $x$ I 6 .

Fig. 85. Anterior end of foot in ventral view, the extruded mouth region showing above. $\times 5$.

Fig. 86. Left salivary gland in side view. $\mathrm{x}$ Io.

Fig. 87. Right salivary gland in side view. $\mathrm{x}$ Io.

Fig. 88. Anal papilla. $x$ Io.

Fig. 89. Median portion of typical tooth of radula. x 146. 





\section{Plate XVII.}

Spurilla braziliana MacFarland.

Figs. 90 and 91. Outline sketches of preserved specimen from left and right sides. The dorso-lateral cereta have all been removed, the outline of their bases showing their relative position. The mouth region and reproductive openings are partly everted and much distorted, and the rhinophores are strongly contracted. $\times 5$.

Figs. 92 and 93. Inner surfaces of left and right mandibles. $a$., superior margin ; $b$., inferior margin ; $c$., posterior tip of masticatory process; $d$., fulcrum, or hinge, with single crest in left mandible; $e$., the same, with double crest in right mandible. $\mathrm{x} \times 6$. 

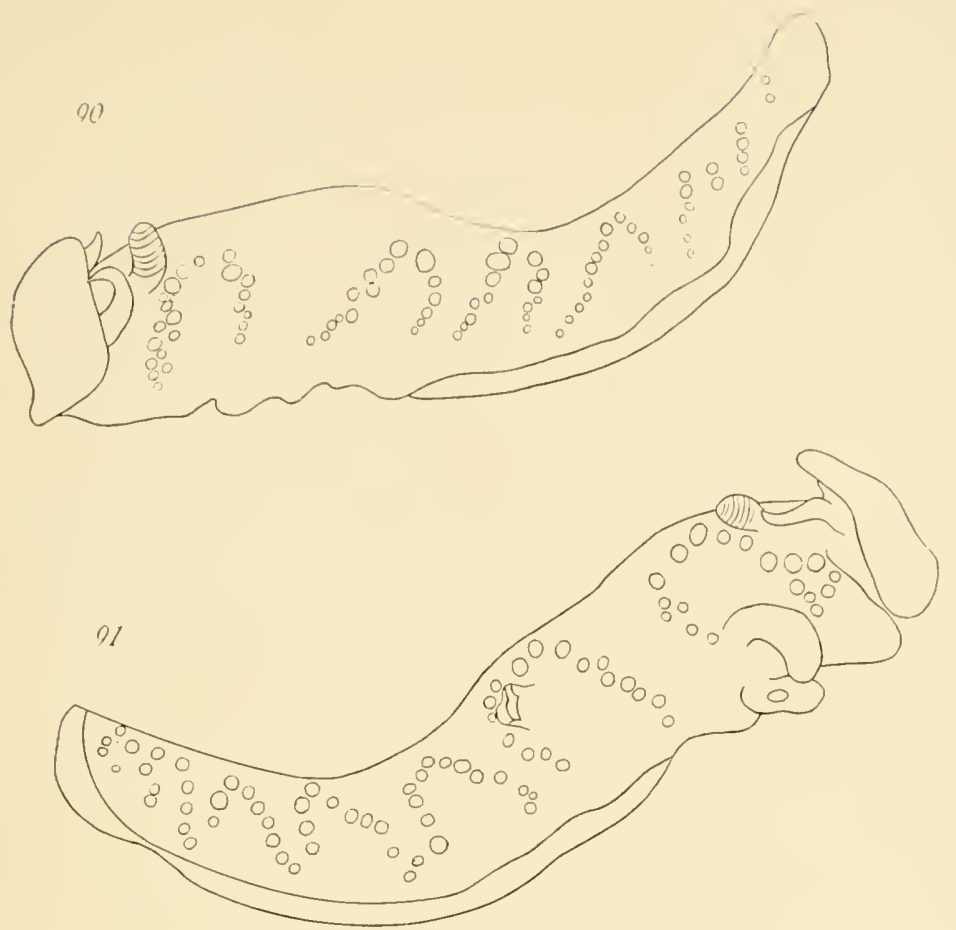

Q2

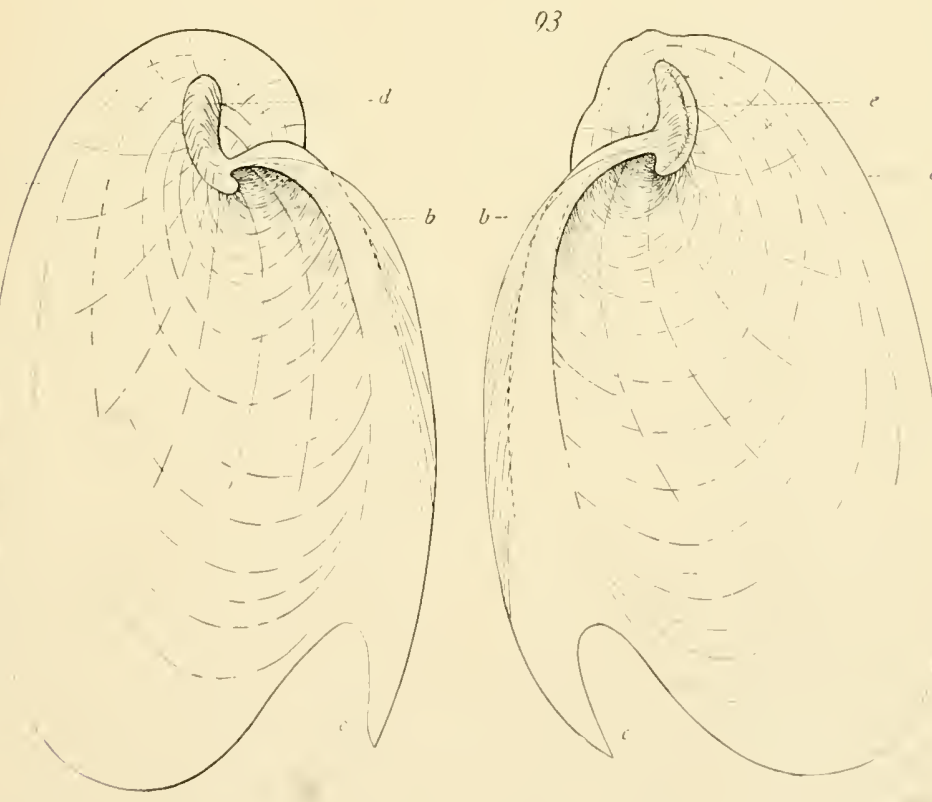




Plate XVIII.

Spurilla braziliana MacFarland.

Fig. 94. Detail of head, or hinge region of right mandible, inner surface. a., superior margin; $b$., inferior margin; $c$., the fulcrum, bearing double longitudinal crests bounding a longitudinal groove, into which the single crest of the left mandible fits; $d$, ventral margin of the anterior portion of the masticatory process. $\times 45$.

Fig. 95. Detail of head region of left mandible, inner surface. Lettering as in preceding figure. The fulcrum, $c$., bears a single crest. $\times 45$. 




\section{Plate XIX.}

\section{Spurilla braziliana MacFarland.}

Fig. 96. Central Nervous System from above. The buccal and olfactory ganglia are not shown; the basal ends of the olfactory nerves, olf. $n$., are seen arising from the cerebral portion of the cerebro-pleural ganglion complex, c. pl.g. The nerves are indicated in Roman, I-VIII, in uniformity with the figures of Trinchese, cited in the text. ped. g., pedal ganglia; ped. com., pedal commissure; pl. com., pleural commissure; cer. buc. con., cerebro-buccal connective; $e$., eye; ot., otocyst, in front and slightly beneath it the otic ganglion. $\times 46$. 


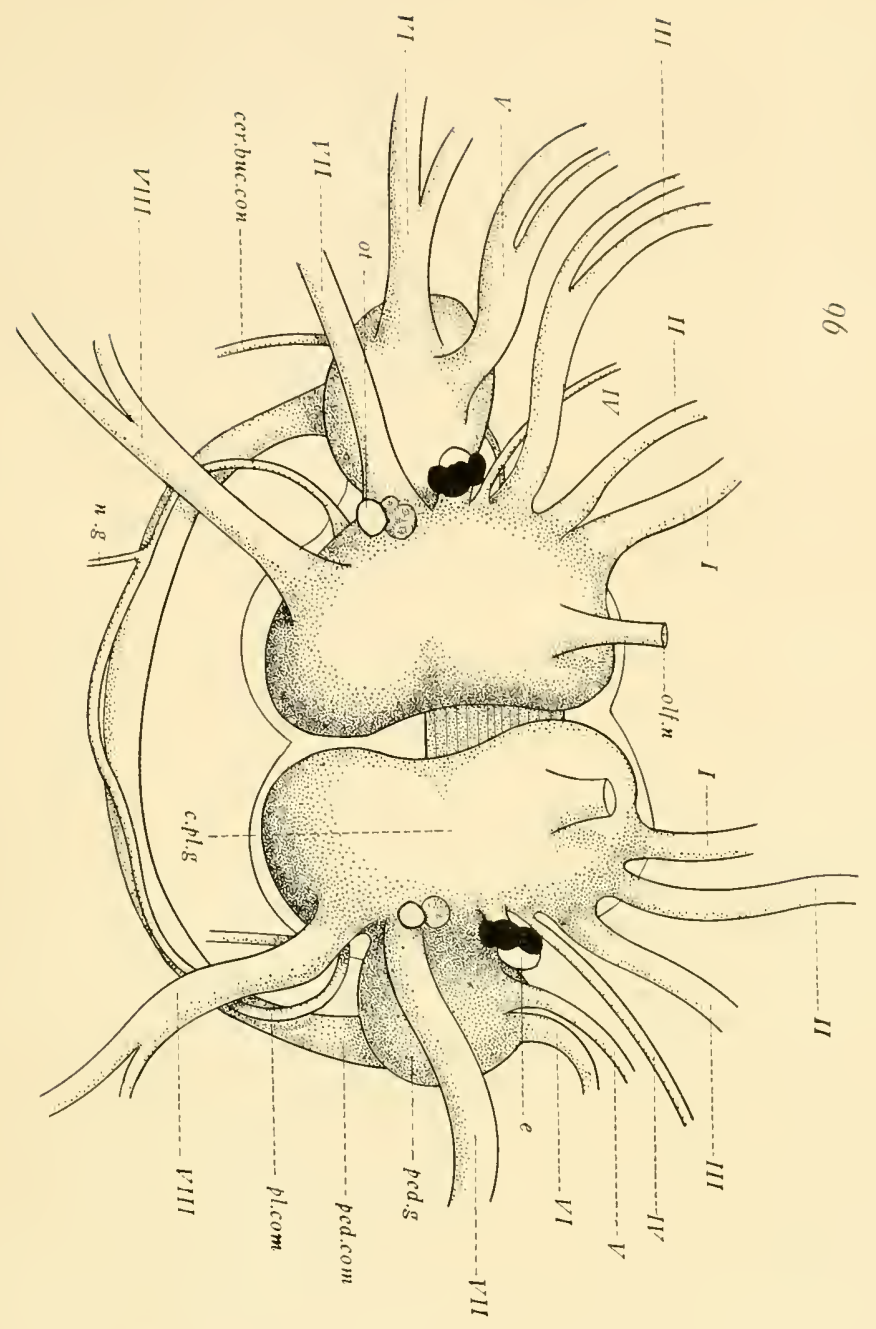




Printed by

Cbe Stantep-Uaplor Company San Francisco 





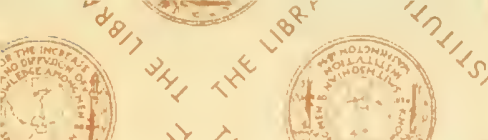

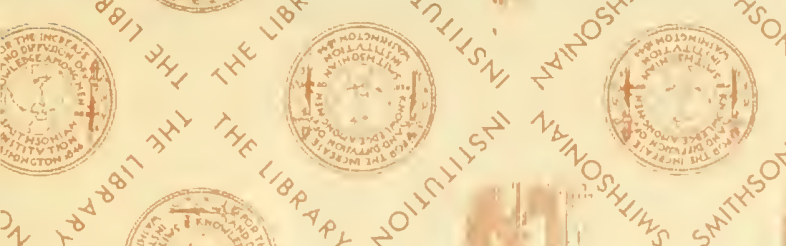

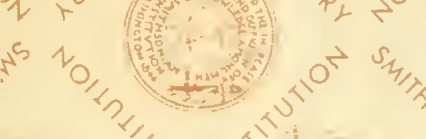

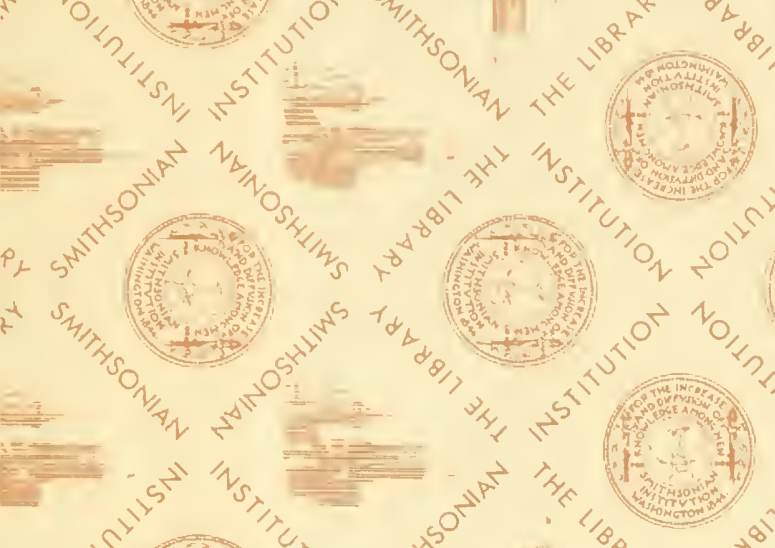

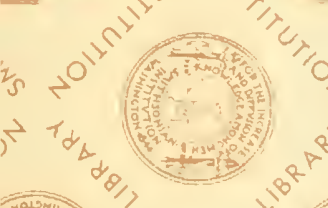

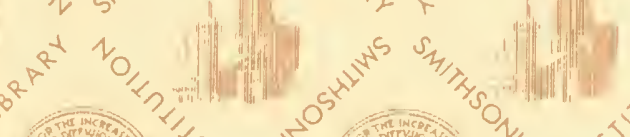

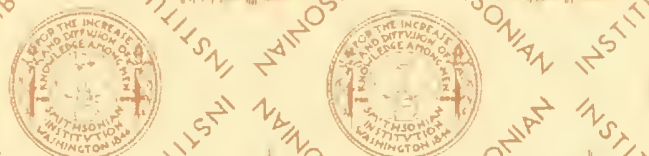
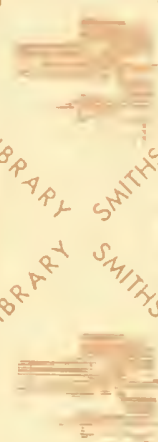
की C/8 क्षिता (

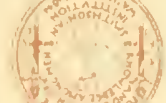

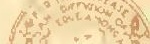

II

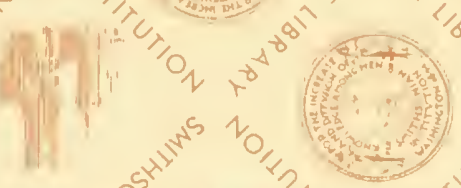

- 
SMITHSONIAN INSTITUTION LIBRARIES 